DESIGNING SOLAR THERMAL SYSTEMS

FOR ARCHITECTURAL INTEGRATION

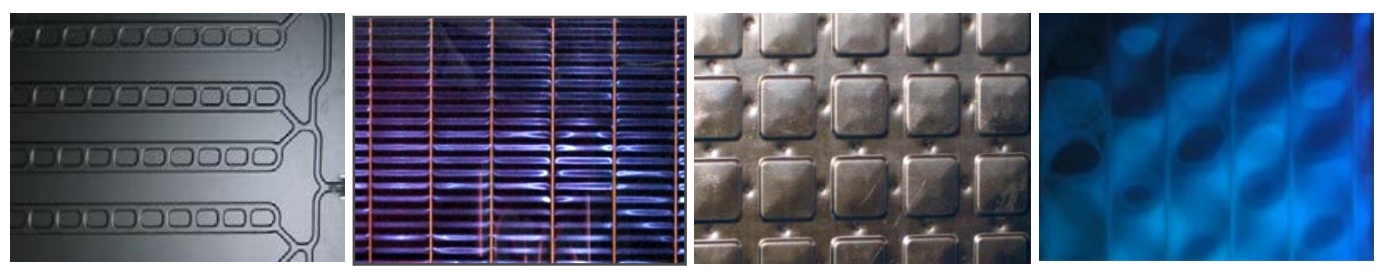

criteria and guidelines for product and system developers

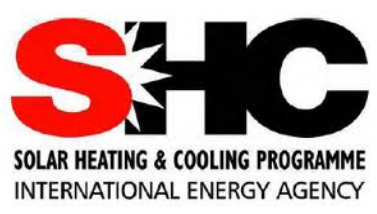





\section{DESIGNING SOLAR THERMAL SYSTEMS FOR ARCHITECTURAL} INTEGRATION

Criteria and guidelines for product and system developers

Keywords

Solar energy, architectural integration, solar thermal, active solar systems, solar buildings,

solar architecture, solar products, innovative products,

building integrability.

Editors:

MariaCristina Munari Probst

Christian Roecker

November 2013

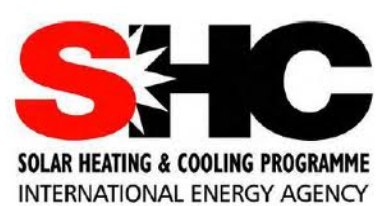





\section{AUTHORS AND CONTRIBUTORS AFFILIATIONS}

\author{
Maria Cristina Munari Probst \\ (editor, author) \\ EPFL-LESO \\ Bâtiment LE \\ Station 18 \\ $\mathrm{CH}-1015$ Lausanne \\ SWITZERLAND
}

mariacristina.munariprobst@epfl.ch

\section{Alessia Giovanardi}

(contributor)

EURAC research, Institute for

Renewable Energy

Universitá degli Studi di Trento

Viale Druso 1

I-39100 Bolzano, ITALY

alessia.giovanardi@eurac.edu
Christian Roecker

(editor, author)

EPFL-LESO

Bâtiment LE

Station 18

$\mathrm{CH}-1015$ Lausanne

SWITZERLAND

christian.roecker@epfl.ch

Marja Lundgren

(contributor)

White Arkitekter

P.O. Box 4700

Östgötagatan 100

SE-116 92 Stockholm

SWEDEN

marja.lundgren@white.se
Maria Wall - Operating agent (contributor)

Energy and Building Design

Lund University

P.O. Box 118

SE-221 00 Lund SWEDEN

maria.wall@ebd.Ith.se 


\section{ACKNOWLEDGMENTS}

The authors are grateful to the International Energy Agency for understanding the importance of this subject and accepting to initiate a Task on solar energy and architecture. We wish to thank all our respective national Executive representatives and national funding bodies for funding this work, namely:

- Swiss Federal Office of Energy (OFEN)

- Ecole Polytechnique Fédérale de Lausanne (EPFL)

- Stiftung Südtiroler Sparkasse (Fondazione Cassa di Risparmio di Bolzano)

- European Academy of Bozen/Bolzano (EURAC)

- ENEA - Agenzia nazionale per le nuove tecnologie, l'energia e lo sviluppo economico sostenibile

- SINTEF Building and Infrastructure, Norway

- Norwegian University of Science and Technology (NTNU)

- Swedish Energy Agency

- Danish Energy Agency

- ARQ, body of two foundations established by White Arkitekter

Finally, our gratitude goes to our helpful Operating Agent Maria Wall and to Anne Grete Hestnes and Jens Windeleff for their crucial initial support to this Task. 


\section{EXECUTIVE SUMMARY}

The lack of products adapted to building integration is still today a major barrier to the widespread of solar thermal systems in the building practice. The features of the large majority of market products are not yet meeting architects' interest, so that solar thermal remains in their mind as a purely technical element to be either avoided or hidden somewhere on the roof.

To change this situation and finally meet architects' expectations, products developers have to truly understand building integration. This document describes in details building integration issues and shows step by step the practical ways now available to provide adapted products.

Chapter 1 and 2 focus on general architectural integration issues, structuring the topic into functional, constructive and formal (aesthetics) aspects. General recommendations on system development are then provided, focusing on gradual targeted levels of product integrability:

- Basic level of integrability: ensuring module formal flexibility.

- Medium level of integrability: providing dummies (i.e. non-active elements).

- Advanced level of integrability: providing a complete roof/façade system.

Chapter 3 analyses in detail the practical development possibilities offered by the latest technical advances. For each of the three considered solar thermal technologies (glazed flat plate, unglazed flat plate and evacuated tubes collectors), the different multifunctionality options are listed, and then the technical options available to provide flexibility in terms of collector dimensions, jointing, surface colours and textures are detailed.

Chapter 4 provides a practical example of product development that followed the given recommendations. The step by step development description highlights the various process stages and the related required competences.

Chapter 5 consists of a collection of innovative market products, whose characteristics are synthesised in datasheets. Each datasheet provides a short description of the product through texts, images and schemes, together with a synoptic table evaluating the product integrability features, as discussed in the previous chapters.

The document ends with a short conclusion chapter. 
CONTENTS

2. ARCHITECTURAL INTEGRATION AND SYSTEM DEVELOPMENT RECOMMENDATIONS 11

2.1 Definition of architectural integration 12

2.2 Functional and constructive integration: collectors as multifunctional constructive elements

2.3 Formal (aesthetic) development aspects

2.3.1 Architects' needed flexibility when working on building integration

2.3.2 System characteristics affecting building formal integration quality

2.3.3 Concept of gradual levels of integrability

2.4 Market trends / users preferences

2.5 Production feasibility and eco-impact

3. PRACTICAL GUIDELINES FOR EACH SUBTECHNOLOGY 19

3.1 Glazed Flat Plate Collectors $\quad 19$

3.2 Unglazed Flat Plate Collectors $\quad 30$

3.3 Evacuated Tubes Collectors 36

4. EXAMPLE OF DEVELOPMENT PROCESS: SOLABS PROJECT

4.1 Context 41

4.2 Project phases $\quad 41$

4.3 Integration criteria $\quad 41$

4.4 Design methodology $\quad 42$

4.5 Users' wishes $\quad 42$

4.6 The resulting collector 43

4.7 Integration simulations $\quad 46$

4.8 Lessons learned $\quad 47$

5. EXAMPLES OF INNOVATIVE PRODUCTS FOR BUILDING INTEGRATION 49

6. CONCLUSION 95

7. REFERENCES AND FURTHER READING 97

ANNEX: IEA SOLAR HEATING AND COOLING PROGRAMME 99 


\section{INTRODUCTION}

In the last few years solar energy has been recognized in many countries as the most promising renewable energy for building application, so that solar thermal collectors are more and more installed on the building envelope. But too often, they still look like added technical elements unrelated to the building architecture. One main reason lies in the fact that most systems are at present conceived by energy specialists (collector manufacturers, mechanical engineers), without the due implication of building professionals (architects, envelope manufacturers). The result is a market offer mainly consisting of products difficult to integrate in building designs due to their limited flexibility (in dimensions, texture, colour, jointing). Adapted products exist, but remain very rare.

This situation can be changed, and progresses are underway. Solar collectors can be conceived as multifunctional envelope systems merging several functions in one single building element, easing the integration work while convincing potential customers. Offering added formal flexibility will allow installing collectors in areas where standard products would not be suitable, increasing the part of the building envelope adapted to solar use.

In the following section the building integration problematic is presented at all functional, constructive and formal levels and a methodology for the development of new multifunctional systems suitable for building integration is proposed (chapter 2). Recommendations of practical development considering the specificities of each sub technology (glazed flat plates, unglazed flat plates, vacuum tubes) are then extensively described in section 3 with special attention to the desired flexibility in module dimensions, jointing, colours and textures, and to the possible technical ways available today to satisfy these expectations.

Inspiring examples of innovative products especially developed for building integration are documented at the end of the booklet (chapters 4 and 5). 


\section{ARCHITECTURAL INTEGRATION ISSUES AND SYSTEM DEVELOPMENT RECOMMENDATIONS}

Most existing solar collectors are developed as purely technical elements, starting from the "energy production" point of view only, sizing the collectors to optimise energy collection, manufacturability, handling and installation, but only giving a marginal attention to architectural integration issues. In a typical development process, an industrial designer just brings the last touch to the design, improving somewhat its look, not its "integrability".

Collectors must be developed to respond to their own technical constraints, but can furthermore become building components, easy to integrate into the building envelope. They should possibly fulfil more than one function, consequently easing integration efforts and reducing the overall cost [1],[2].

A few main characteristics distinguish the various solar thermal technologies, determining their integration possibilities:

- the medium used for the energy transportation (air, water...)

- the materials composing the collector (plastic, metal, glass...)

- the intrinsic form of the collector (flat plate, multilayer flat plates, vacuum tubes)

These characteristics have a major impact on the architectural integration possibilities at all levels: functional, constructive and formal.

New designs should explore the possibilities compatible with the collector functioning, to meet also building integration requirements, users' expectations and production constraints (manufacturability, standardisation, costs...see diagram 1 on page 17)

As written above, itmust be kept in mind that as these new collectors will be more "building oriented", there might be unavoidable trade-offs on efficiency or cost to accept, but this can be compensated by a broader acceptance and better implementation possibilities. This means also that there is now room for a new palette of collector types with a clear "building function", each addressed to a specific building application, such as metallic cladding, glazed façade element, balcony fence, tilted roof shingle, etc.

Taking this approach implies to follow a new collector development procedure, very different from the traditional one, whose prerequisite is the appropriate composition of the design team. For the development of these multifunctional construction elements, the design team should have competences in the fields of solar energy production, architecture and building technology. 


\subsection{Definition of architectural integration}

The architectural "integrability" of solar modules can be considered from all the three points of view of architecture: functional, constructive and formal (aesthetic). Relevant possibilities and constraints in relation to these three different aspects of the integration are described in the coming sections, and are summarized in the scheme at page 17 (diag. 1, §2.5)

\subsection{Functional and constructive integration: collectors as multifunctional construction elements.}

The main recommendation for the functional integration is to consider multifunctionality, i.e. finding envelope function(s) compatible with the considered technology. This means defining how to combine the materials and forms characterizing the collector technology with the functions, the structure and the materials of the specific part of the envelope they will replace.

Compatible envelope functions vary considerably depending on the specific ST(Solar Thermal) technology (glazed collectors/unglazed collectors / vacuum tubes). The following recommendations present the global perspective, while practical details and examples will be discussed in chapter 3 .

The need for a functional/constructive integration of active solar elements into the building envelope has been theorized by several researchers. The main stressed advantages these elements bring are the reduction of the overall cost and the smaller architectural integration effort.

Integrating solar modules in the building envelope means to integrate the energy collection function (active production of solar energy) while preserving/ensuring the other envelope functions. A good knowledge of the latter is therefore fundamental to understand which parts the various collectors could replace. However, solar collectors are not only used in envelopes (separation of inside/outside) but can also be used in external separation elements, like balconies, or in external equipment, like canopies.

Building envelopes have the following main protection and regulation functions:

- $\quad$ Protection from intrusion, rain, wind and noise;

- $\quad$ Insulation from winter cold and excessive summer heat;

- $\quad$ Regulation of the visual relations inside/outside and outside/inside;

- Supply of fresh air, of daylight and of passive solar gains;

- $\quad$ Regulation of users' comfort, while reducing the use of non-renewable energy for heating, cooling and lighting to a minimum.

To comply with these needs, the envelope is articulated into different parts, opaque and transparent, composed by fixed and/or mobile elements, each of them fulfilling a specific set of functions [3],[4],[5],[6]:

- The opaque parts fulfill mainly protection functions (from intrusion, rain, wind, noise, heat, cold).

In buildings responding to the new energy standards, opaque parts are mainly composed by multilayer systems. The optimization of the protection function from heat and cold makes it a common practice to use an external insulation layer, as this helps avoiding important thermal bridges and related condensation problems. This practice requires the use of an external protection (cladding). 
The opaque envelope parts are mainly composed of fixed elements (with the exception of doors and - rarely - opaque ventilation elements).

- The transparent (or translucent) parts are meant to collect daylight and passive solar thermal gains, to provide the visual contact with the outdoor, while still ensuring the whole set of protection functions. Transparent parts are mainly composed of mobile components and systems: to regulate daylighting and passive solar gains, the visual relation inside/outside, and in most cases also the natural ventilation.

Integrating a new component for "solar collection" into the building envelope requires to understand where (opaque parts, transparent parts, fixed/mobile elements) and how this added element can be made compatible with the other envelope parts, materials and functions.

The compatibility level will be different according to the characteristics of the selected solar technology and the characteristics of the specific chosen envelope element. In any case the new multifunctional envelope system has to safely meet all the related standard building construction requirements:

- The collector load must be correctly transferred to the load bearing structure through appropriate fixing;

- The fixing should avoid thermal bridges and the global U-value of the wall should not be negatively affected;

- The collector must withstand fire and weather wear and tear;

- It must resist wind load and impact, and should be safe in case of damage;

Dedicated sections will detail the specifics of the three main solar technologies and their implications for the collector development (Chapter 3).

\subsection{Formal (aesthetic) development aspects}

\subsubsection{Architects' needed flexibility when working on building integration}

Please note that in this context, the word "formal" refers to the appearance of elements. It is used where common practice would use "aesthetical", or "architectural", as it is more accurate. Moreover, this avoids confusion with the broader meaning of "architectural integration".

To successfully develop products helping architects integrate solar systems, it is crucial to understand the formal (aesthetic) criteria that command the quality of integration: functional and constructive integration criteria can be easily described; formal criteria are more problematic, and are often described as subjective. But as demonstrated by a survey conducted in 2004 among a large group of EU architects and engineers, objective criteria do exist also in this field [9].

The survey demonstrated two important points in evaluating the formal quality of integration:

- Architects' judgements were consistent with each other, confirming the existence of general criteria used as common evaluation base.

- Engineers' and façade manufacturers' judgements were more dispersed and, more important, always less demanding regarding integration quality. 
These differences in judgements confirm that appreciating architectural quality rely on architects professional competences, showing the importance of using architects' skills when dealing with formal issues.

\subsubsection{System characteristics affecting building formal integration quality}

The survey results underlined that all system characteristics affecting building appearance (i.e. all formal characteristics) have an impact on integration quality. These characteristics can be summarized as follows:

1. Shape and size of the modules

2. Type of jointing

3. Absorber colour

4. Collector material and surface texture

5. Size and position of collector field

For a completely successful integration, all these characteristics should be coherent with the overall building design logic. Consequently, the more the flexibility offered by a product for each characteristic, the easier the integration work for the architect.

\subsubsection{Concept of gradual levels of integrability}

Three progressive levels of integrability can be defined: basic, medium and advanced. [diagram 1, page 17]. Using this approach can help producers improve their products offer in corresponding progressive steps.

- Basic level of "integrability": Ensure collector formal flexibility

In order to be adaptive to specific contexts and buildings (both new and retrofits), solar systems must be able to provide flexibility in the module characteristics affecting building appearance:

- Module shape and size should offer a maximum dimensional freedom to cope with the great variability of building dimensional constraints.

- Offering an appropriate selection of jointing is an added means to interact correctly with the building envelope.

- A reasonable palette of collector colours and surface-finishing improves interfacing collectors with other colours and surface textures of the building.

From a practical point of view, offering a total formal freedom can make the production process too complicated and result in an uneconomical product. To help offer a satisfactory level of flexibility within cost effectiveness, the user's wishes and market trends may be evaluated, either through market analysis end/or specific surveys (like in the case of the EU project Solabs, chapter 4, section 5).

The main specific possibilities to offer extended freedom within the intrinsic constraints of the three solar thermal technologies are treated in chapter 3. 


\section{- Medium level of "integrability": Provide non-active elements}

The next integration step is to offer non-active elements, similar to the solar modules, but fulfilling only the added envelope function; they will help position and dimension the whole system field according to building composition needs. These elements are called "dummies", even though this word is slightly misleading in the case of the multifunctional modules, since these non-active elements still fulfil a real function (e.g. the cladding). They are used for architectural coherence, when areas of different solar exposure or when some parts of the building skin require small elements that cannot be economically produced as solar collectors (Fig. 2.3-1 a-b-c).
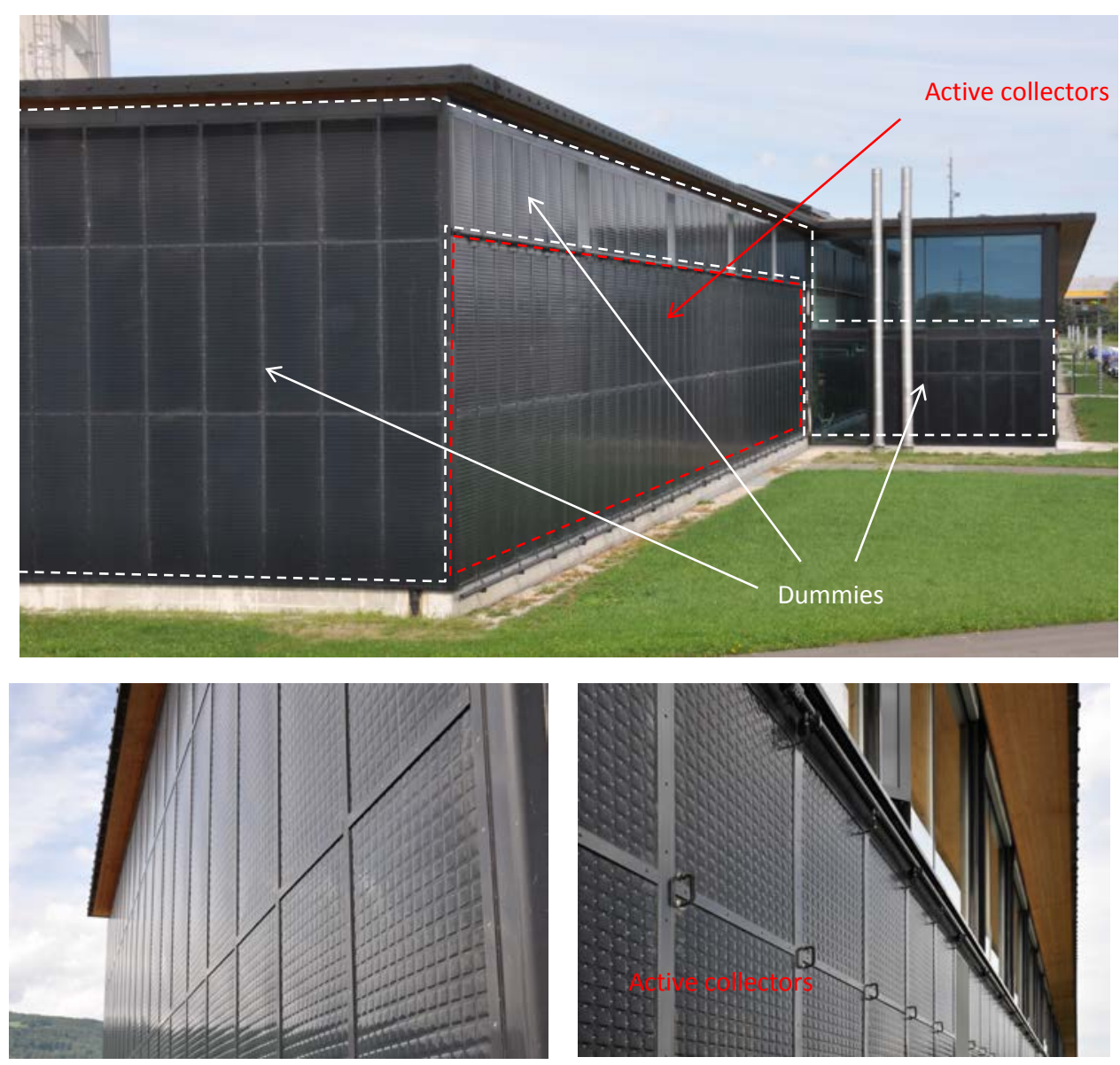

Fig. 2.3-1 a-b-c: Use of non-active elements in CeRN building in Bursins (Energie Solaire SA unglazed collectors system): Non-exposed facades are covered by non-active elements (left) having the same appearance as active ones (right, with connections). Only the external metal sheet is used in these parts rather than the double metal sheet normally used for the proper collectors.

\section{- Advanced level of "integrability": Provide a complete roof/façade system}

The third and maximum integrability level is reached when a complete active envelope system is offered by providing also all the needed complementary façade interface elements (jointing/finishing/angular components). This brings the additional advantage that the architect has to deal with one unique partner for the façade/the roof. 
To develop such integral solar envelope systems, two approaches can be considered:

1. Start from the collector and complete the system by designing all the necessary envelope elements around it.

This path gives the maximum freedom to designers, and might offer some additional functionality in the non-active elements, but at the extensive cost of developing a whole façade/roof concept.

\section{Start from the roof/façade system}

The second approach means to adapt the new multifunctional collector to an already existing façade/roof system.

This option will probably require some adaptations to the collector initial design and to the original envelope system (piping transfer, colour on demand etc...), but it will be in most cases quicker to develop, more cost effective and offer access to an existing market (this approach was for instance taken by the facade and roof manufacturer Rheinzink to develop its Quick Step Solar Thermie roof system, conceived to be compatible with the already existing Rheinzink Quick Step roof covering system - see chapter 5: Innovative products).

\subsection{Market trends /users preferences}

To ensure that the new collector will have a market, the desired level of freedom and the aesthetic preferences of the potential users have to be investigated. Existing market analysis and/or specific surveys can be used for this purpose.

Knowing users' expectations helps decide which compromises can be made and which ones should be avoided regarding the level of flexibility to be offered by the new product.

\subsection{Production feasibility and eco-impact}

Manufacturability and production cost of collectors and associated system elements need also to be considered. In this analysis, the overall construction cost reduction resulting from the multifunctional use of the collector should be taken into account. $A$ key challenge lies in the careful balancing of standardization needs and the user's desired freedom.

As for the economic cost, the energy cost of the multifunctional system can also be evaluated. The embodied energy required for the production/distribution/ mounting/dismounting of the system should be considered. The global eco-impact of the system can then be evaluated in the light of the energy savings resulting from the solar energy production and also from the merging of several envelope functions in one element. This point is especially important considering the global goal of the solar technologies and the ecological sensitivity of target customers.

Diagram 1 summarizes the whole development process to provide collectors as part of multifunctional envelope systems. 


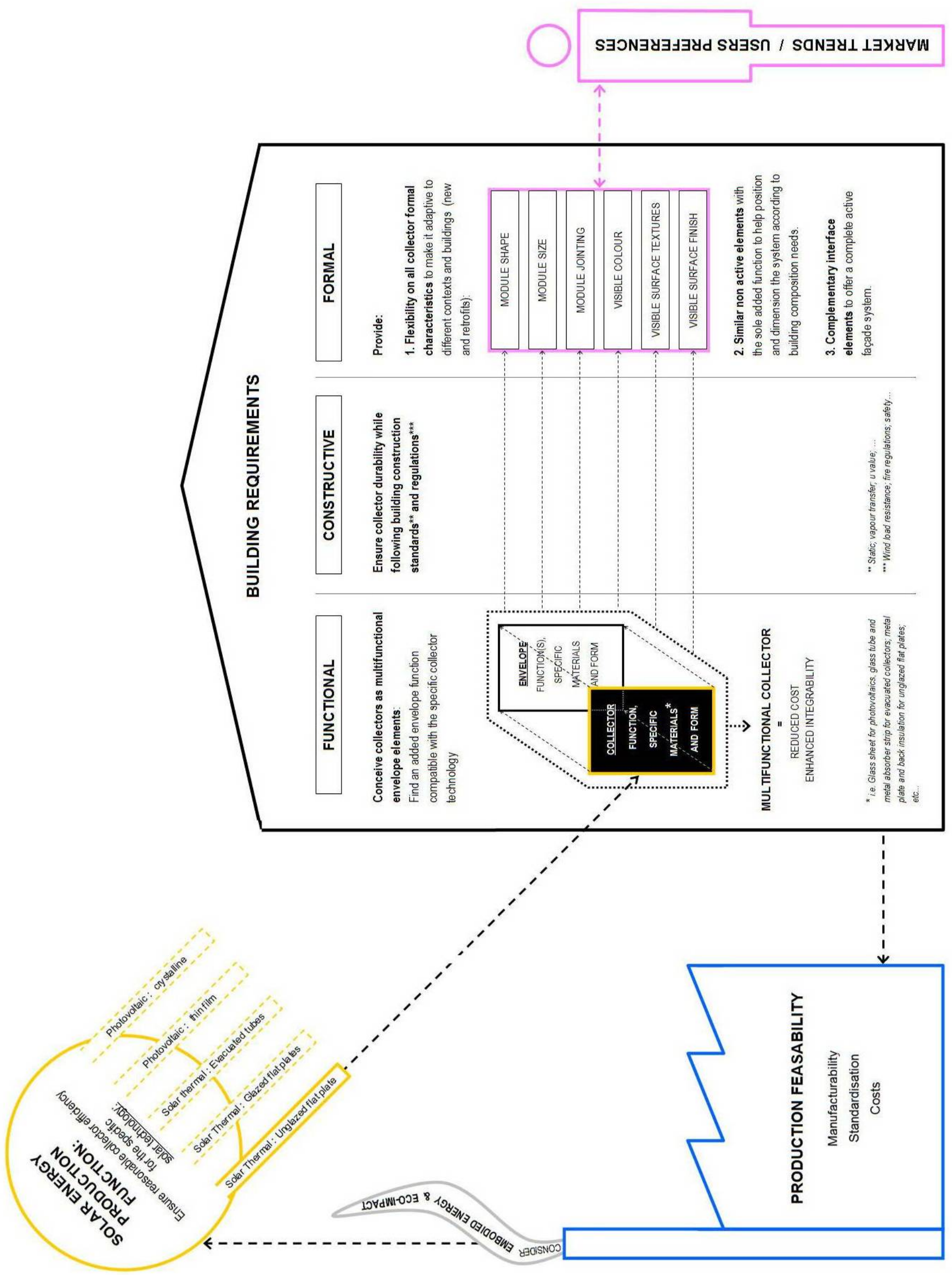




\section{PRACTICAL DEVELOPMENT GUIDELINES}

The following sections describe for each specific solar thermal technology (glazed flat plates, unglazed flat plates and evacuated tubes), the technical solutions and/or the architectural options available today to help meet the system development recommendations presented in the previous chapter.

This information should help manufacturers find new solutions toward the production of ST collectors conceived as part of multifunctional active envelope systems.

\subsection{Glazed Flat Plate Collectors}

\section{Multifunctionality}

The sandwich structure of glazed flat plate collectors makes them well suited for the integration into the building envelope layers, greatly favoring multifunctionality.

The collector layers can be merged with the envelope ones, so as to provide multifunctional components able to fulfill the traditional envelope functions, and in addition capable to produce energy.

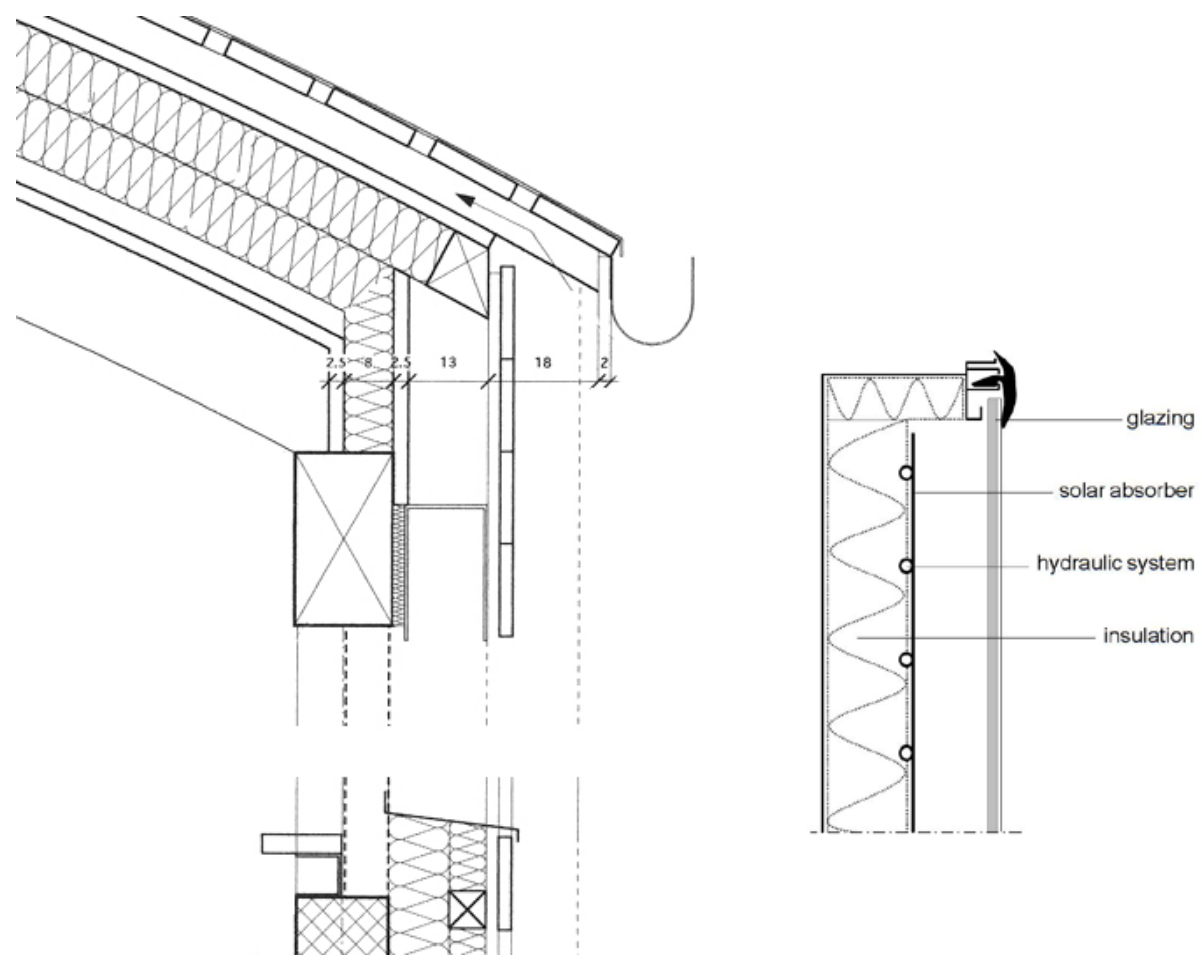

Fig. 3.1-1 left: cross section of a multilayered building envelope, with peripheral insulation. Fig. 3.1-1 - right: cross section through the layers of a glazed flat plate collector.

In roof applications, the external collector glazing can take over the roof covering function. Waterproofing issues have then to be treated carefully: both the jointing between modules, and the jointing with other possible roof finishing (e.g. tiles, shingles or metal covering) have to be made perfectly watertight within a design still adapted to 
building aesthetic expectations (see the jointing dedicated section, p. 25). The collector insulation can then be merged with the roof insulation, when compatible with vapor transfer issues, with great advantages in terms of insulation performances, but also in terms of costs and handling(On the problematic of vapor transfer issues and condensation risks when integrating collectors into the envelope layers, please refer to [4] [10]).
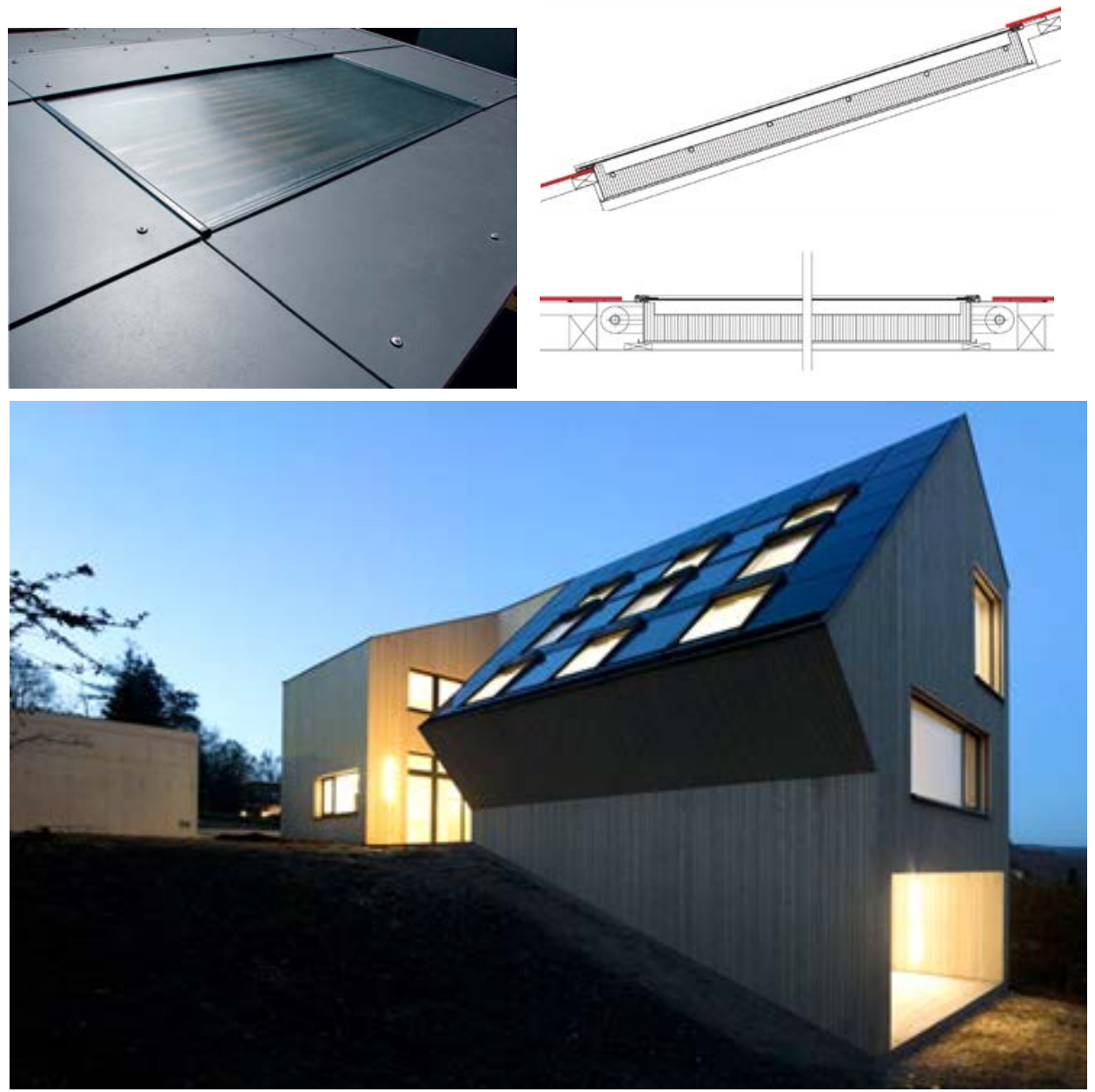

Fig. 3.1-2 up: Integration of a glazed flat plate collector as part of the multilayer roofing system, picture and details (Credits Eternit / Soltop, www.eternit.ch; www.soltop.ch).

Fig. 3.1-2 down: Velux sunlight house, Austria (credits: VELUX / Adam Mørk).
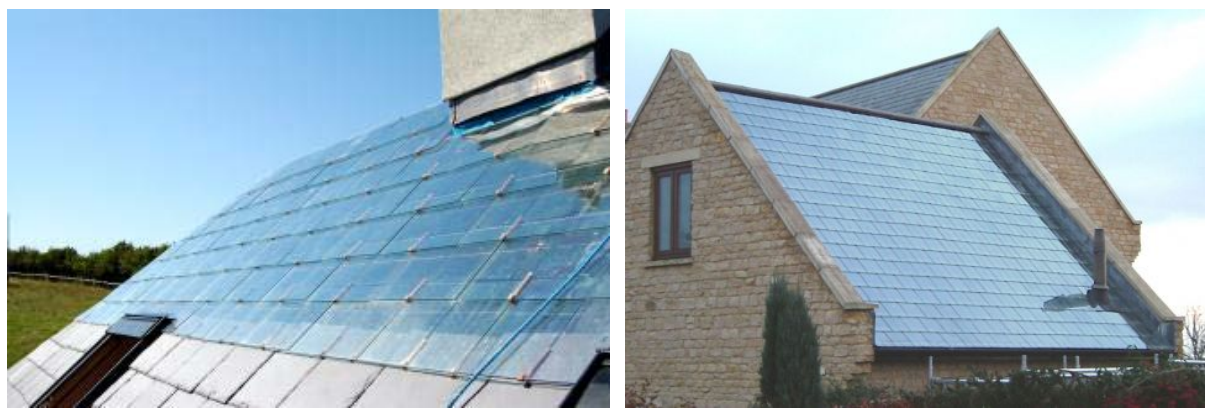

Fig. 3.1-3: Solar thermal roofing Solex Roofing (credits: www.solexenergy.co.uk). 
In façade applications, the external collector glazing can easily replace standard claddings, taking into account that the constructive typology of the hosting envelope has a major impact on the specific system implementation possibilities: a plain masonry wall, very common in building renovations, will raise different issues than a prefabricated metal envelope, a wooden building structure or a glass facade. Like in roofing applications, the back insulation of the glazed collector can be merged with, or can complement, the building's own insulation layer, with the above mentioned advantages (figs. 3.1-4 to 3.1-8). As mentioned before, vapor transfer through the different wall layers has to be carefully studied, to really provide effective solutions.

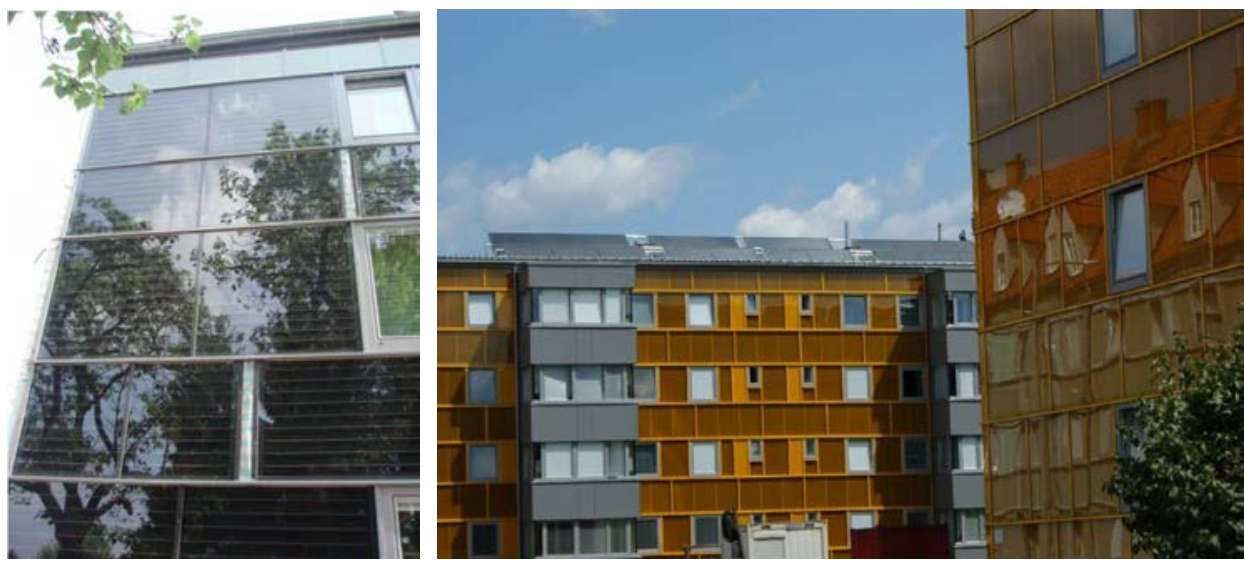

Figs. 3.1-4 and 3.1-5: Large scale prefabricated solar renovations in Austria (source : AEE-INTEC/ Gap Solutions) [http://www.estif.org/].

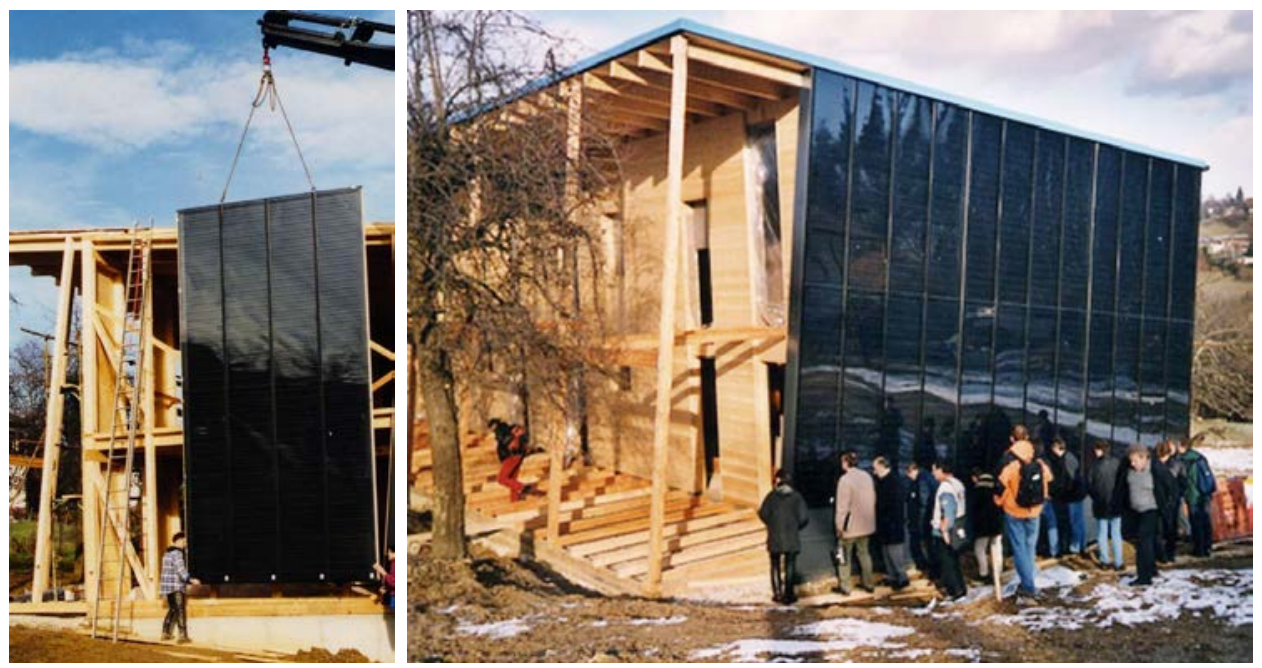

Fig 3.1-6: Two-family dwelling, Austria, 2001. Project management I. Bergmann, W. Weiss AEEINTEC, AKS Doma façade collectors (credits AEE INTEC).
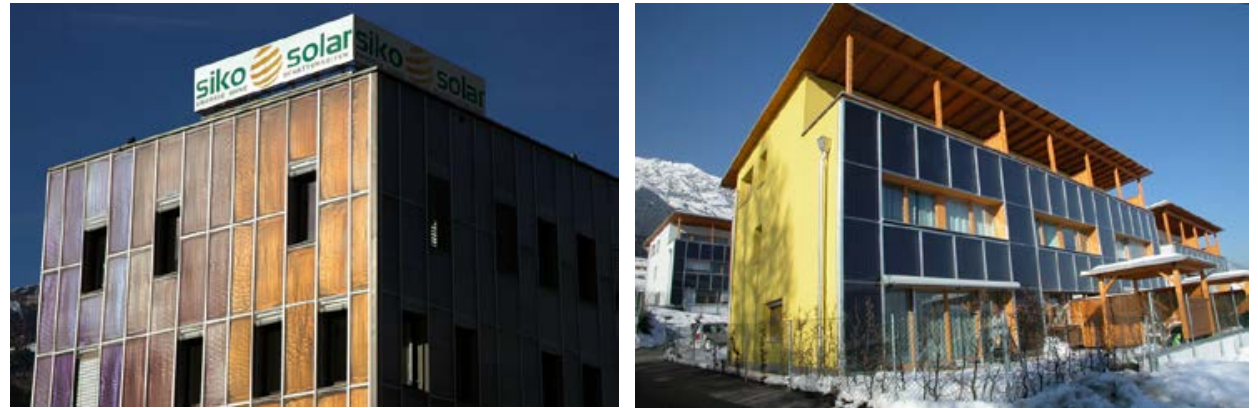

Figs 3.1-7 and 3.1-8: SIKO INTEGRAL façade collectors systems in Austria (credits: www.solar.at). 
Balcony applications can also be considered. Clearly, in this case the insulation of the collectors cannot be used as active insulation for the building.

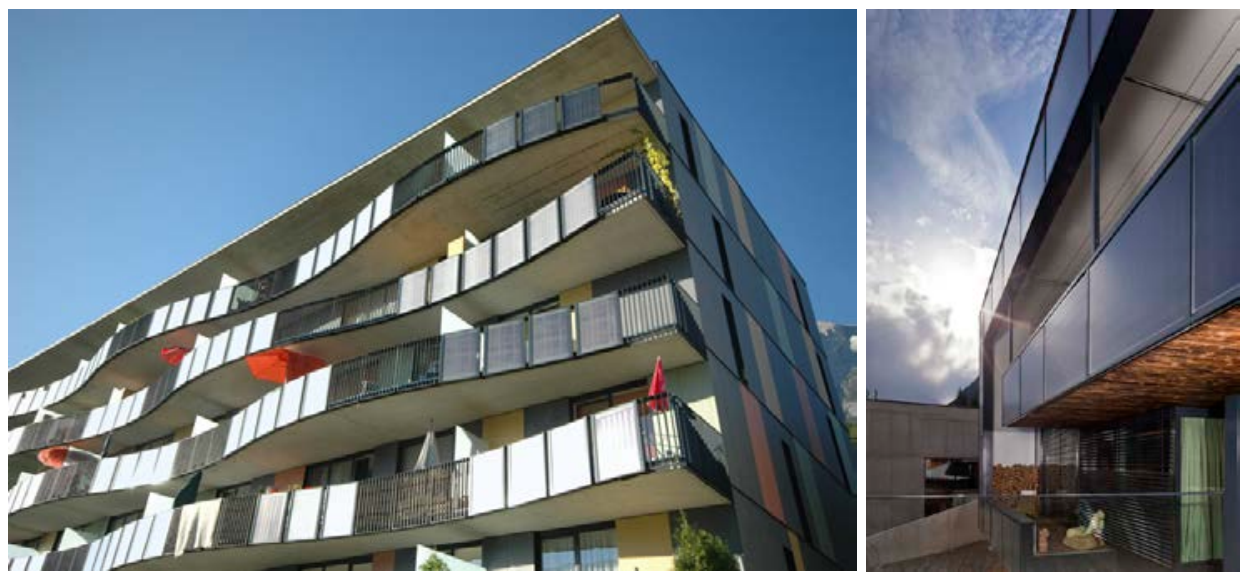

Fig. 3.1-9: SIKO INTEGRAL collectors as balcony fence (www.solar.at).

Sun shading applications have also been explored by some architects (Fig. 3.1-10). The thickness and weight of standard glazed flat plate collectors, together with their orientation needs (high tilting to vertical installation) often results in a certain architectural heaviness.

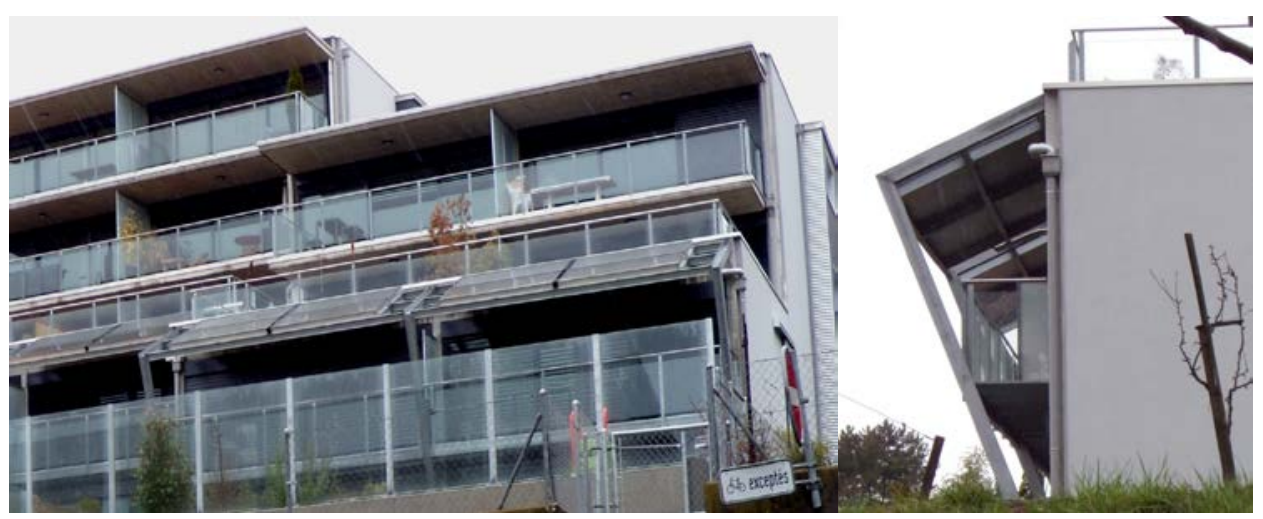

Fig. 3.1-10: Glazed flat plate collectors used as sun shading systems (credits EPFL-LESO).

A recent development has made available thinner glazed collectors modules based on triple glazing technology. (see Fig. 3.1-11). Their module thickness is only $3.8 \mathrm{~cm}$, versus the $10-12 \mathrm{~cm}$ of standard products. Besides simplifying integration into existing building facades, the reduced thickness also allows using the collectors into glazed facades, mounting them in the same frames that are used for triple glazing.
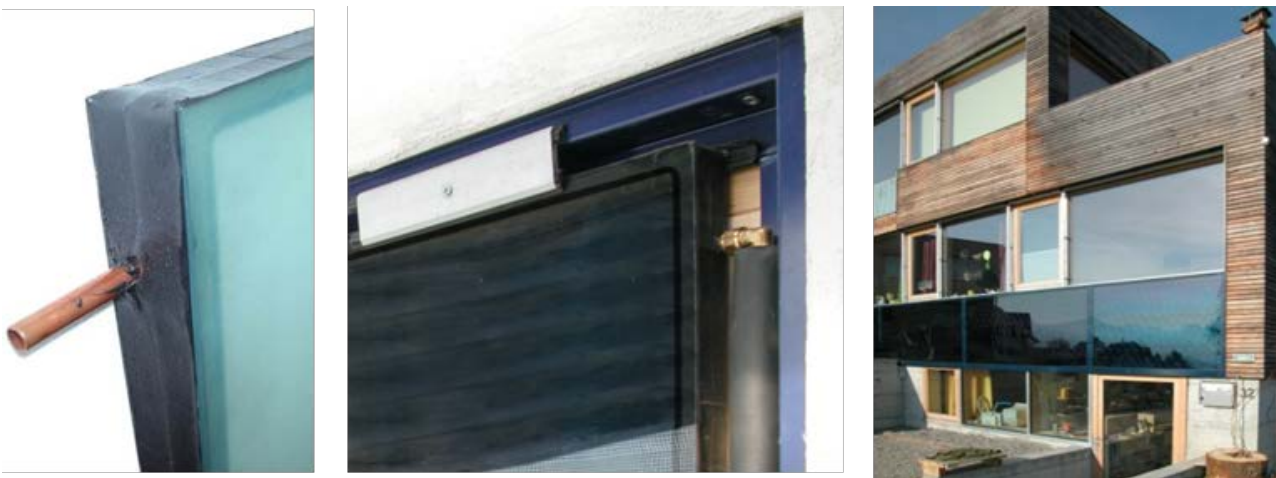

Fig. 3.1-11: Thin collectors based on triple glazing technology ( $\mathrm{H}+\mathrm{S}$ Solar) (see chapter 5). 
Even though the major applications for glazed flat plates are taking place in the opaque part of the envelope, new semi-transparent products are opening the way also for applications into the transparent parts. These kinds of applications are mainly intended as glare control systems, and are coupled with daylighting strategies (Fig. 3.1-12 left and right). As the glare control is ensured by the solar absorber placed behind the glazing, summer overheating issues have to be carefully addressed. One option is to use these elements in external ventilated double skins (Fig. 3.1-12 centre).
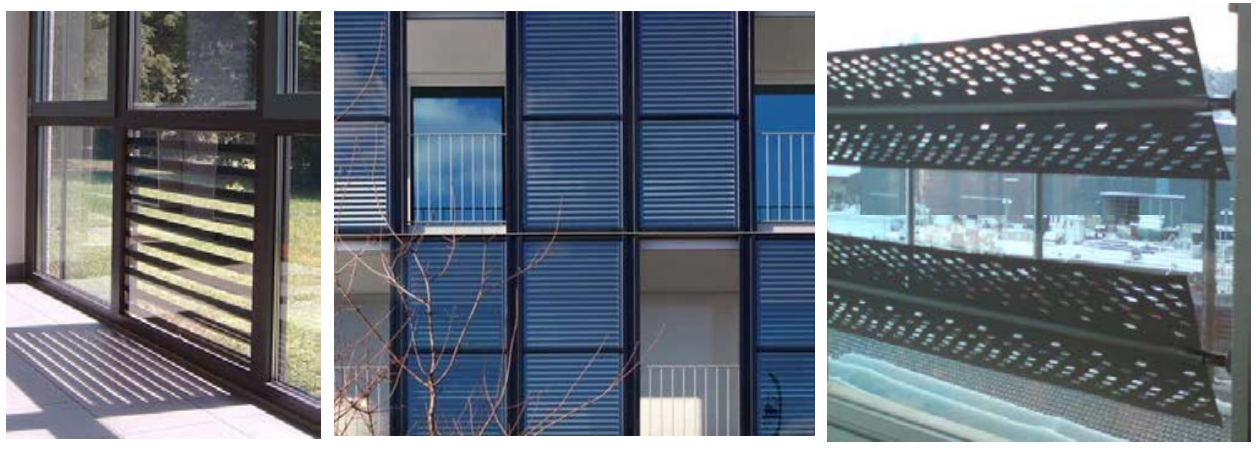

Fig. 3.1-12 left: RobinSun Solar Thermal Glass (www.robinsun.com); Fig. 3.1-12 center: RobinSun Solar Thermal Glass used as double skin system; Fig. 3.1-12 right: SSolar - White, Protected Strips absorbers (www.ssolar.com) (see product details in chapter 5).

Finally, a particular case is the one of polymeric glazed flat plat collectors. Their structure is similar to the traditional metal/glass collectors, but the flexibility of plastic materials and their reduced weight offers perfect conditions for good and innovative new design solutions. Only very few products do exist today, but research and developments are ongoing, and a dedicated IEA Task is presently tackling the subject, with promising results [18].
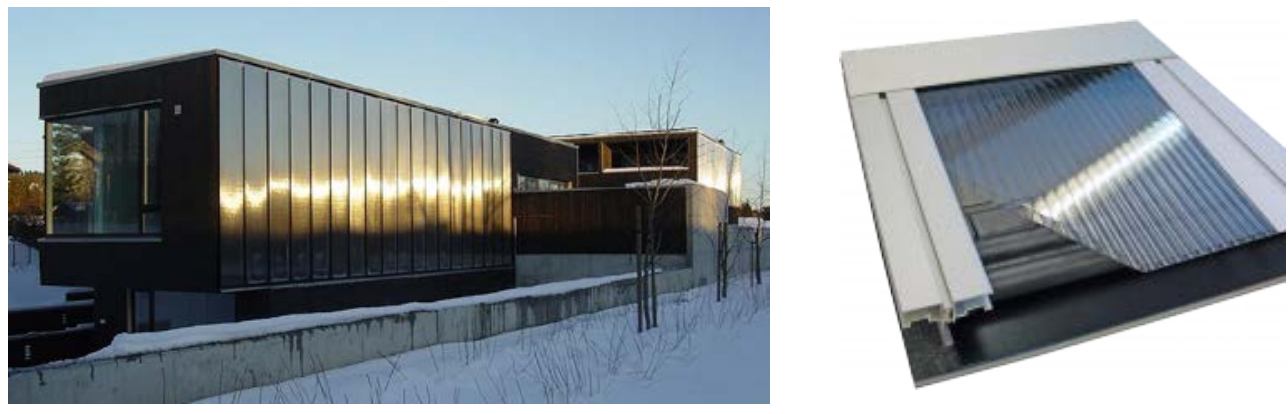

Fig. 3.1-13 Aventa polymeric collectors, facade mounted and product detail (credits: arch. Dahle/Dahle/Breitenstein AS, www.aventa.no) (see product details in chapter 5).

To help imagine more in detail in which ways new multifunctional systems could be developed, and what kind of flexibility these products could offer, the following paragraphs describe the possibilities offered by glazed flat plate collectors in terms of dimensions, jointing, colors and finish.

\section{Module dimensions}

Offering a certain module dimensional freedom is very important for the collector system to be able to cope with the great variability of building dimensional constraints. In glazed collectors, the solar absorber is protected by a glass and is generally placed in 
a casing, hosting also a back insulation layer. As a result, the mechanical constraints over the absorber are minimal (much less severe than for unglazed collectors, for instance), offering several solutions for the dimensional variability of the modules.

Small module variations can be obtained by varying the external casing size while keeping the same standard absorber plate inside. Larger variations require adapting the absorber dimensions, and consequently providing variability in the hydraulic system One solution is the use of cut to length absorber strips. The small width of the strips and their freely chosen length make it possible to compose absorbers of any form and shape, so that the limits in module dimensions are almost only depending on the available dimensions of the glass, and its cutting process. This system is used for instance by Austrian manufacturers AKSDoma and Winkler (Fig3.1-14)

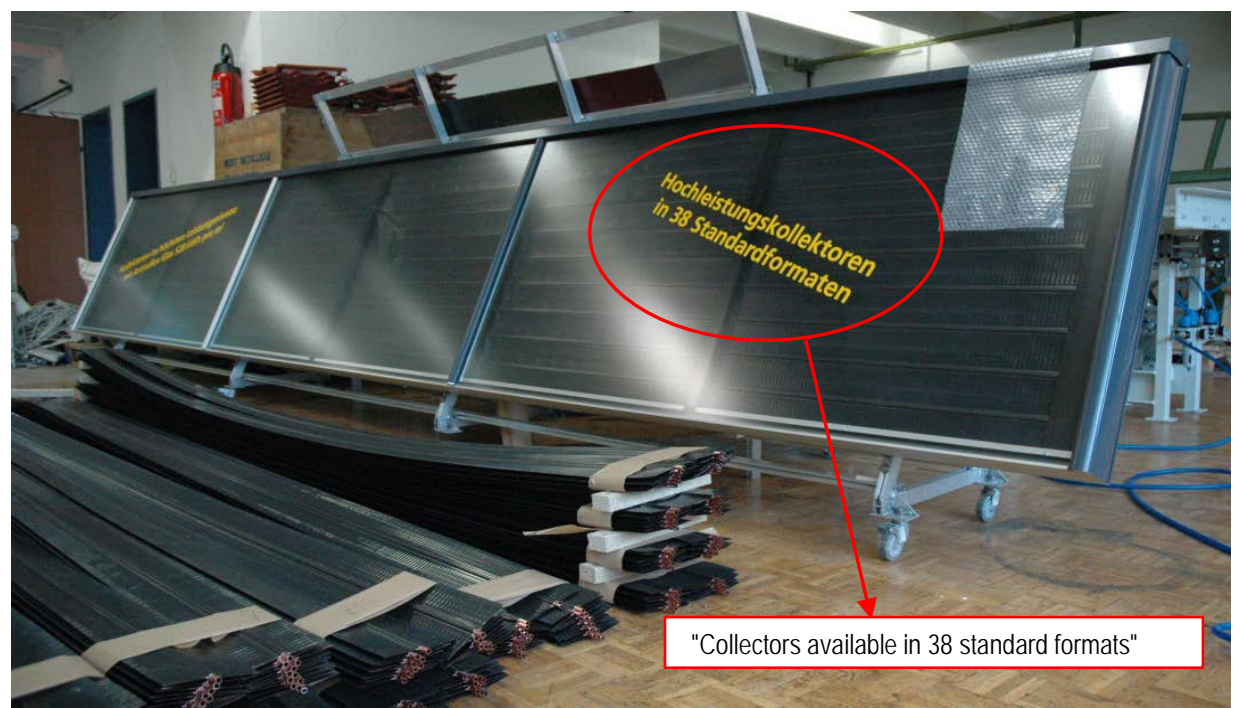

Fig. 3.1-14: Winkler glazed collectors system for facade: available in 38 "standard" formats.

Another way to provide absorber dimensional freedom could be the use of the rol bond technology. Roll-bond sheets are produced by rolling two aluminum sheets together under high pressure, while letting the hydraulic channels free to be "blown up". The cost of designing and "printing" the hydraulic circuit is very low, which allows producing small quantities at reasonable cost, and let manufacturer answer specific tenders with affordable custom made products.
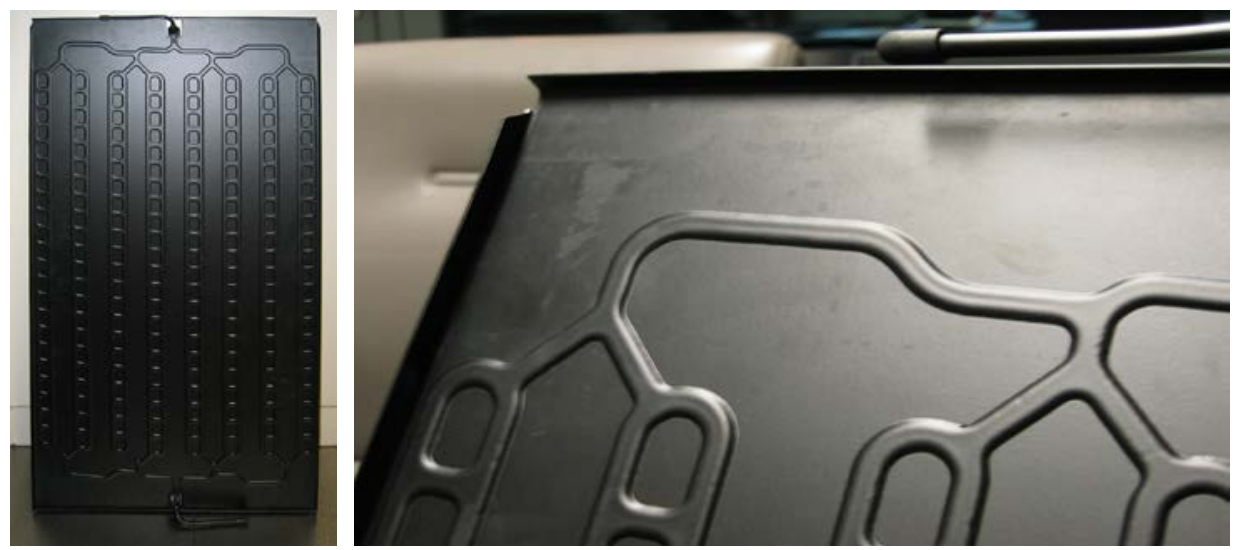

Fig. 3.1-15 a: Solar absorber prototype with hydraulic system using the roll bond technology. Fig. 3.1-15 b: Technology detail: blowing up the hydraulic circuit between 2 aluminum plates. 


\section{Jointing}

The impact of visible module jointing is often underestimated, but has actually an important influence on the integration quality. Different jointing types (framed jointing, negative jointing -i.e. profile free jointing-, horizontal jointing profile, overlapping jointing...) underline differently the modular grid of the building (or its absence).

In glazed collectors, the topic of jointing refers to two different issues: the jointing between the cover glass and the casing of the absorber, and the jointing between two collectors or between the collector and an adjacent envelope element.

The choice of the first joint that fixes the glass and ensures air/water tightness affects fundamentally the jointing between the modules themselves and should be designed carefully.

For factory built modules, a typical solution for the first joint is shown in Fig. 3.1-16. This technically satisfying solution presents the problem of imposing a large black rubber element (EPDM) in the front (visible) part of the collector, limiting the freedom in the way to deal with the inter-module jointing. Trying to keep this first joint as thin and discreet as possible offers more possibilities for the second one.
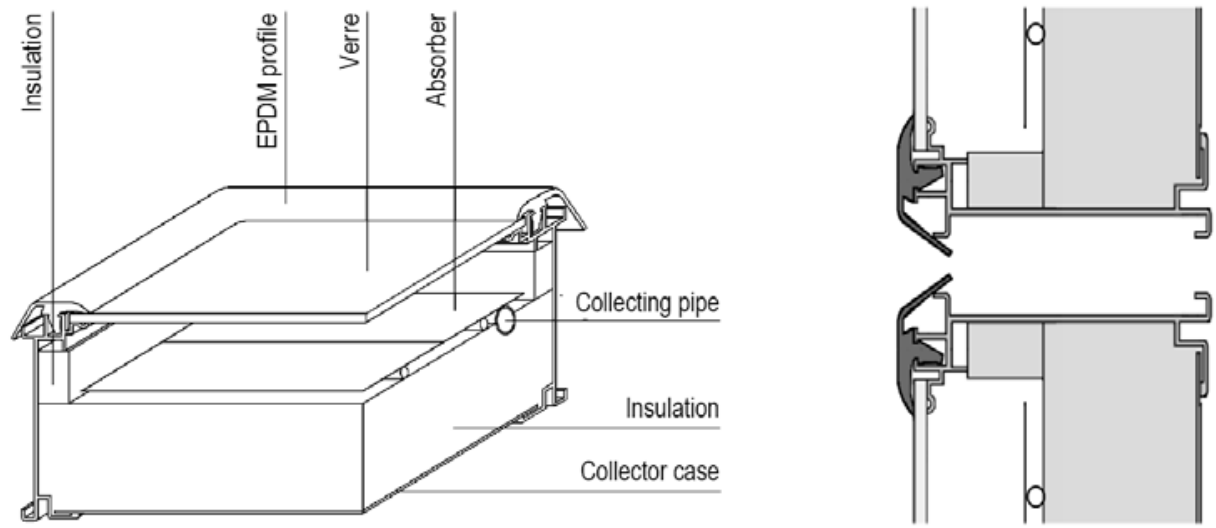

Fig. 3.1-16: Already assembled collector modules using EPDM rubber jointing to fix the glazing to the collector case.

A good solution to this issue is the use of the thin collectors based on triple glazing technology $(38 \mathrm{~mm}$.) (see product example fig. 3.1-11, Page 22). These collectors have almost no apparent casing joint, allowing the use of mounting and jointing techniques close to the ones used for standard windows (Fig. 3.1-17).
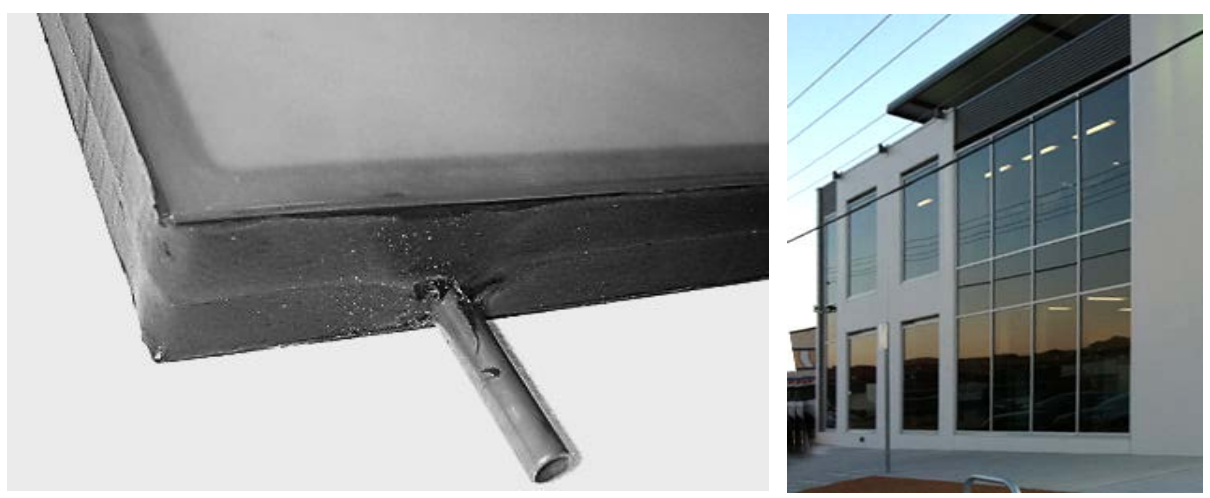

Fig. 3.1-17: Thin module with lateral peripheral jointing. 
The collector assembly process and its mounting on the building also have a major influence on the type of solutions that can be offered to users (pre- assembled collector boxes to be mounted on facades or roofs, or on-site assembled collectors, mounted during building construction). An option is to use these on-site assembled collectors for roofing, with proper jointing to ensure the water tightness.

For façade collectors assembled on site, the two joints are often combined in a single one, using the collector glass as cladding element. In this case, and using part of the collector insulation as building insulation, on site collectors offer an aesthetically interesting solution while saving components. The glass can be fixed using standard facade metal frames holding two modules' glass (or by punctual fixing), and the water tightness ensured by much slimmer rubber profiles, placed behind the glass or hidden by the fixing system (see examples in Fig. 3.1-18).
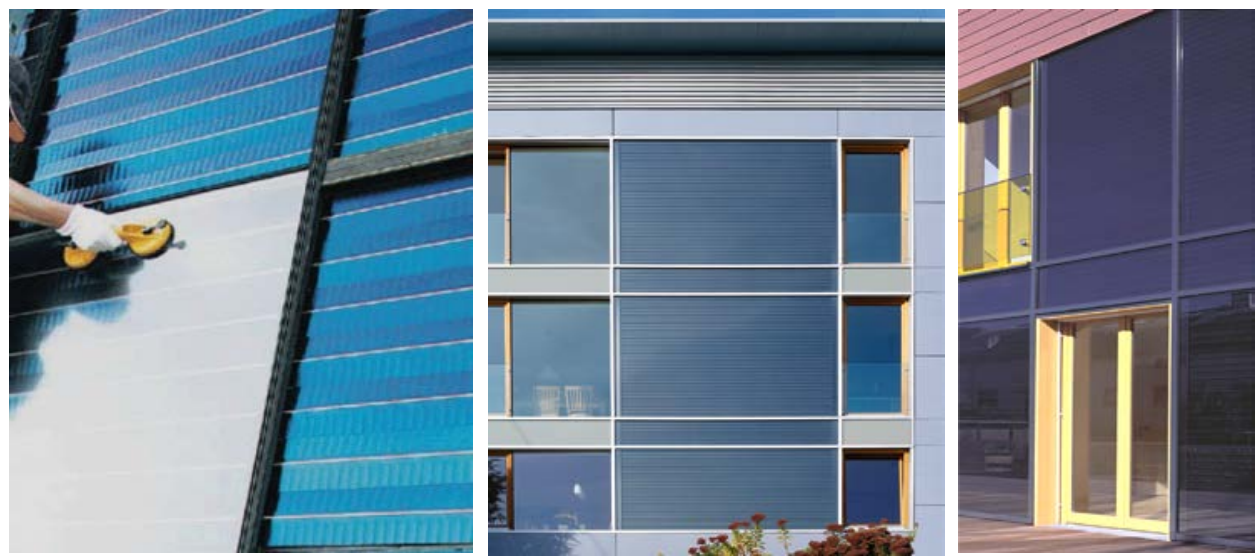

Fig. 3.1-18 a: glass fixing and jointing detail proposed by AKS Doma (VarioSol system).

Fig. 3.1-18 b: AKS Doma frame jointing: profile available in different colours.

Fig. 3.1-18 c: AKS Doma collectors mounted on Diakonie Wohnheim, Salzburg, Brandmüller\& Brandmüller architects.

The combination of free size choice for the collector with the use of specially developed jointing for on-site mounting gives very convincing results, as shown in the Fig. 3.1-18.

\section{Collector colour}

In the case of glazed collectors, the colour issue can be treated either at the absorber or at the glazing level.

At the absorber level several colouring possibilities are available, thanks to the weather protection offered by the covering glass.

One solution is the use of magnetron sputtering deposited "coloured" coatings, applied on the metal rolls to achieve selectivity. These coatings are characterized by low emissivity $(\varepsilon)$ and good absorption $(\alpha)$ values, and come in different, but always dark, colour shades. As this process requires coating large amounts of material in the same colour (a whole metal roll), the standard colour palette has to remain very small, and tailored colours can only be provided in case of extra-large scale projects.

Another option to colour the absorbers is the use of selective paints (as described in section 3.2 Fig. 3.2-6). The advantage of this solution is the possibility to apply the painting to already formed absorbers. This process is easier to apply for small quantities, and allows manufacturer to widen their products' colour palette. 
Yet completely different options are available when using the glass to provide the colour effect. Several techniques have been explored and can be considered when conceiving new systems. One major innovation comes from spectrally selective coatings developed for glazing at EPFL (Switzerland).

These thin films are able to reflect a small selected portion of the visible spectrum while letting the rest of the energy pass through (see Fig. 3.1-19 left). [19]. Several colour shades have been produced with a reflection strong enough to limit the view of the black absorber behind the glass, while only reducing the energy transmission by approx. 5\% (Fig. 3.1-19 right). The shade of the coloured reflection can be adjusted by shifting the peak of the filter within the visible range of the solar spectrum. In order to mask the absorber under all lighting conditions an additional diffusing treatment has to be applied on the glazing. Adding this diffusing layer at the outside part of the glass makes it possible to completely hide the absorber and obtain stable quality colours, without causing additional efficiency losses (see Figs. 3.1-19 left and right).
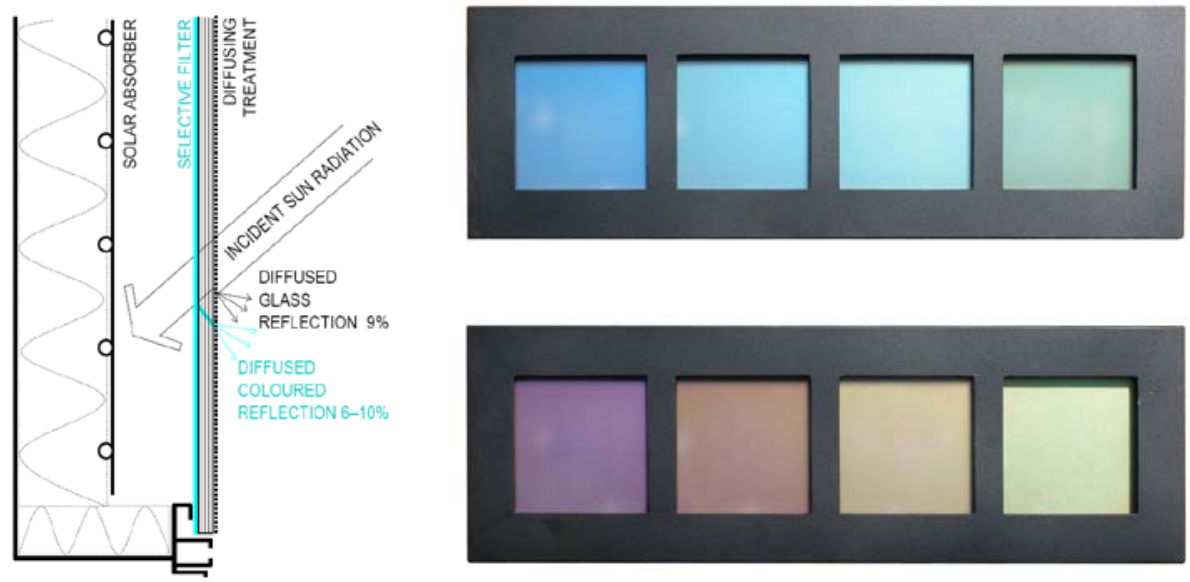

Fig. 3.1-19 left: Principle of coloured filter and diffusion layer.

Fig. 3.1-19 right: Various shades of acid etched coloured glasses in front of an Energie Solaire absorber: the absorber is completely hidden.

The major advantage of this new, visually non transparent, thermal glazing is that it can be used at the same time as collector glazing in front of solar absorbers and as facade cladding on non-optimally exposed areas of the building envelope. This makes it possible for a façade with active and non-active parts to have a homogeneous appearance.

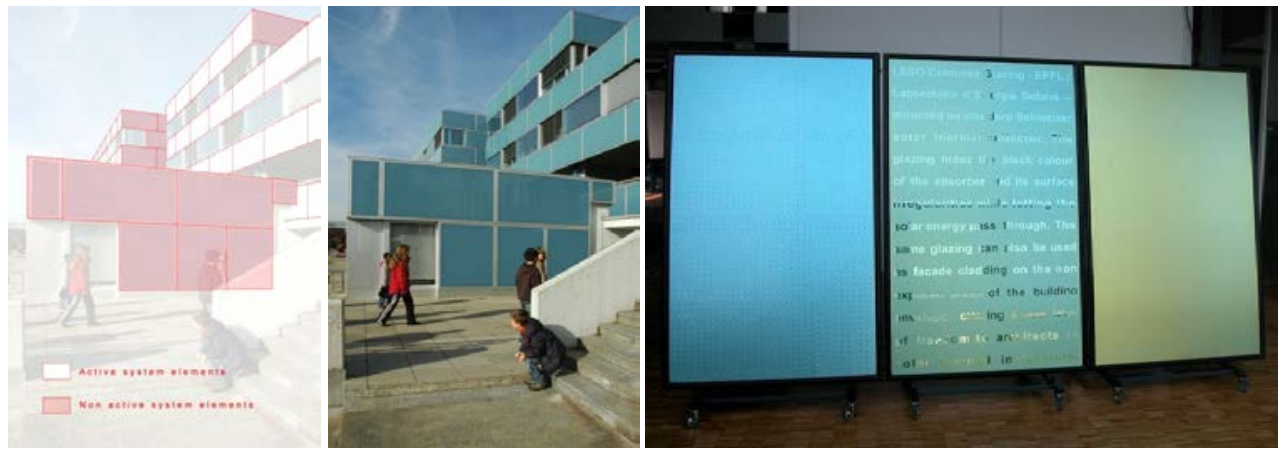

Fig. 3.1-20 left and center: Same glazing in front of active and non-active parts of a façade.

Fig. 3.1-20 right: Real size modules showing coloured solar thermal collectors for facades with the black absorber not visible through the glass. 
Silk printing, already used on glass for decoration and advertisement, could be a low cost alternative to colour collectors glazing. But as the printed parts block the sun radiation and reduce the collector performances proportionally to the printed area, only very light patterns can be considered. This approach has been tested, but never used yet in real products. A good appearance can in fact be obtained with dense printing (inducing high losses) while lighter patterns with better efficiency are still less convincing. The samples displayed in Fig. 3.1-21 show that under direct sunlight, even dense patterns cannot completely mask the irregularities in the underlying absorber.

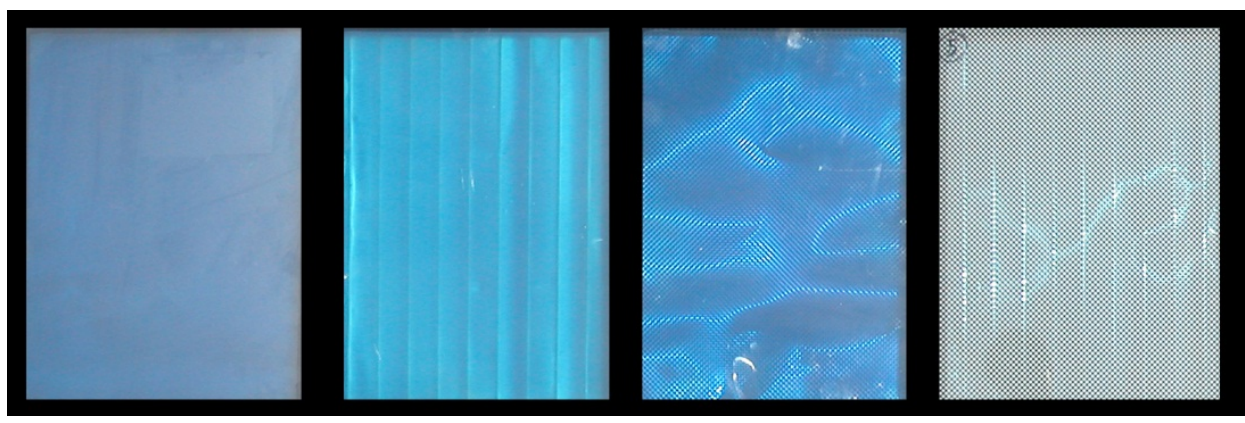

Fig. 3.1-21: Irregular absorber surface corrugations, visible behind silk printed glasses under direct sun (Samples produced by Christoph Hutter, $\mathrm{H}+\mathrm{S}$ Solar).

\section{Visible surface textures and finish}

As for the colour issue, both the glass and the absorber play a role in the perceived texture/finish of glazed flat plate collectors.

Many different textures and patterns are available today for the absorber surface (corrugated, embossed, perforated, regular/irregular...; matt, glossy, structured....), mainly depending on the surface coating choice and on the hydraulic system type/fixing (tubes, welding, gluing ...) (Fig. 3.1-22 a-b-c-d).
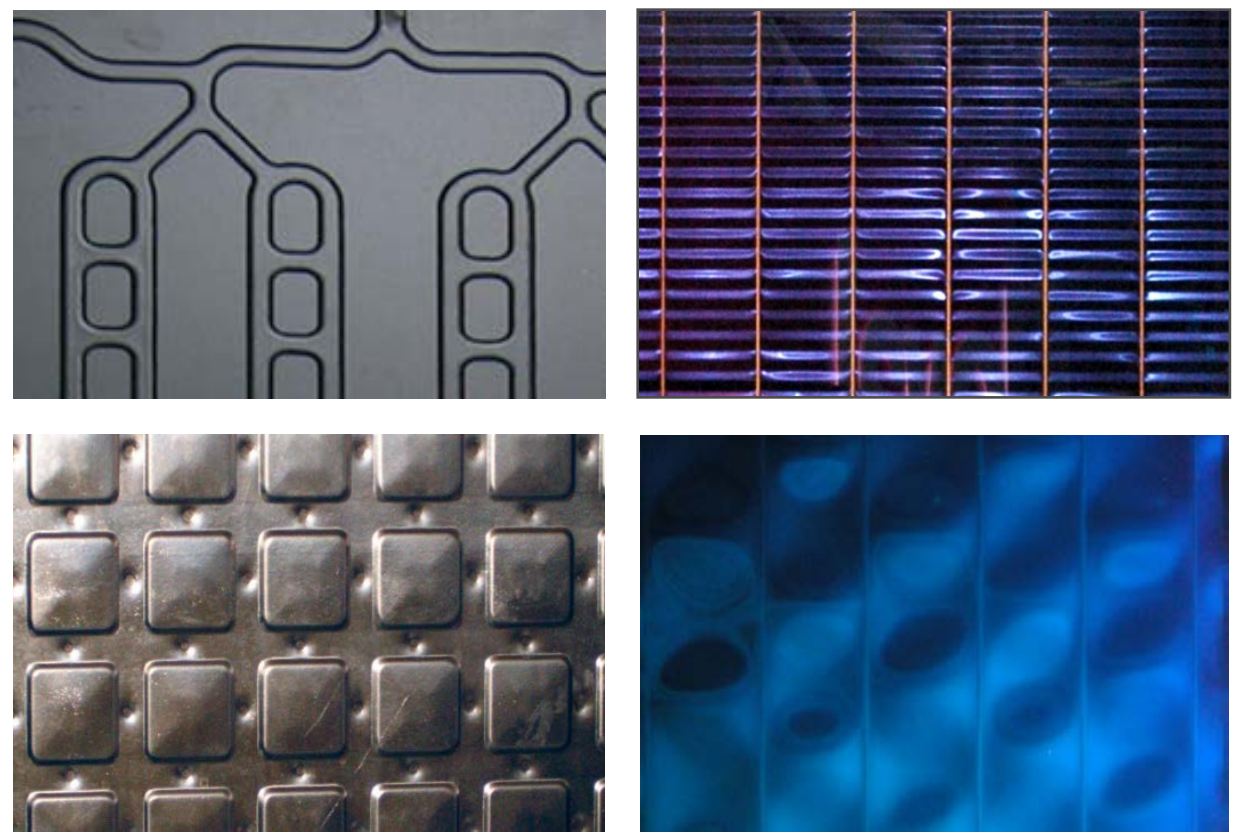

Figs. 3.1-22 a-b-c-d: Various absorbers surface geometries (and hydraulic system welding types) proposed by different manufacturers. 


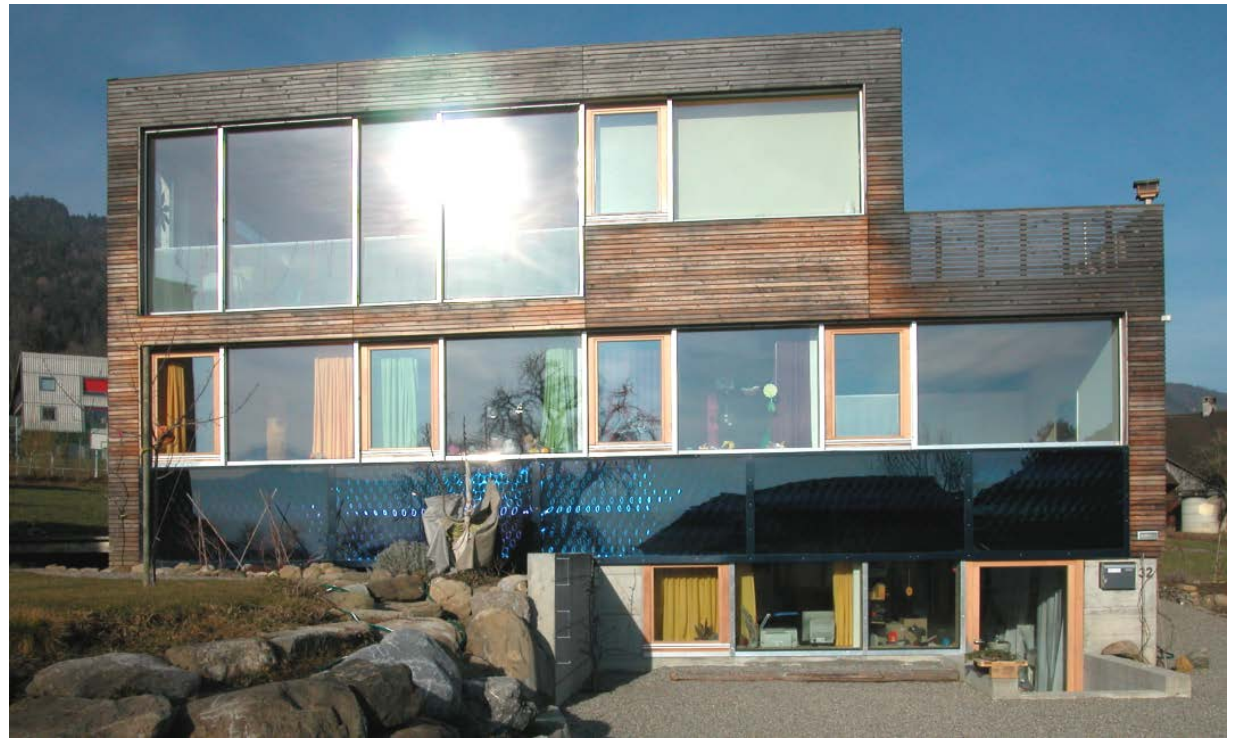

Fig. 3.1-23: Visual impact of the absorber texture under direct sunlight (Pict. H+S Hutter).

For the glass the different finishing options are on the contrary depending mainly on aesthetic choices. Structured glasses and acid etching treatments reduce the reflexions on the glass and can greatly diminish the visibility of the absorber.

Several glass finishing are available on the market, but the constraints of using extra white glass for solar collectors reduces the choice for industrial products. Only a small selection of structured extra-white glass is available today (Fig. 3.1-24) and industrial extra white acid etched glazing is still hard to find.
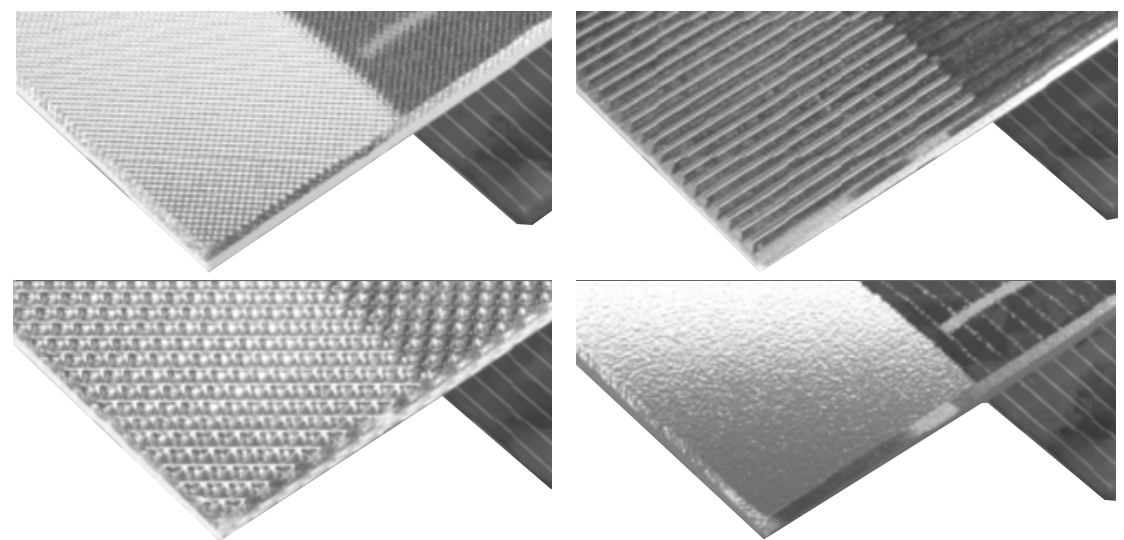

Fig. 3.1-24: Various surface textures patterns (obtained by lamination-roll glass) offered by SaintGobain for the Albarino extra white glass family. (Image made from Saint-Gobain pictures: http://nordic.saint-gobain-glass.com). 


\subsection{Unglazed Flat Plate Collectors}

\section{Multifunctionality options}

As for glazed collectors, roofing applications and façade cladding offer good multifunctionnality opportunities for unglazed flat plate collectors.

When used as multifunctional cladding, though, the absorber of unglazed collectors is not protected by a glass and has then to resist shocks and weather. The absorber coating has to be durable, and its metal plate has to be able to take over correctly all the protection functions of the cladding or roofing element, ensuring water tightness when needed.

One safe way to ensure these building functions is to inspire the new system from existing envelope systems like metal roofing, or metal claddings (planks claddings, cassette claddings or profiled sheets claddings).

An inspiring example of such approach is the Quickstep ${ }^{\circledR}$ Solar Thermie collector system (Fig. 3.2-1) made by Rheinzink on the basis of their much older standard Quickstep product for roofs. The two products are compatible and have exactly the same appearance so that the active modules can be easily integrated anywhere in the roof area (see product details in chapter 5 , innovative products).

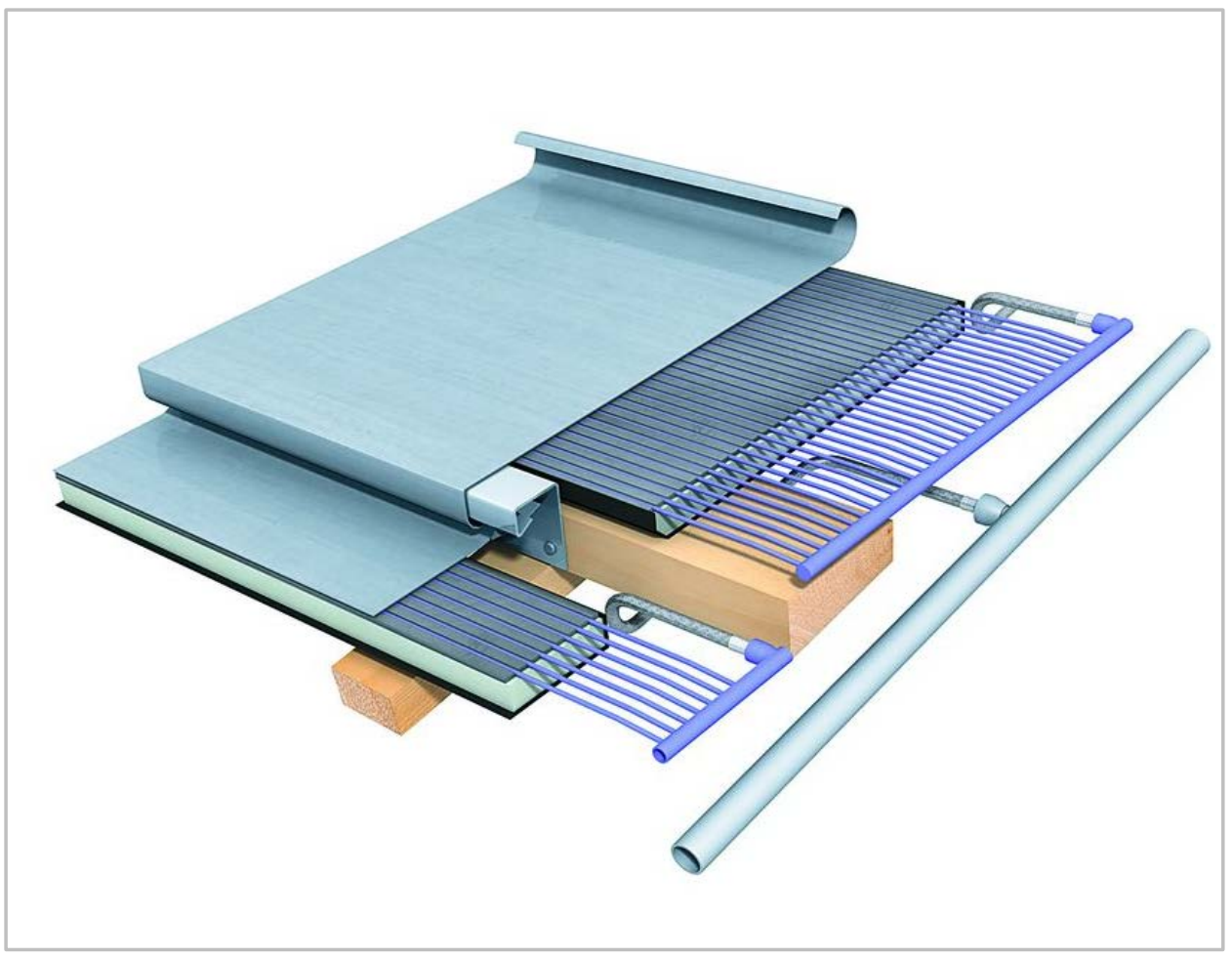

Fig. 3.2-1: QuickStep ${ }^{\circledR}$ Solar Thermie, from Rheinzink (credit Rheinzink).

An example of innovative unglazed multifunctional product for facades, is provided and thoroughly documented in chapter 4 (Solabs plank systems).

Finally, another example, the Energie Solaire Solar Roof deserves to be mentioned. This collector has not been developed as part of an existing envelope system, but the characteristics of its absorber make it a perfect multifunctional element for both roof 
covering and façades cladding. The selective black surface allows very good energy performance for an unglazed system, and its peculiar fully irrigated heat exchanger made of two structured stainless steel sheets allows the integration on all types of roof profiles, even curved ones. But most of all it allows the use of non-active elements (made of the external metal sheet only) of any shape and size to be used as dummy elements and complete the façade/roof covering system (Fig. 3.2-2 left. See also Figs. 3.2-1 a b c and 3.2-8).
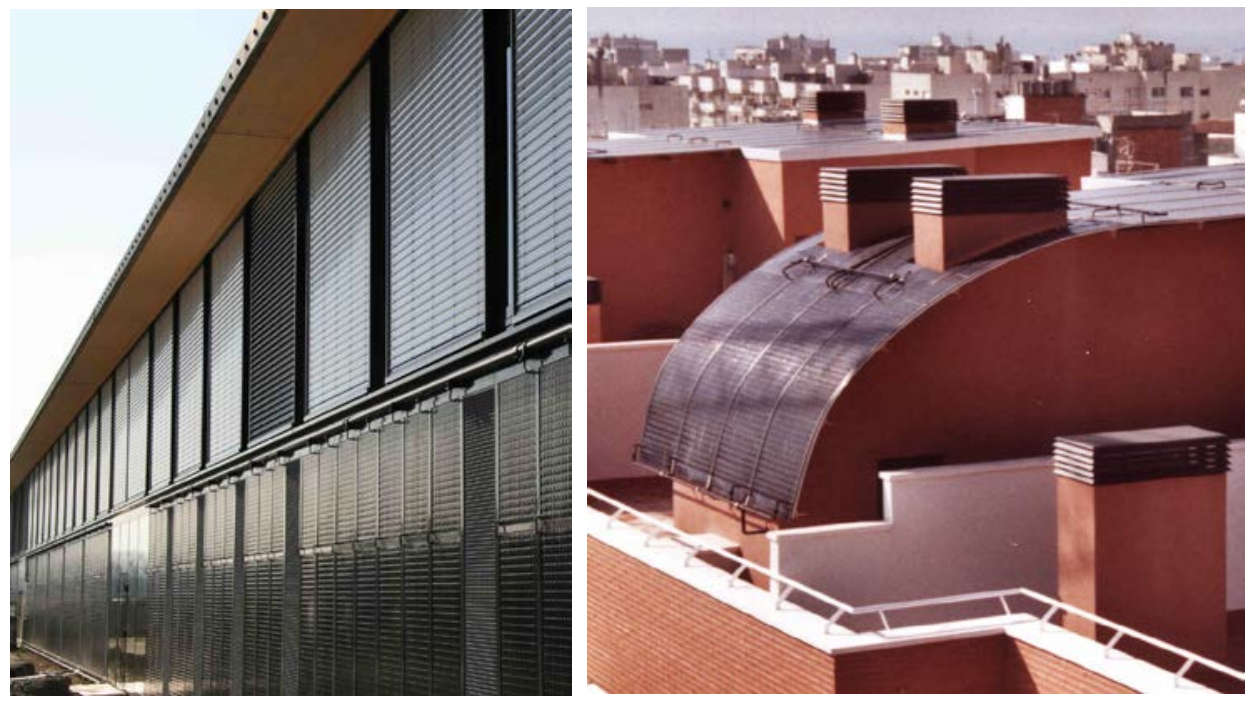

Fig. 3.2-2 left: Façade integration of unglazed flat plate collectors used as façade cladding.

Fig. 3.2-2 right: Roof integration of unglazed flat plate collectors used as roof covering. Credits Energie Solaire SA.

\section{Module dimensions}

The module dimensional freedom is the most important asset to cope with the great variability of building dimensional constraints, especially in renovation projects.

One practical approach can be by referring to the situation of the metallic cassettes and planks cladding elements: architects ask for an almost complete dimensional freedom when working with cassettes (Fig. 3.2-3), and planks are available cut to length, and with a small height, easing the dimensional adaptation to the facade.

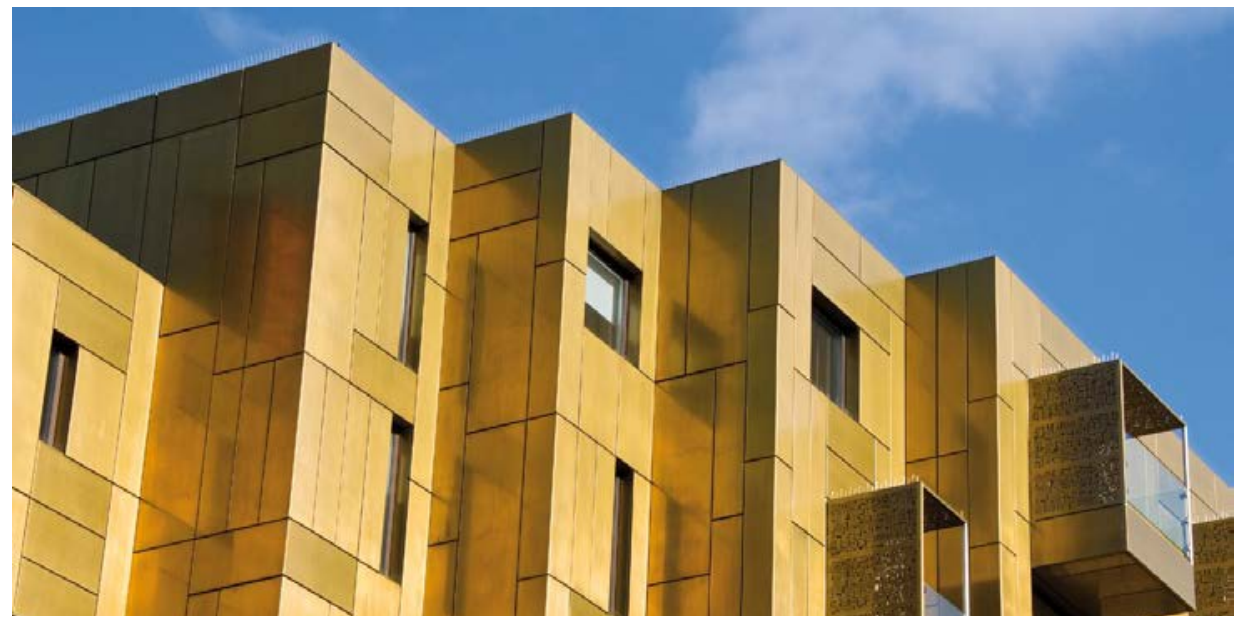

Fig. 3.2-3 Façade cladding with cassette system (http://www.kme.com/). 
This required high flexibility is difficult to achieve with solar collectors, but possibilities do exist to work in that direction.

For flat plate collectors the dimensional flexibility depends mainly on the level of flexibility offered by the hydraulic system of the absorber. If possible, this freedom should not require reconsidering the whole pattern of the hydraulic system for every size (for instance by taking a modular approach). As the absorber is not protected by a covering glass, the cut to length absorber strips solution mentioned for glazed collectors (page 24) is not easily applicable for unglazed systems.

One interesting solution lays in the roll-bond technology (see description in section 3.1 and Figs 3.1-15, 3.2-9 a b c), offering real possibilities of extensive dimensional freedom even when producing small quantities.

Another solution is to work with plank shapes, with a fixed and small enough plank width, using glued or welded piping system behind the front metal sheet. This approach was taken by the EU project Solabs, aiming to deal with the building dimension variability within a relatively standard module (see project details in section 5 ).

\section{Jointing}

As unglazed flat plate collectors are technically simple, they can be assembled without the need of peripheral jointing. The interface jointing between the modules can easily be developed in the form of a smooth negative jointing, very common in facade metal claddings (Fig. 3.2-4 left).

Alternatively, this jointing type can also use standard covering profiles, according to building specificities and the architect's approach (Fig. 3.2-4 right).
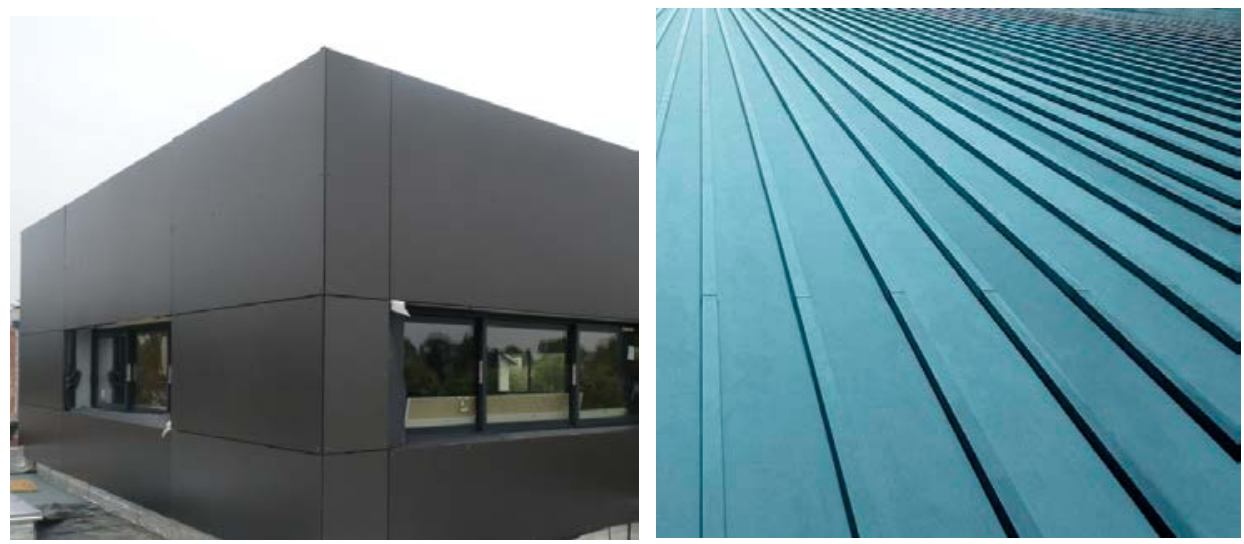

Fig. 3.2-4 left: Negative jointing between cassettes in a metallic façade cladding (Ducry SA).

Fig. 3.2-4 right: Jointing using covering profile in a roofing system (Rheinzink).

When using collectors as roofing elements, the jointing has to ensure perfect water tightness, and needs a very careful attention. Again the experience brought by the building practice in existing roofing systems should be used (Fig. 3.2-5). 

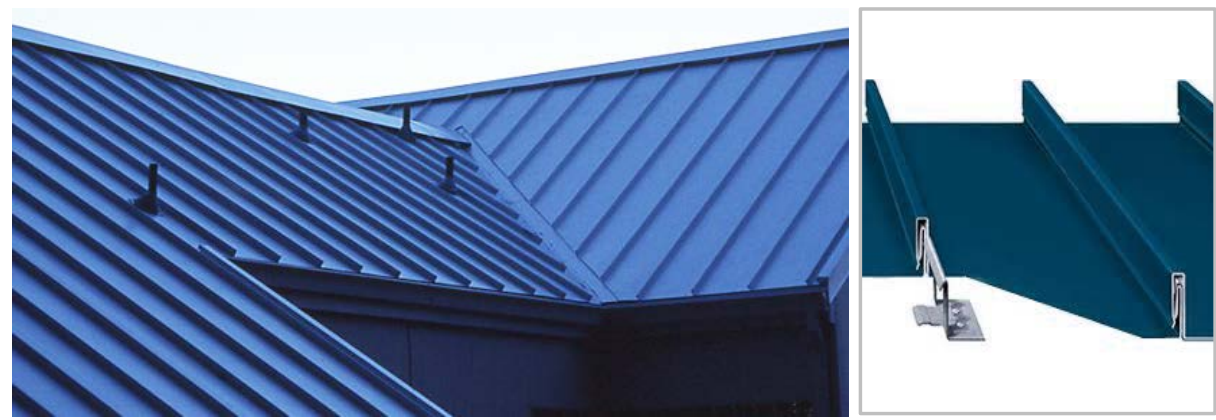

Fig 3.2- 5: Example of possible jointing solution for unglazed flat plate collectors: standing seam technique (right: standing seam technical detail).

\section{Collector colour}

The perceived colour in unglazed collectors results only from the coating or from the material of the absorber plate, which is usually black, to optimize heat collection. Black absorbers should remain an option, but other colours can be provided nowadays, at the cost of a somewhat reduced efficiency. An important challenge is to offer coloured coatings (paint or deposition layers) keeping relatively high absorption and low emissivity levels, while being stable enough to be weather resistant. One option is to use thickness insensitive spectrally selective (TISS) paints, like the ones developed by the National Institute of Chemistry of Ljubljana, offering various colour shades. The great advantage of this solution is that these paints can be applied on the already formed collector, allowing manufacturers to propose a wide color palette, also including colour on demand (Fig. 3.2-6).

The coloured absorbers obtained by magnetron sputtering used in glazed flat plate collectors are usually not suitable without additional protective treatment, due to their sensitivity to outdoor conditions.
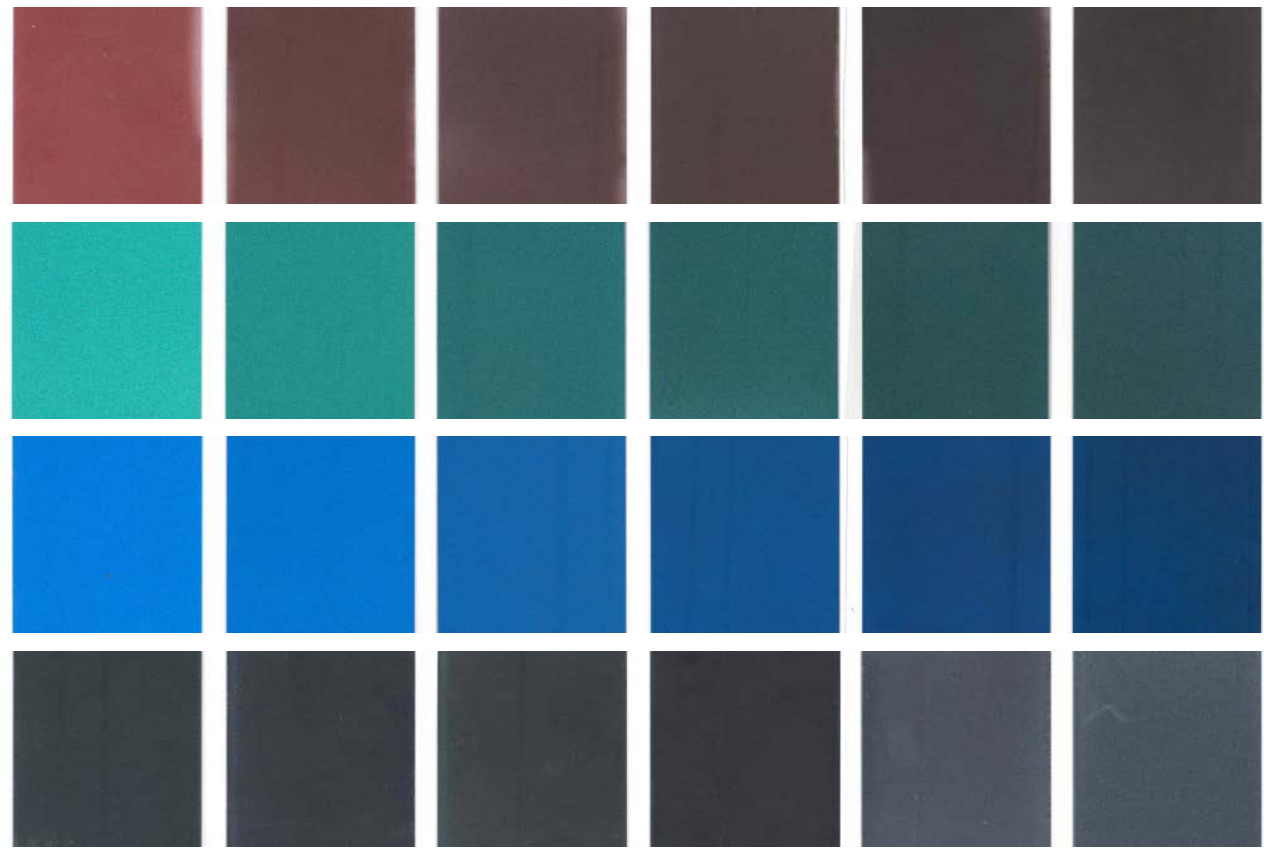

Fig.3.2-6: Thickness insensitive spectrally selective paints (TISS) palette developed at the National Institute of Chemistry Ljubljana, Prof. Boris Orel, within EU project Solabs. 
In several applications requiring less severe constraints on efficiency, like pool heating, unglazed collectors are often made of synthetic material. In these cases the use of coloured absorber materials can also be an option (Fig. 3.2-7).
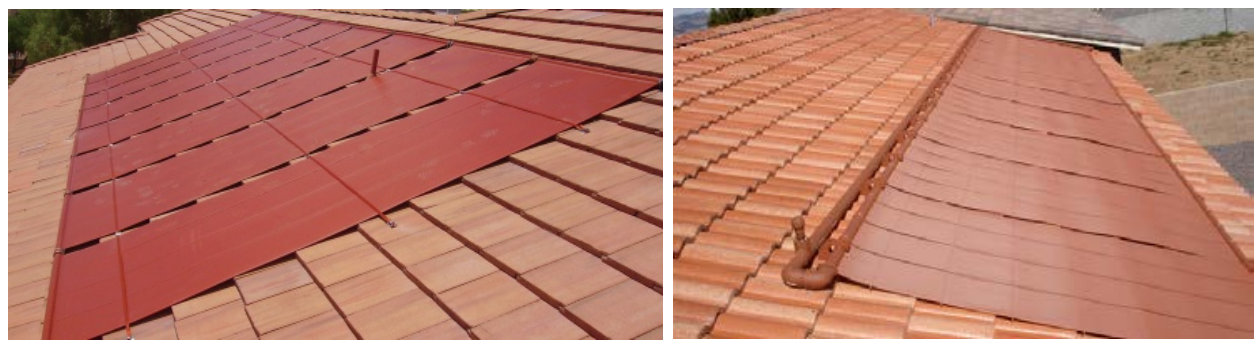

Fig. 3.2-7: Absorbers using non-selective colour material to match terracotta tiles roofing.

\section{Visible surface textures and finish}

In unglazed collectors, the visible texture/finish depends only on the absorber itself, as it is the most external layer of the collector (no glazing to hide its appearance). The absorber, as already mentioned in the above section on dimensions, is strongly affected by the hydraulic system type, so that working on collector finish means also working on the hydraulic system concept. If the hydraulic system is made of pipes, the collector appearance is affected by the technology used to fix the pipes: a traditional spot welding will bring different marks on absorbers than laser welding or gluing.

For instance, the SOLABS plank collector prototype (see development in chapter 5) can have a smooth painted surface thanks to the use of a complex gluing system behind the absorber (Fig. 3.2-8).

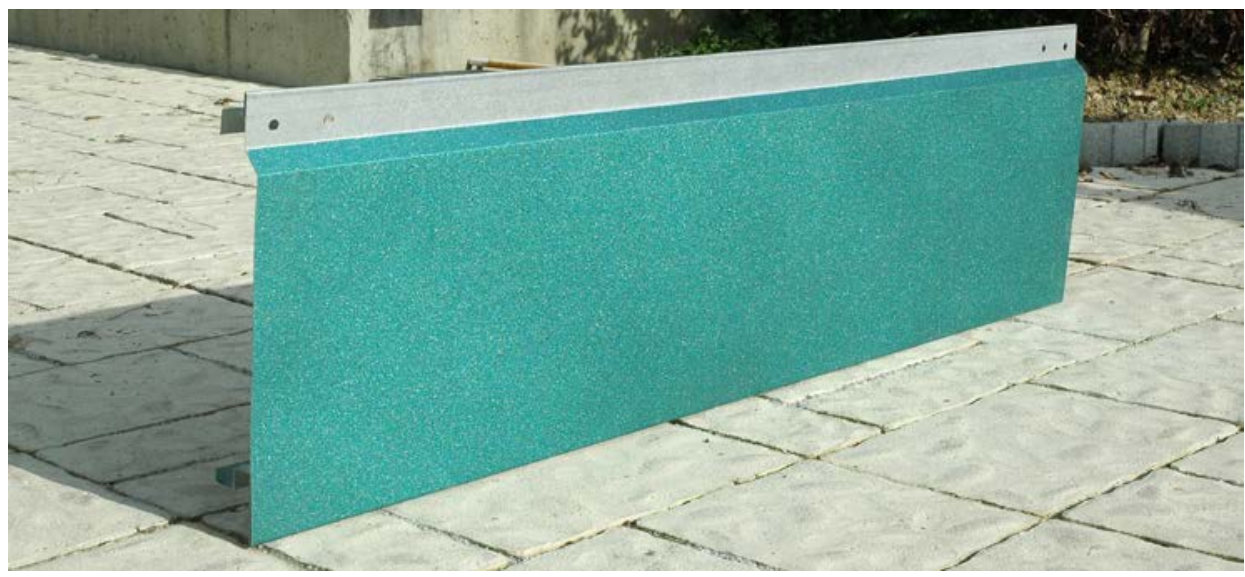

Fig. 3.2-8: Smooth absorber surface on SOLABS collector.

Different approaches can also be taken, but always starting from the hydraulic system design. The collectors of Energie Solaire have for instance a hydraulic pattern made by two off-setted metal sheets with embossed squares (Fig 3.2-9 left), whose embossed squares are clearly visible and strongly characterize the product (Fig. 3.2-9 right). 

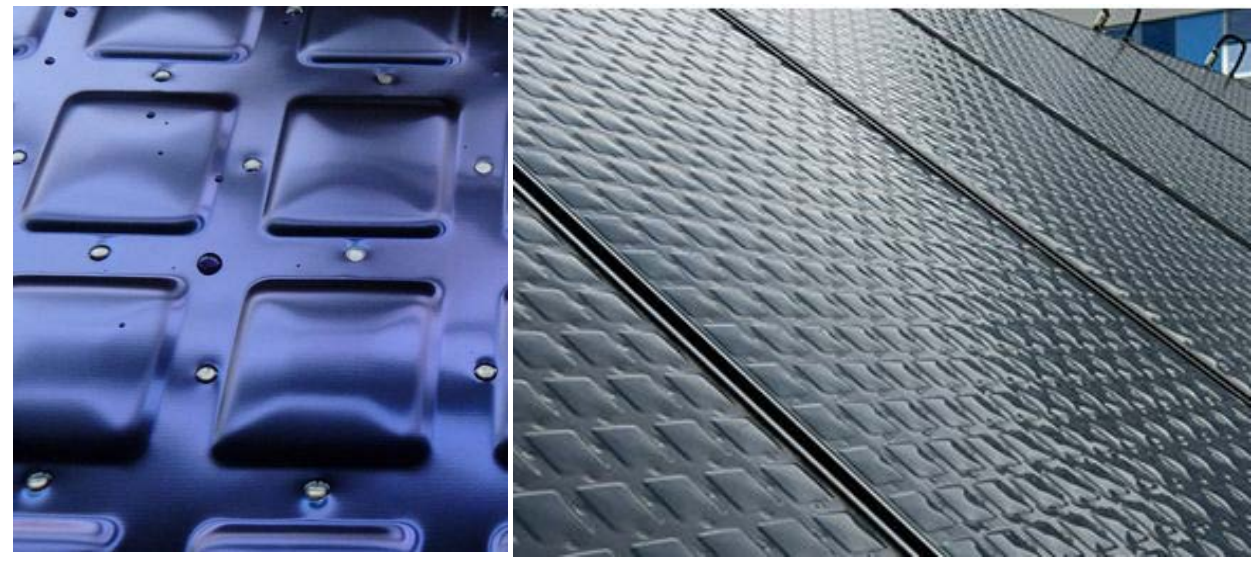

Fig. 3.2-9 left: Embossed squares pattern of Energie Solaire absorber.

Fig. 3.2-9 right: Texture appearance of installed Energie Solaire collectors.

The roll-bond technology allows developing inexpensive innovative hydraulic circuit paths and let the hydraulic channels be either well visible on the absorber external face, or completely invisible, with a totally flat, mark free, external absorber surface (Fig. 3.2-10 a).

The two examples in Figs. 3.2-10 b and 3.2-10 c demonstrate the variety of possible patterns with this technology.
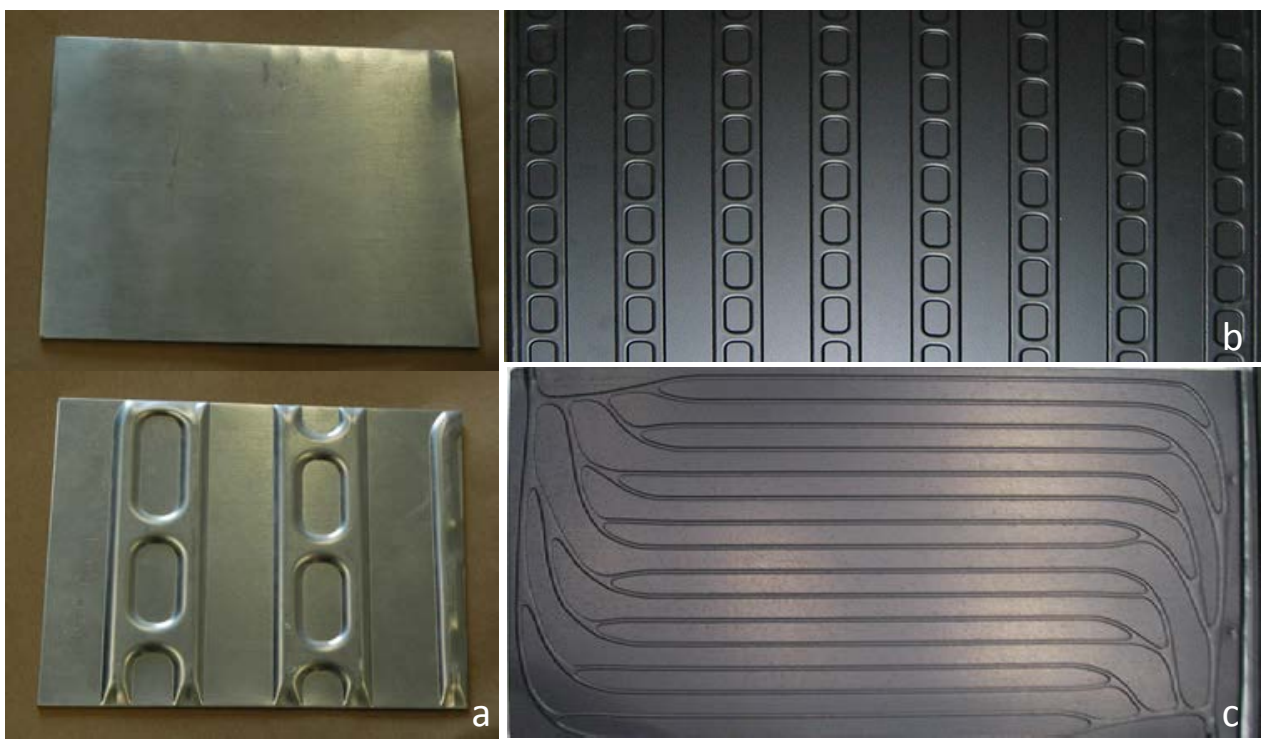

Fig. 3.2-10a: Two faces of a roll-bond "single blow" sample: back face with visible piping pattern, front face flat (pict. EPFL-LESO).

Fig. 3.2-10b: Classic roll-bond pattern design (CGA).

Fig. 3.2-10c: Complex absorber texture allowed by roll-bond technology specificities (ALCAN). 


\subsection{Evacuated Tubes Collectors}

\section{Multifunctionality options}

Differently than glazed and unglazed collectors, vacuum tubes modules result from the addition of autonomous energy collection elements (the tubes) that can be assembled at wish (Fig. 3.3-1 left). The integration possibilities of these collectors in the building envelope are hence very different than the ones seen for the sandwich structured flat plates (glazed and unglazed). The main difference is that the assembled tube modules are not watertight and are visually semi-transparent, making them less suitable for multifunctional applications in the opaque envelope parts (Fig. 3.3-1 right).
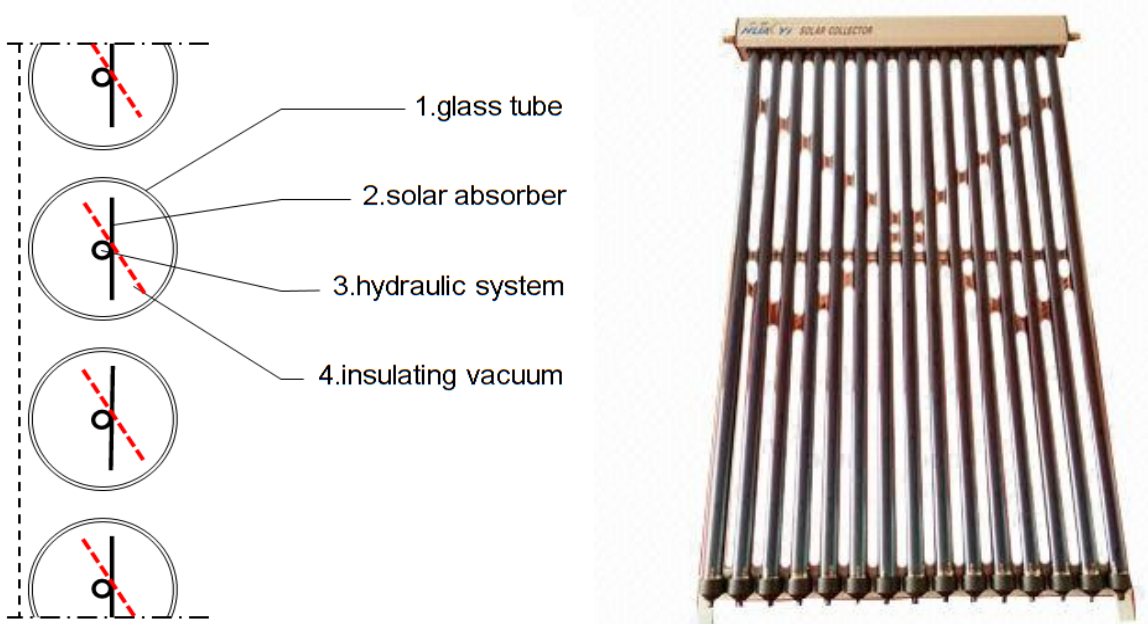

Fig 3.3-1- left: vacuum tubes collector structure, Fig 3.3-1- right: standard vacuum tubes collector module.

On the other hand, they offer great opportunities of implementation in other envelope elements, which are usually less interesting for flat plate applications.

Replacement of balcony eaves is probably the simplest multifunctional application for this technology, with a certain number of application examples already available

(Fig. 3.3-2).
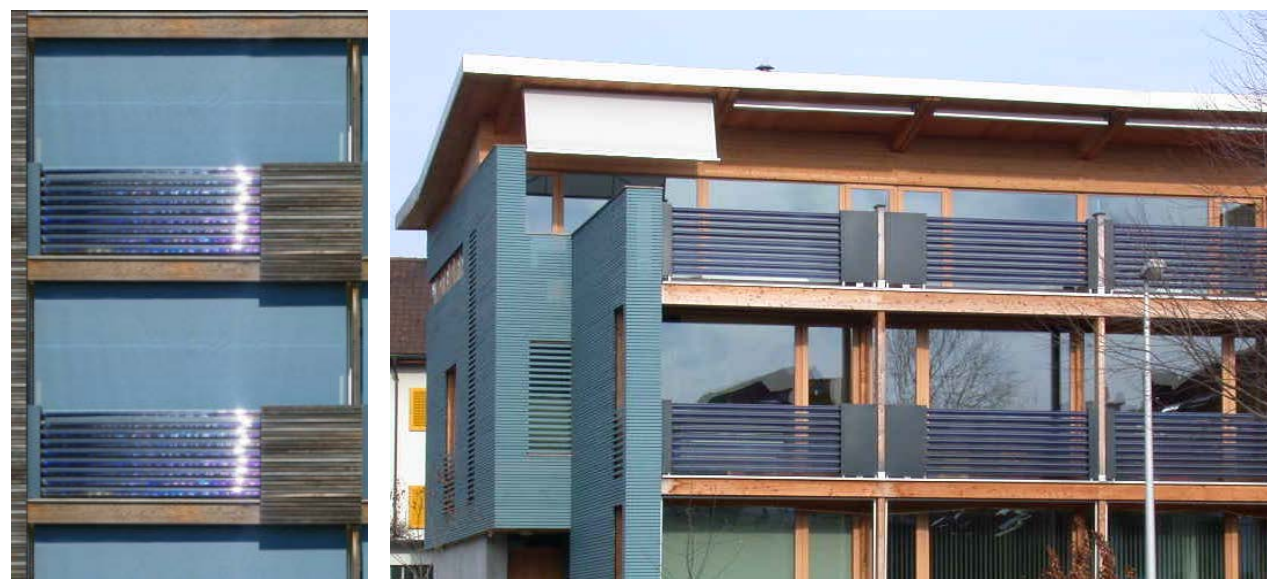

Fig. 3.3-2: Schweizer Energie vacuum tube collectors used as balcony eaves (www.schweizerenergie.ch), architect Beat Kaempfen, Zurich. 
The partial transparency of this type of collectors allows using them also as partial shading devices, in front of exposed glass surfaces (Fig.3.3-3, Fig. 3.3-4) [21].
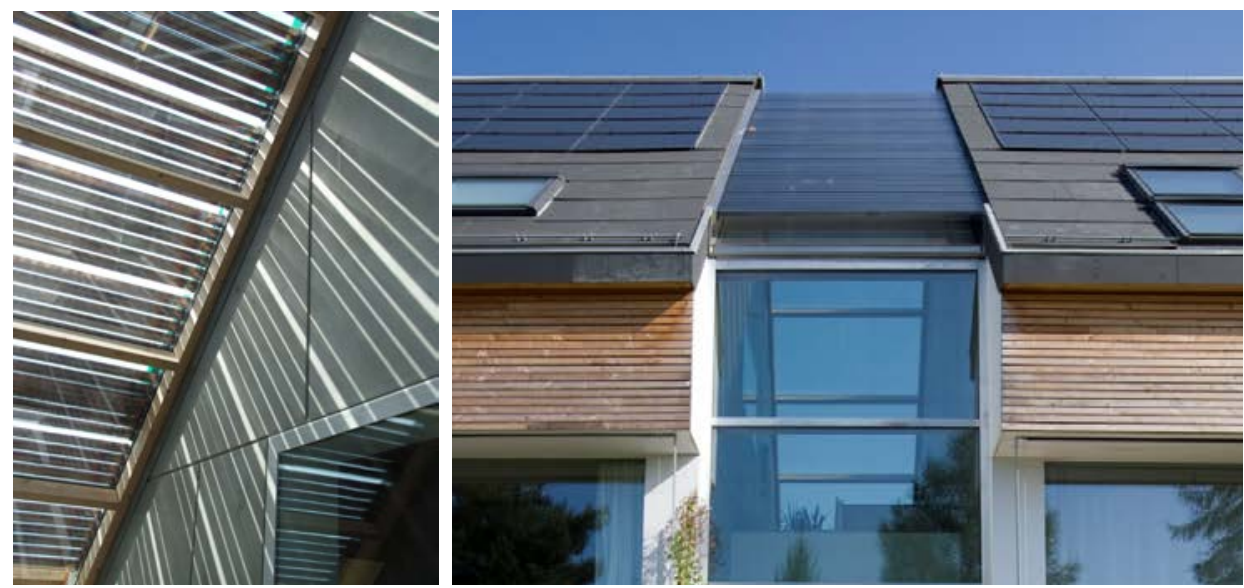

Fig.3.3-3 Evacuated tubes collectors used as glazed roof sun shading (left: inside view, right: outside view), Dübendorf residential building, Beat Kaempfen 2008.
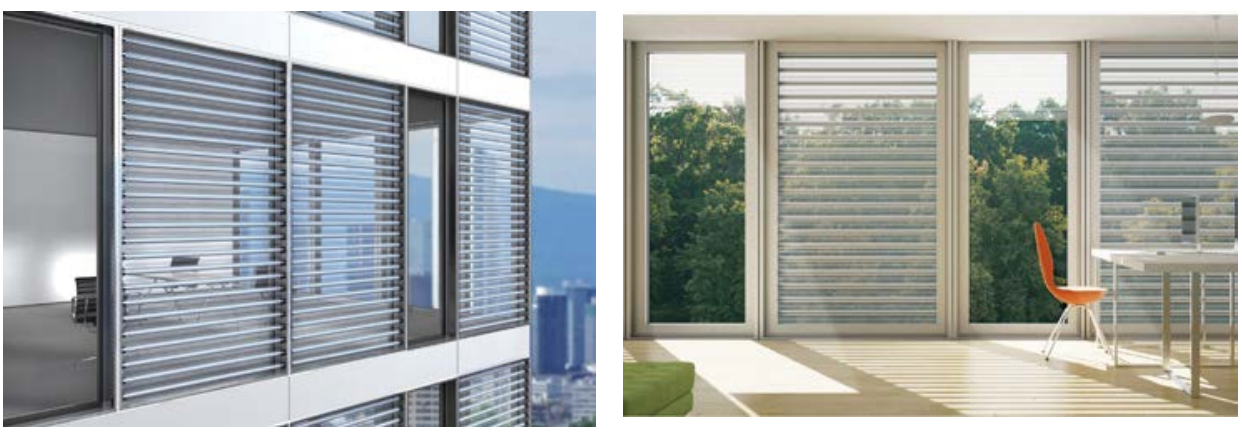

Fig. 3.3-4: Example of innovative façade system: integration of evacuated tubes and semiperforated mirrors into a window - External and internal views (C) Universität Stuttgart, IBK 2).

The possibility to orient the single tubes (and their absorber) independently from the tilt of the whole collector (Fig. 3.3-1 left) also opens the way to new applications, allowing in particular the horizontal mounting, less suitable for flat plates.

External shading devices can then be designed using vacuum tubes collectors as novel solar pergolas (Fig.3.3-5).

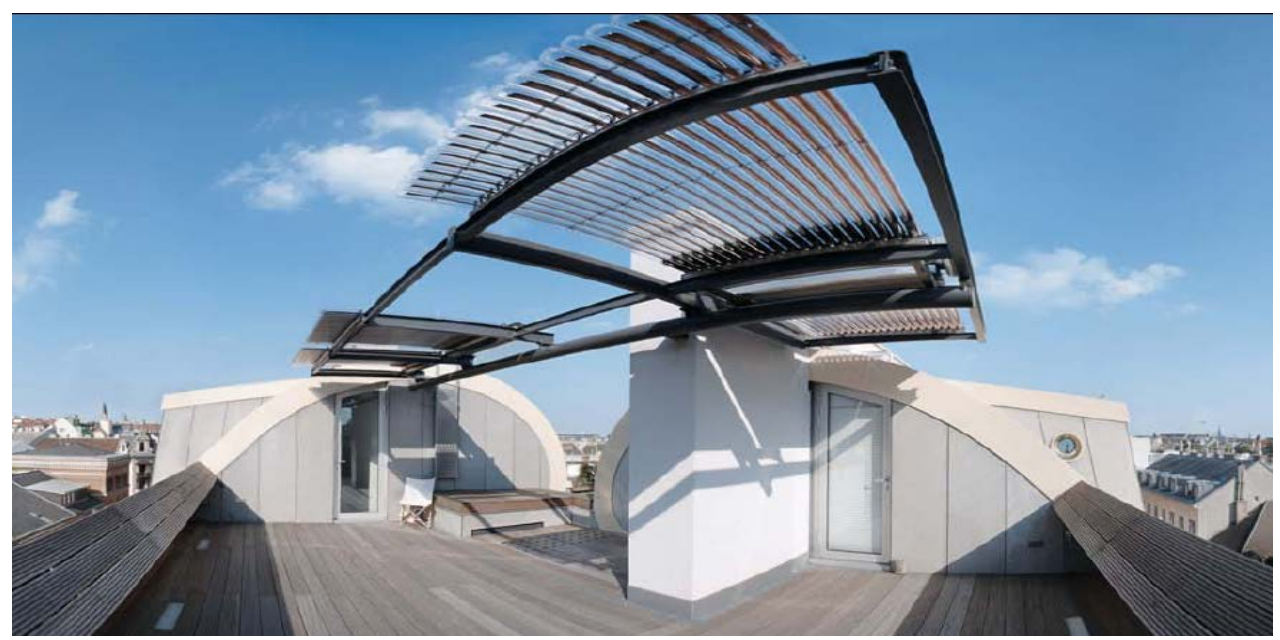

Fig.3.3-5: Evacuated tubes collectors used as deck sun shading. RaU Architekten, Vienna. Credits: RaU Architekten. 
In very hot climates, double roof systems providing horizontal building shading and producing energy could also be a very effective and innovative application for vacuum tubes. The systems would shade the building, reducing overheating, and it would produce high temperature energy, perfect for cooling use. Even if presently not yet explored (Fig. 3.3-6 a-b-c), this type of applications promises to be very effective and architecturally attractive.
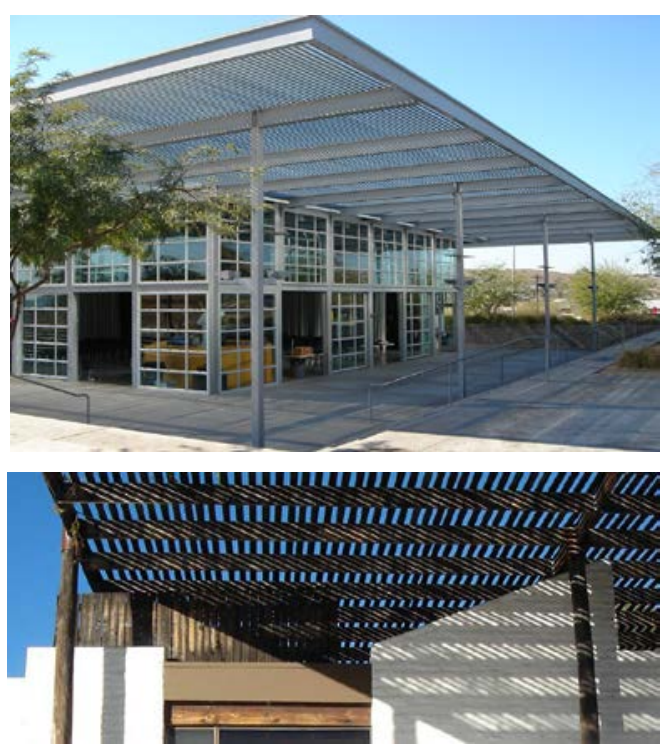

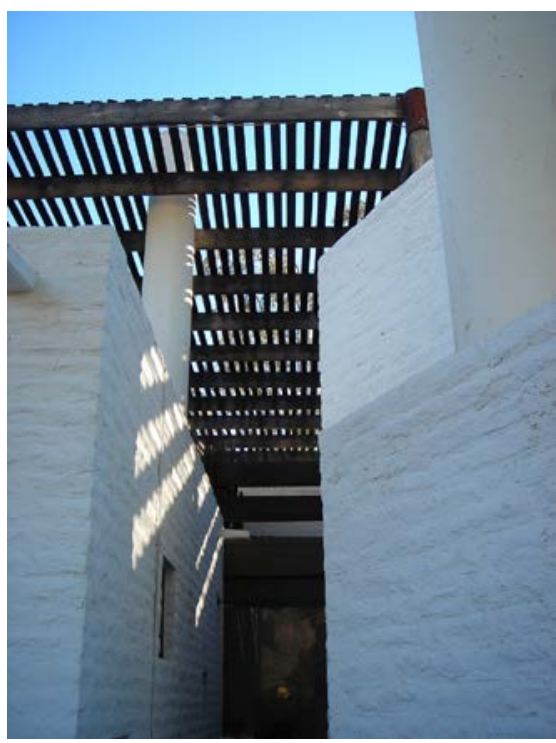

Fig. 3.3-6 a-b-c: Examples of double roofs conceived to reduce building heat (a: double tin roof in Arizona architect n.a; b and c: double roof on a private house in Arizona. Architect Judit Chafee, credits Marja Lundgren).

Of course vacuum tubes can still be applied also in the opaque building parts, as added solar elements. The collector won't become a multifunctional envelope element, but good composition results can still be achieved also with this more traditional approach (Fig 3.3-7).
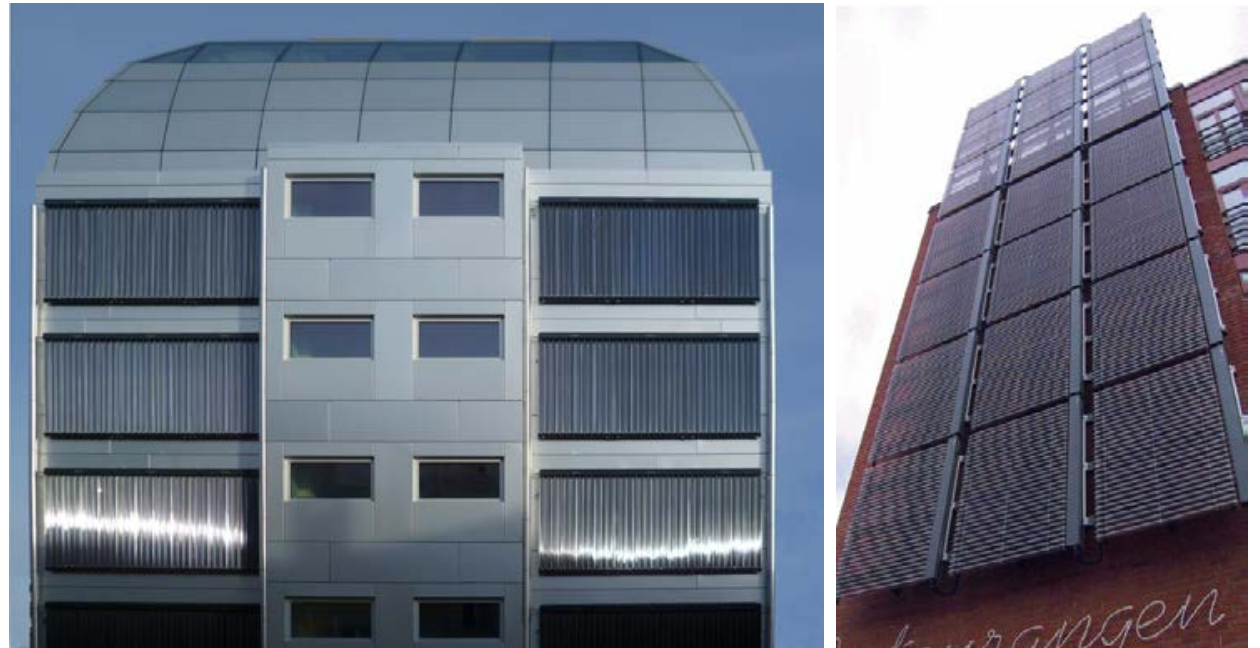

Fig. 3.3-7 left: Evacuated Tubes collectors in front of metal cladding (Hotel Swissnights Lausanne).

Fig. 3.3-7 right: Large detached evacuated tubes field in front of a Malmö building ( Västra Hamnen, Malmo). 


\section{Module dimensions}

Dimensional flexibility relates to the two main collector elements: the tubes and the connecting manifold.

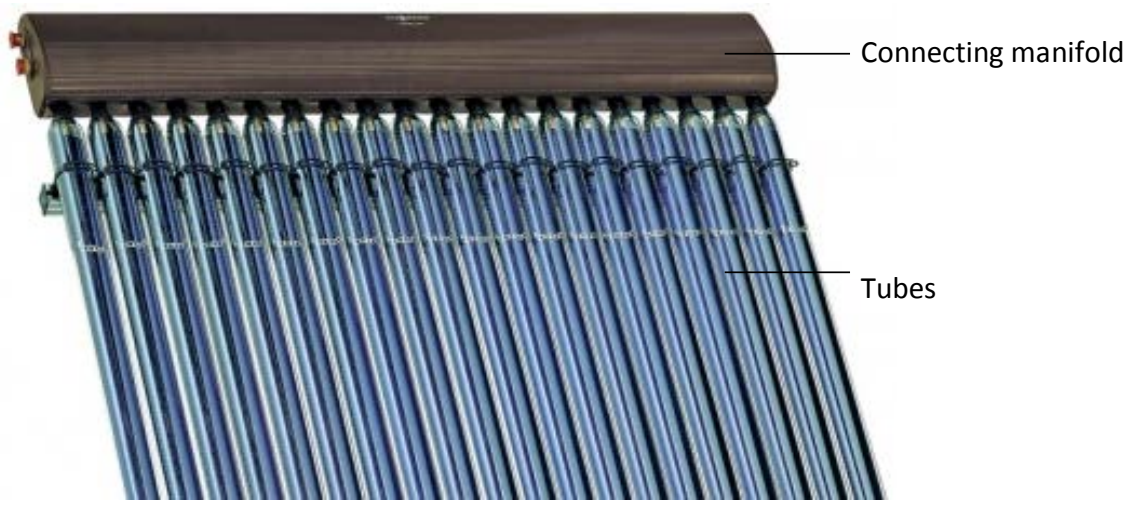

Fig 3.3-8: Evacuated tubes collector: tubes and manifold.

For the tubes, basic dimensional options would be to offer the possibility to choose the module tubes number, and their length. It is not necessary to provide a total freedom in these dimensions: a few targeted options are generally sufficient to greatly widen the set of possible applications.

Additional freedom can then be offered on the mounting distance between the tubes, and on their diameter, which would be very useful in many of the applications proposing partial shading as an added functionality (Figs. 3.3-2 -3 -5).

The dimensions of the manifold connecting the tubes are essentially driven by the number, diameter and spacing of the tubes, but options could be offered, for instance slimmer appearance, or main piping placed behind the tubes field.

\section{Jointing}

In vacuum tube collectors the jointing issue mainly relates to the manifold element, as the collector itself do not usually compose a closed unit.

The connecting manifold hosts the jointing of each tube with the whole hydraulic system, and is often also the connection between two adjacent modules. Due to these functions, it is generally characterized by a large width, quite imposing and recognizable at the building scale. In general, though, not much attention is given to its design. Nevertheless, developing multifunctional envelope systems will require dealing with these aspects to find adapted solutions.

\section{Collector colour}

The "colour" of the tubes is given by the layer deposited either on the inside tube or on the internal metallic absorber, and as evacuated tubes are used to maximize the energy collected, little variations are possible while keeping optimum efficiency. At present, black and dark blue are the only available colours. As options arise to bring additional colours to the flat plate absorbers, similar opportunities might be offered in the future for the absorbers of evacuated tubes. Thin films glass treatments similar to the ones described for glazed flat plate collectors could also make coloured tubes available, but both options remain unexplored up to now. 

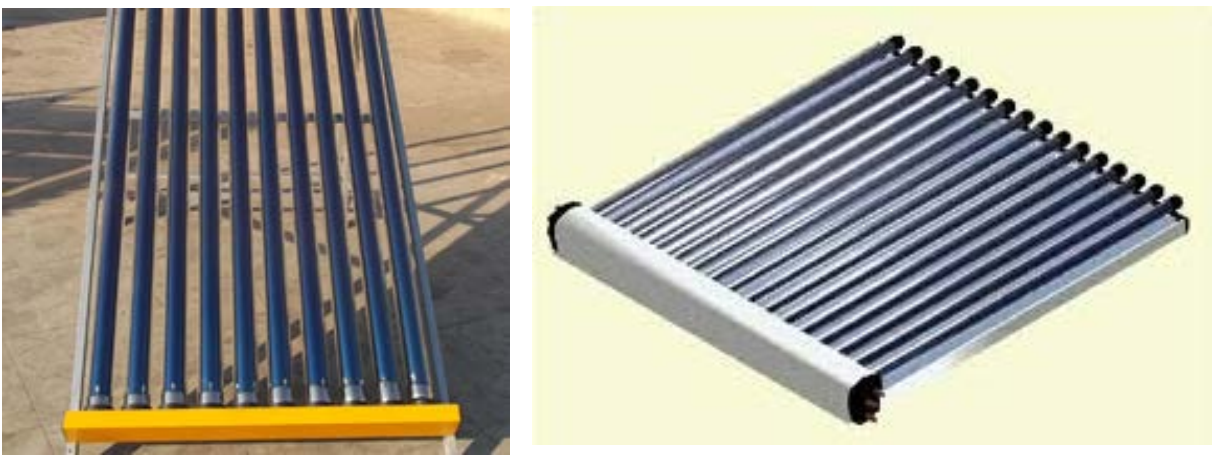

Fig 3.3-9: Evacuated tube collectors: coloured manifolds.

Colouring the manifold cover offers more possibilities for customization, and should be available with complete colour freedom, as there are no constraints linking the manifold colour to its function (Fig. 3.3-9).

\section{Visible surface textures and finish}

This technology offers very little freedom in texture and finishing, as the tubes have to be highly transparent and made of glass. It is possible to work on the glass finish of tubes using surface treatments similar to the ones used on glazed flat plate collectors (acid etching, screen-printing), but this doesn't seem a priority to us. When considered from afar, the "texture" of the collector is in fact mostly resulting from the rhythm of the juxtaposed tubes (their size and spacing) (Figs. 3.3-2, 3.3-3, 3.3-4, 3.3-7).

This underlines again the already mentioned importance of proposing a targeted choice in tubes size and spacing. 


\section{EXAMPLE OF DEVELOPMENT: THE SOLABS PROJECT}

(Based on an original paper "SOLABS: Development of a Novel Solar Thermal Facade Cladding System" published at Eurosun 2006)

This chapter describes the actual development process of the SOLABS EU project as an example of building-oriented, multifunctional, collector development.

\subsection{Context}

The EU project SOLABS (Feb 2003- Dec 2006) aimed at developing a novel unglazed solar thermal collector for building façade, resorting to coloured selective coatings on steel material. In a context where the lack of solar design was considered to be one of the main reasons for the slow spread of solar thermal technologies (even when the technology was already efficient and cost effective), the project intended to produce a novel collector conceived as a multifunctional construction element, to ease the architectural integration (both in new buildings and in renovations), and able to meet the users' aesthetics expectations.

\subsection{Project phases}

To be able to produce a new collector meeting the above described goals, the architectural integration issues were articulated into four phases:

1 - Identification of the general architectural criteria defining the integration quality.

2 - Selection of potential collector concepts.

3 - Exploration of users' wishes and preferences for the proposed options.

4 - Development of the final collector combining users' expectations and technical needs.

\subsection{Integration criteria}

A large survey over the way(s) European architects and engineers perceive the integration quality of Building Integrated Solar Thermal (BIST) was designed and conducted at the beginning of the project (170 fully completed questionnaires)[20].

The questioned were asked to rate the global integration quality of ten selected examples of existing BIST. A detailed evaluation of the module sizes, shapes and colours in relation to the integration context was also proposed, to help clarify the bases of the global judgment.

The architects' votes were remarkably consistent, confirming the existence of general criteria defining quality in architectural integration of BIST (see detailed criteria description in refs [1], [6]). They can be summarized in two points:

- System size and position, module size and shape, jointing type, collector surface texture and material are characterizing integrations as much as does the absorber colour does. Each of these characteristics has to be coherent with the whole building design logic for the integration to be considered successful.

- The use of the energy system as a multifunctional construction element (façade cladding, roof covering etc...) can greatly ease the integration design work. Building design logic is easier to follow when the architect has to balance fewer elements. 


\subsection{Design methodology}

A new collector design has to be defined within the formal limits imposed by its specific solar thermal technology.

In this case, the SOLABS team had to explore the formal possibilities offered by the unglazed - hydraulic - flat plate - collector technology, with the added constraint to use steel for the absorber.

As unglazed thermal collectors for façades are de facto façade metal claddings, the original approach was to select options directly inspired by existing façade metal claddings (already developed to respond to building needs), rather than from existing solar collectors.

For evaluation, these claddings were divided into three families:

- Profiled sheets: very large non-modular metal sheets providing a homogeneous covering thanks to the absence of visible jointing between the cladding sheets.

- Cassette modules: modular elements of geometrical proportions varying from 1:1 to 1:4, with visible jointing, well-suited for cladding of large wall surfaces. Due to the visible jointing, the careful choice of the module dimensions is the key to a successful cladding.

- Panel planks: cut to length modules with a width ranging from $20 \mathrm{~cm}$ to $40 \mathrm{~cm}$. The maximum length of individual planks is usually $4.00 \mathrm{~m}$. The variable width of the reveals (from 0 to $30 \mathrm{~mm}$ ) makes the use of even standard modular element more flexible, so that the panel-planks can be used for the cladding of numerous architectural objects.

As only cladding types able to support a hydraulic system could be taken into account, profiled sheets were skipped, being hardly adaptable from the technical point of view. Cassette modules and panel planks were both considered realistic options for further evaluation.

\subsection{Users' wishes}

A new questionnaire was designed to explore the users' preferences (mainly addressed to architects, but also to engineers and façade manufacturers) for collector appearance.

Each collector characteristic was investigated in terms of aesthetic criteria and desired freedom/standardization.

Module shape, size, jointing

- The cassette:

The first question was on the acceptable level of standardisation / flexibility. The majority of the interviewed architects selected as a minimum requirement a cut to length module, to have at least the freedom in one dimension. Moreover almost one third of the architects said that a made to measure module was a prerequisite. For the jointing, the profile free solution (negative jointing) was the most appreciated. Frame jointing was well behind, even though it was still considered acceptable.

- The plank:

For the panel-plank the question was on the most suitable panel width, as the plank length freedom is already characterizing this kind of cladding. The ideal size satisfying most of the interviewees was around $30 \mathrm{~cm}$. 
A variable width reveal was considered a suitable jointing technique by all the interviewees, architects and engineers, in order to have a flexible panel plank solar element in both dimensions.

All interviewees considered both the cassette and the plank to be valid solutions for the SOLABS unglazed collector, with a slightly better rating for the plank (Fig. 4.5-1) .

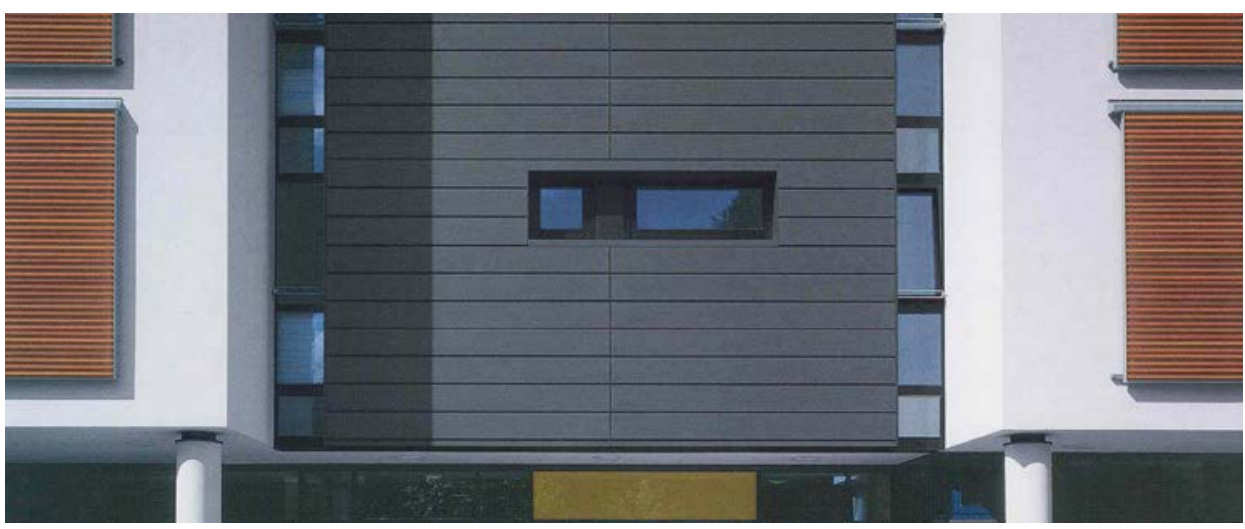

Fig. 4.5-1 Façade cladding using metallic plank system.

\section{Surface colours}

The wishes concerning the number of colours to be provided in the SOLABS palette brought a definitive challenge. Two thirds of the interviewees wished a palette made of more than ten colours and $40 \%$ of the architects suggested a palette with more than 20 colours. Moreover, for two thirds of the interviewed architects the possibility to freely choose a custom colour was considered to be an essential requisite.

To help define in which direction the SOLABS colour development was to be pushed further, we asked to select three colours (out of 24) which should definitely be included in the SOLABS palette. Architects' most demanded colours were by far the greys, no matter if they came from the North, the Centre or the South of Europe. Blues and reds were also selected options while greens, browns and yellows were less popular.

\section{Surface texture and finishing}

As expected the preferences of both architects and engineers went to the most traditional surface textures proposed: flat and slightly profiled. The also proposed embossed and lenticular perforated surfaces were considered not appropriate for façade use, even though they seemed to interest a few people.

The question about surface finishing left no doubts: $90 \%$ of the interviewees said it should be matt rather than polished.

\subsection{The resulting collector}

A careful balancing work between users' wishes (aesthetic preferences and need for freedom), production feasibility, cost requirements and energy performances was then conducted. The joint efforts of SOLABS engineers and architects, starting from the clear identification of the problems to be solved and the knowledge of users' wishes, made possible the design of the SOLABS plank, that should respond to building needs and to the market demand. 


\section{Choosing module shape and size}

Considering the high level of freedom in module size requested by the users for that option, the cassette was abandoned and the development was focused on the plank. The final designed product (Fig 4.6-1) is a cut to length plank collector of $29 \mathrm{~cm}$ width, with variable negative jointing from 0 to $2 \mathrm{~cm}$, very similar to the largely available plank modules proposed by the façade metal cladding market (fig. 4.5-1).

A hydraulic system is glued to the back of the collector to ensure both an optimal heat transfer and a perfectly smooth front surface. The horizontal piping system is designed to be compatible with the cut to length dimension of the modules. Similarly, the hydraulic junction between the planks, ensured by a brass manifold, is designed to be compatible with the variable width of the horizontal jointing (Fig. 4.6-3).

To extend the range of possible integration solutions, the decision was taken to additionally offer dummy elements, giving the possibility to apply a homogeneous cladding also in non-optimally exposed surfaces or on small areas.

\section{Choosing surface colour, texture, finishing}

The surface of the absorber is flat with a matt finish, as wished by $90 \%$ of the interviewees.

Considering the users' desire of large colour freedom, the decision was taken to use a selective coloured painting to be applied to the already formed collector instead of using coloured coil coated metal sheets to make the collector absorber. With this option, the production of a specific colour is not limited by the need to produce significant quantities, as for coil coating, and a large colour palette can be proposed. As the paint can be produced in small quantities and in short time, customers will also have the possibility to ask for a specific colour on demand.

The coloured selective paintings used in the project were developed by the National Institute of Chemistry of Slovenia, a SOLABS partner. Different absorptance and emittance values ( $\alpha$ and $\varepsilon$ ) characterize the various colours of the palette (Fig. 3.2-4, Fig. 4.6-3 bottom right corner), and the architects will have to select the paint balancing aesthetics and energy efficiency.

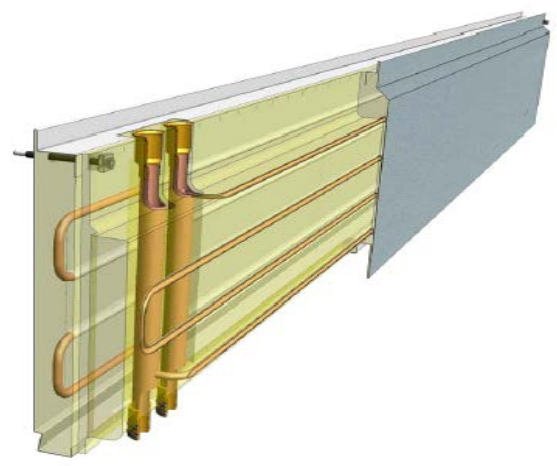

Fig.4.6-1. SOLABS plank hydraulic system.

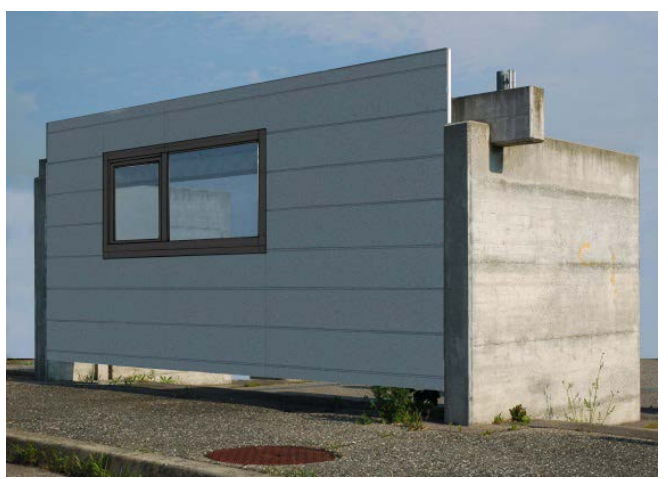

Fig. 4.6-2.Demonstration stand at Demosite-EPFL. 
As described in chapter 2.3.3 in "Advanced level of integrability", this approach offers the maximum flexibility for the design team, as the resulting product demonstrates, but at the cost for the collector manufacturer to develop also all the added elements needed to complete the façade around the active modules. As shown in fig. 4.6-3, this can represent an important amount of work in a field usually not familiar to solar manufacturers.

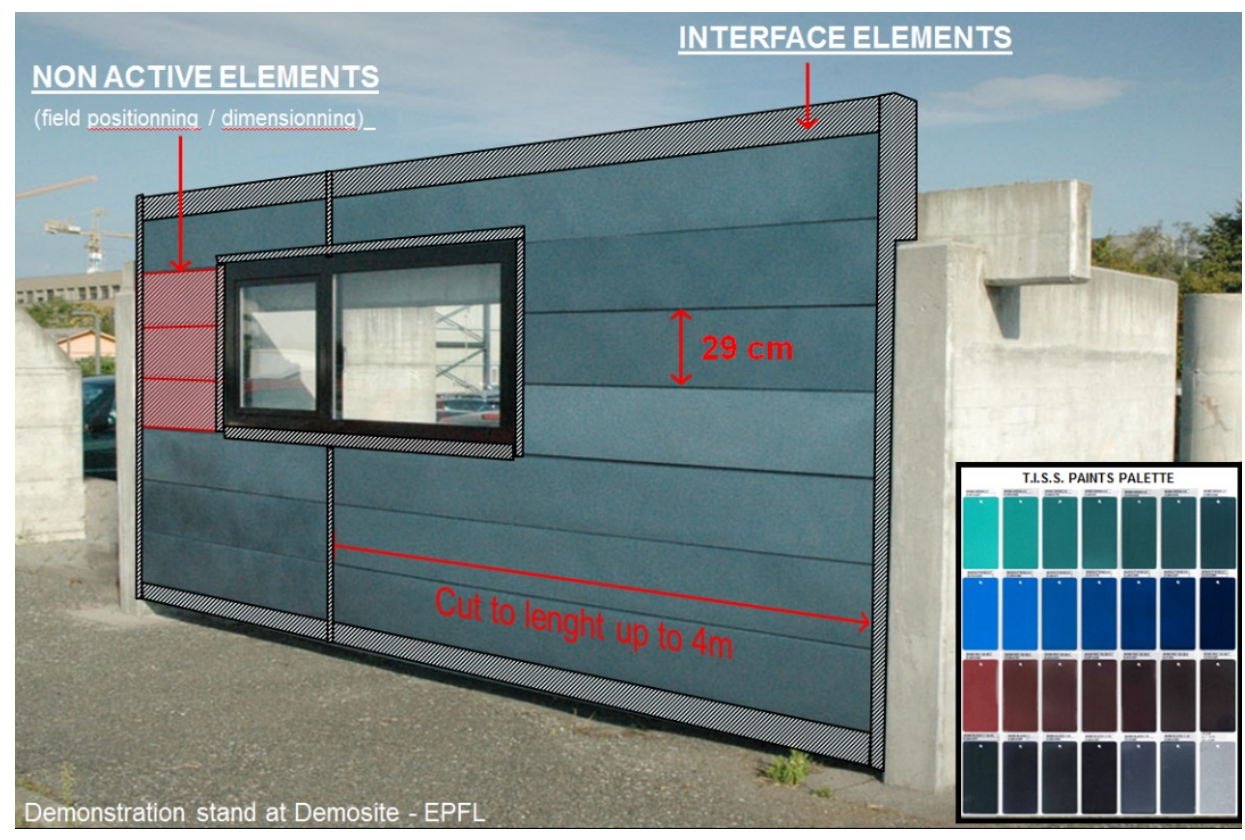

Fig.4.6-3 SOLABS demonstration stand at Demosite, with colour palette. Non active and interface elements needed for façade integration are grey or hatched red.

At a late stage of the project, the alternative approach (2.3.3 in "Start from the roof/façade system") was started to compare with the original one:

Starting from a complete façade cladding plank system, offering all the needed interface elements as standard components, the project team studied the option to adapt the original planks to turn them into a solar thermal collector. Taking advantage of the already completed developments, the solution appeared quite simple, as shown in Fig. 4.6-5. This plank, part of the standard TKS system, was equipped with the same hydraulic system developed for the first version, needing only minor adjustments.

As a result, it appears that this second approach was judged as more efficient, and better corresponding to the respective expertise of the solar manufacturer and the façade system producer.

As shown at Figs. 4.6-4 and 4.6-5, both products look very similar and could use the same palette of selective paints. 

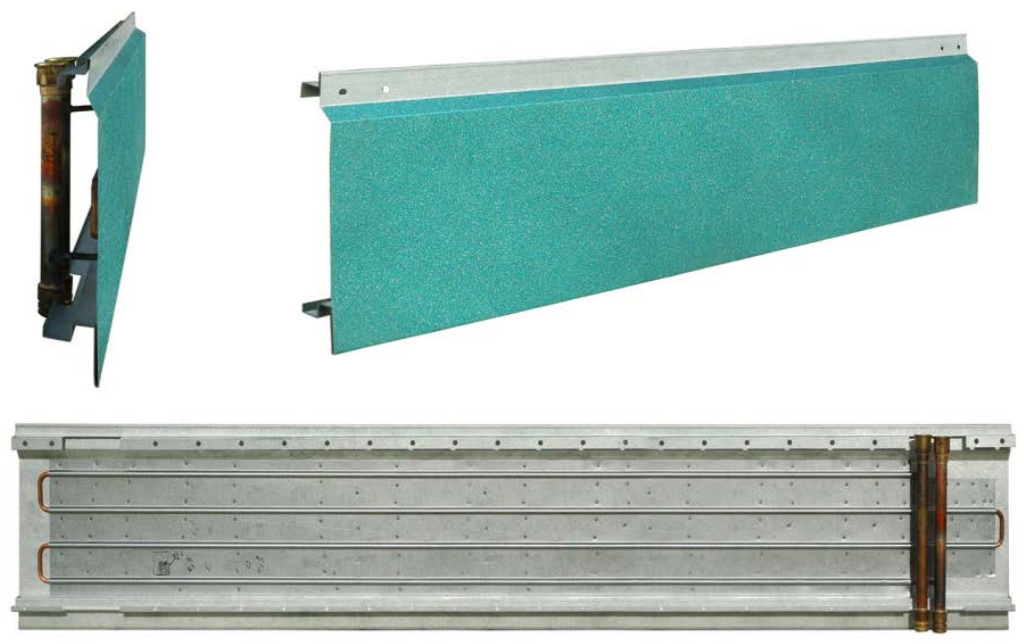

Fig. 4.6-4. SOLABS original plank collector developed from scratch.
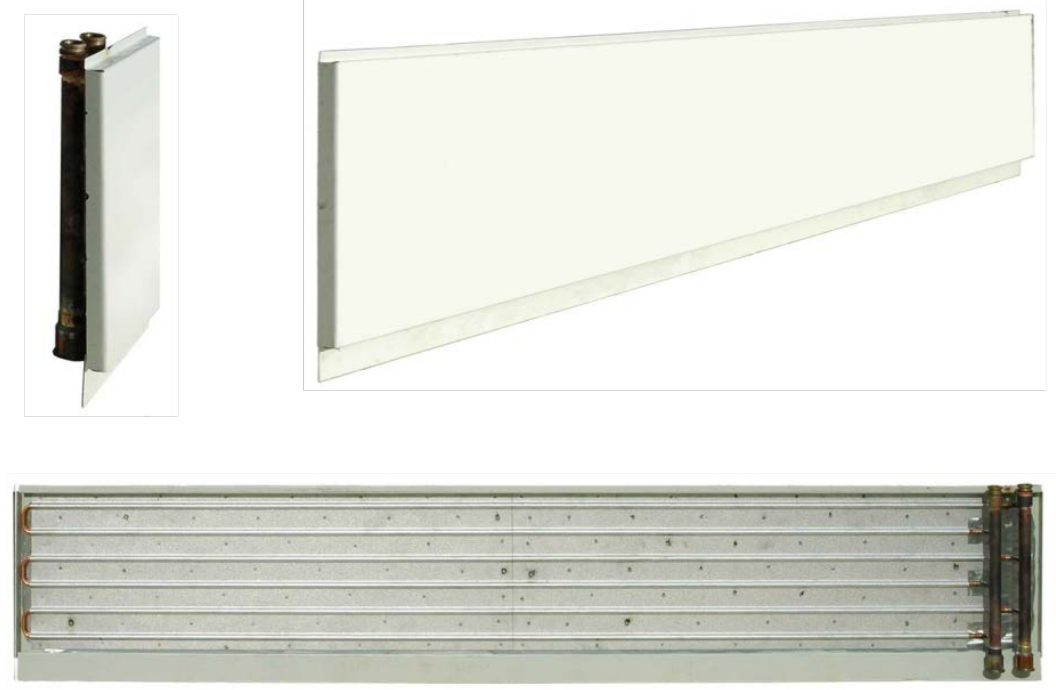

Fig. 4.6-5 SOLABS second plank collector developed from TKS Bausystem plank.

\subsection{Integration simulations}

A few integration simulations (Photoshop) have been proposed to test the formal possibilities offered by the SOLABS collector in relation to the previously described integration criteria.

As a base for the first simulations, one building already proposed in the first part of the questionnaire was chosen (Fig. 4.7-1), whose original integration was rated as just acceptable by the respondent architects.

The existing solar system has been "removed" to restore the appearance of the building before the integration, and to better understand the logic regulating the original design (Fig. 4.7-2). Then a new integration, following the whole building design logic, has been proposed using the SOLABS plank (Fig. 4.7-3). The flexibility of the new collector made it possible, and even easy, to stay within the pre-existing buildings design logic. 

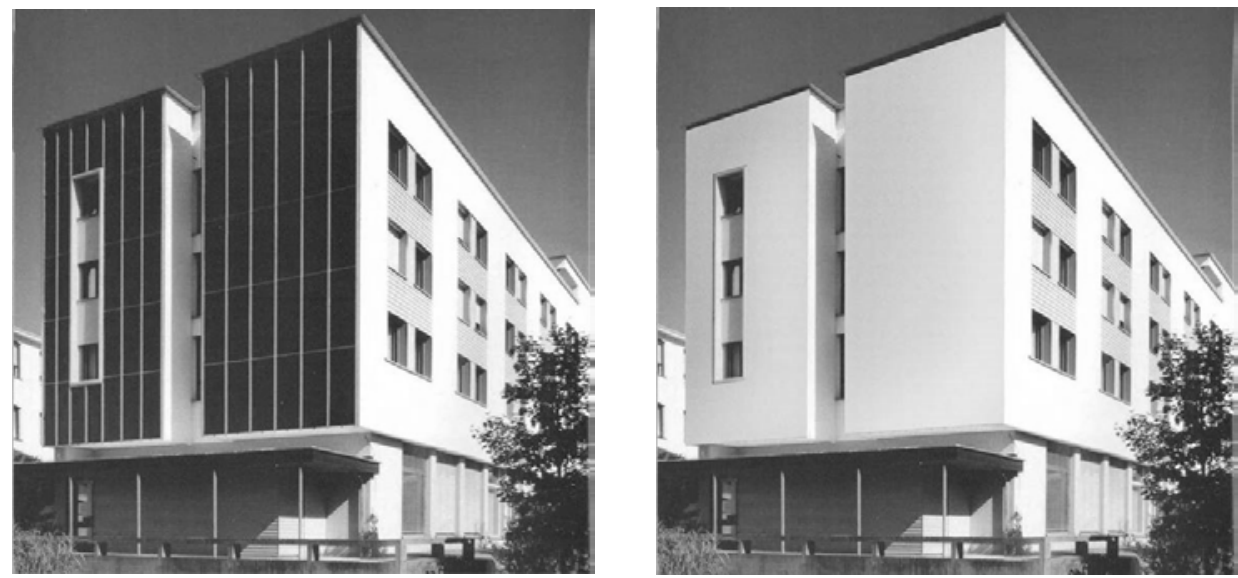

Fig. 4.7-1 Youth hostel renovation (existing integr.) Fig. 4.7-2 The building before the integration.

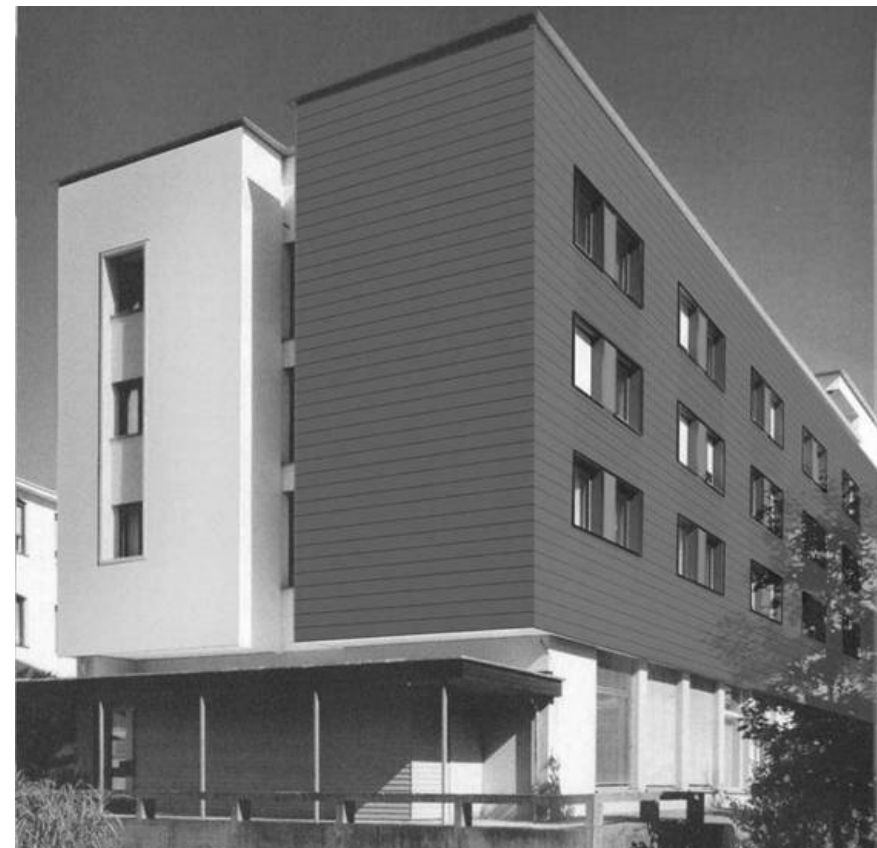

Fig. 4.7-3. New integration using the SOLABS plank.

\subsection{Lessons learned}

The true understanding of the characteristics affecting the integration quality of the collector confirmed the importance of conceiving the novel collector as a multifunctional construction element, and underlined that it had to be flexible enough to adapt to different buildings and contexts.

Consulting the users was fundamental to specify in which direction to focus the research to ensure that the new collector will meet a real market.

The broad range of complementary competences brought in by the different partners of the consortium led to original solutions able to balance architectural quality, energy performance, manufacturing and cost constraints.

The relatively small width of the plank, the flexibility in both dimensions, the availability of dummy elements together with the large choice of surface colours make the novel collector a versatile cladding easy to integrate both in new buildings and in renovations. 
5. EXAMPLES OF INNOVATIVE PRODUCTS FOR BUILDING INTEGRATION

The following pages present a selection of recent products specifically developed for building integration.

Besides a short functional description and general view and detail pictures, a special part highlights the "integrability" characteristics of the product.

Updated data sheets and corresponding products can be found online at http://www.solarintegrationsolutions.org 


\section{winkler VarioSol E collectors system}

\section{Winkler Solar GmbH}

Räterweg 17 A-6800 Feldkirch

solar@winklersolar.com

http://www.winklersolar.com

Winkler VarioSol is a glazed flat plate system conceived for façades and is characterized by a very high level of freedom both in size and shape of the modules: 38 different standard formats up to $24 \mathrm{~m}^{2}$ are proposed, and almost any customized shape can be provided at a reasonable extra cost. This flexibility comes from the absorber structure made of strips of small width and length cut to measure up to $5 \mathrm{~m}$. Collectors are produced on order so that individual details, like jointing, can be made to measure.

No dummy elements are available, and no choice is given on absorber colour/texture.

ST "Integrability" characteristics
\begin{tabular}{|l|c|}
\hline Multifunctional element & + \\
\hline Shape \& size flexibility & + \\
\hline Glazing: surface texture choice & $+f$ \\
\hline Absorber: surface texture choice & - \\
\hline Absorber colour choice & - \\
\hline Jointing options & + \\
\hline Availability of dummies & - \\
\hline Complete construction system & $+\digamma$ \\
\hline
\end{tabular}
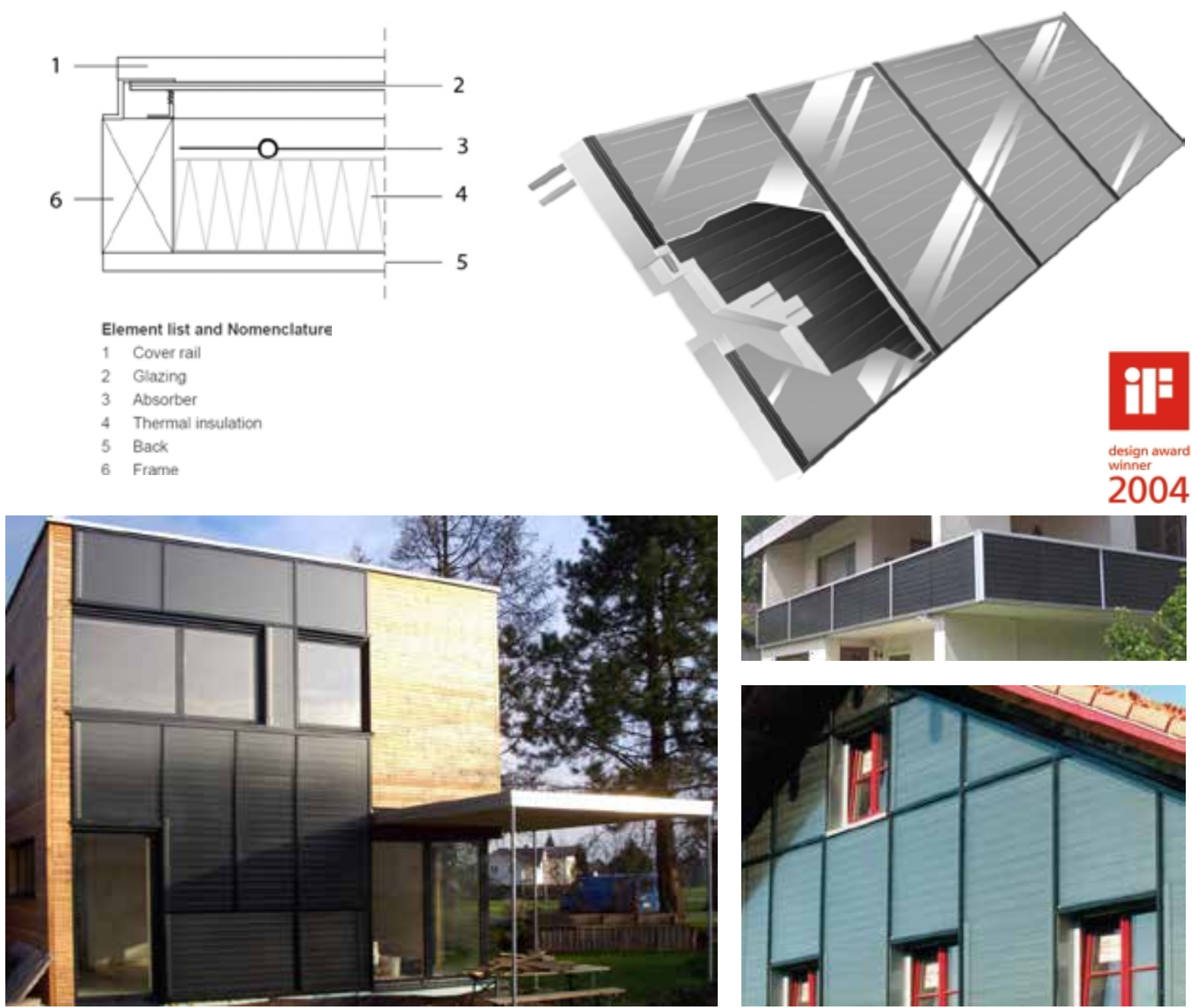



\section{AKS DOMA AKS Doma Flex}

\section{AKS Doma Solartechnik}

Sonnenstrasse 1, 6822 Satteins, Austria

office@aksdoma.com

http://www.aksdoma.com

AKS Doma Flex system is a glazed flat plate system conceived for façades, and is characterized by a very high level of freedom in both size and shape of the modules: 30 different standard formats up to $20 \mathrm{~m}^{2}$ are offered. Customized module shapes and dimensions can also be easily provided. Like for Winkler collectors, this flexibility comes from the absorber structure made of strips of small width and length cut to measure up to $6 \mathrm{~m}$. Jointing of different colours are available.

No dummy elements are available, and no choice is given on absorber colour/texture.

ST "Integrability" characteristics

\begin{tabular}{|l|c|}
\hline Multifunctional element & + \\
\hline Shape \& size flexibility & + \\
\hline Glazing: surface texture choice & - \\
\hline Absorber: surface texture choice & - \\
\hline Absorber colour choice & - \\
\hline Jointing options & + \\
\hline Availability of dummies & - \\
\hline Complete construction system & $+\digamma$ \\
\hline
\end{tabular}
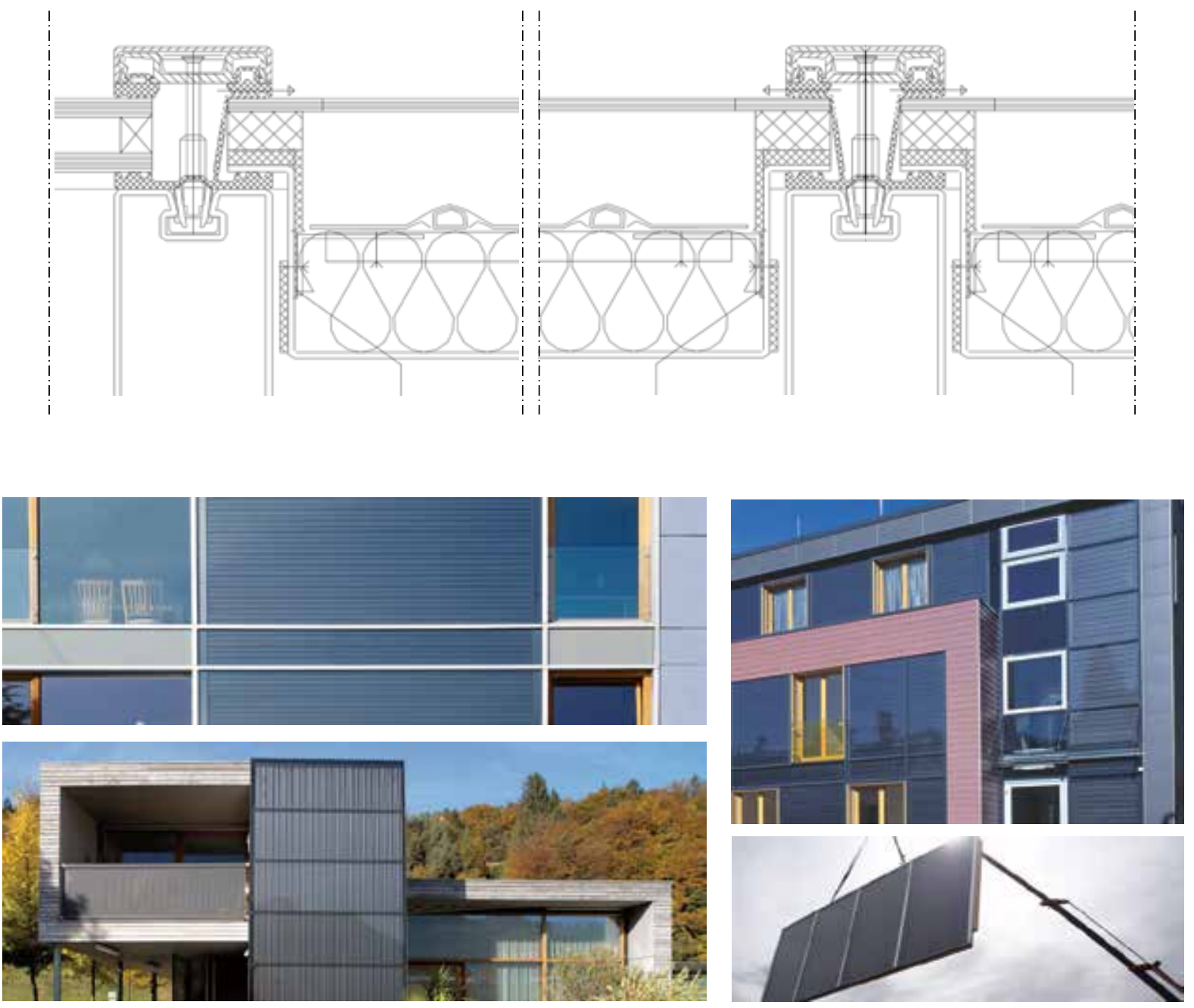



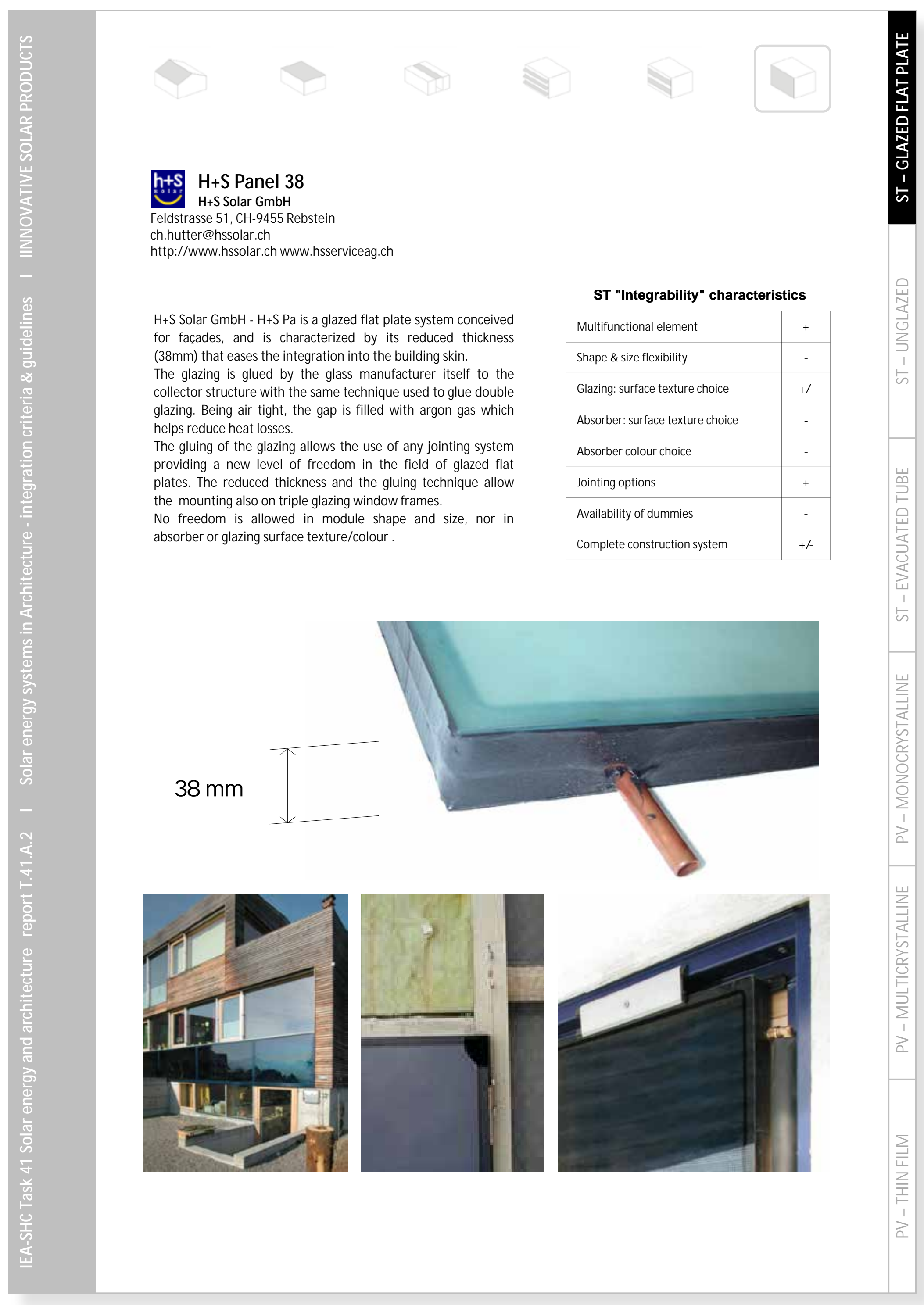





\section{LTAMLaA Solar Thermal Glass Façade}

\section{Heinrich Lamparter Stahlbau GmbH \& Co. KG}

D-34060 Kassel

info@stahlbau-lamparter.de

www.stahl-und-glas.de

The product recently proposed by Heinrich Lamparter Stahlbau $\mathrm{GmbH} \&$ Co. KG is derived from the triple glazing technology. The possibility to mount the collector using standard triple glazing framing systems makes it particularly suitable for the integration into glazed facades; furthermore the very reduced thickness makes it a good option in building renovation. Thanks to the use of a roll bond absorber, the collector offers a very large dimensional freedom. Like for all the other glazed flat plate systems on the market, no dummy elements are available today.

ST "Integrability" characteristics

\begin{tabular}{|l|c|}
\hline Multifunctional element & + \\
\hline Shape \& size flexibility & + \\
\hline Glazing: surface texture choice & $+f$ \\
\hline Absorber: surface texture choice & $+f$ \\
\hline Absorber colour choice & - \\
\hline Jointing options & + \\
\hline Availability of dummies & - \\
\hline Complete construction system & + \\
\hline
\end{tabular}

1. first glass layer, $4 \mathrm{~mm}$

2. space holder for the incorporation of the absorber

3. temperature-proof edge-bond

4. absorber with absorbing layer

5. second glass layer, $4 \mathrm{~mm}$ enamelled

6. temperature-proof edge-bond

7. space holder

8. argon gas-filling

9. third glass layer, $4 \mathrm{~mm}$

10. pressure compensation
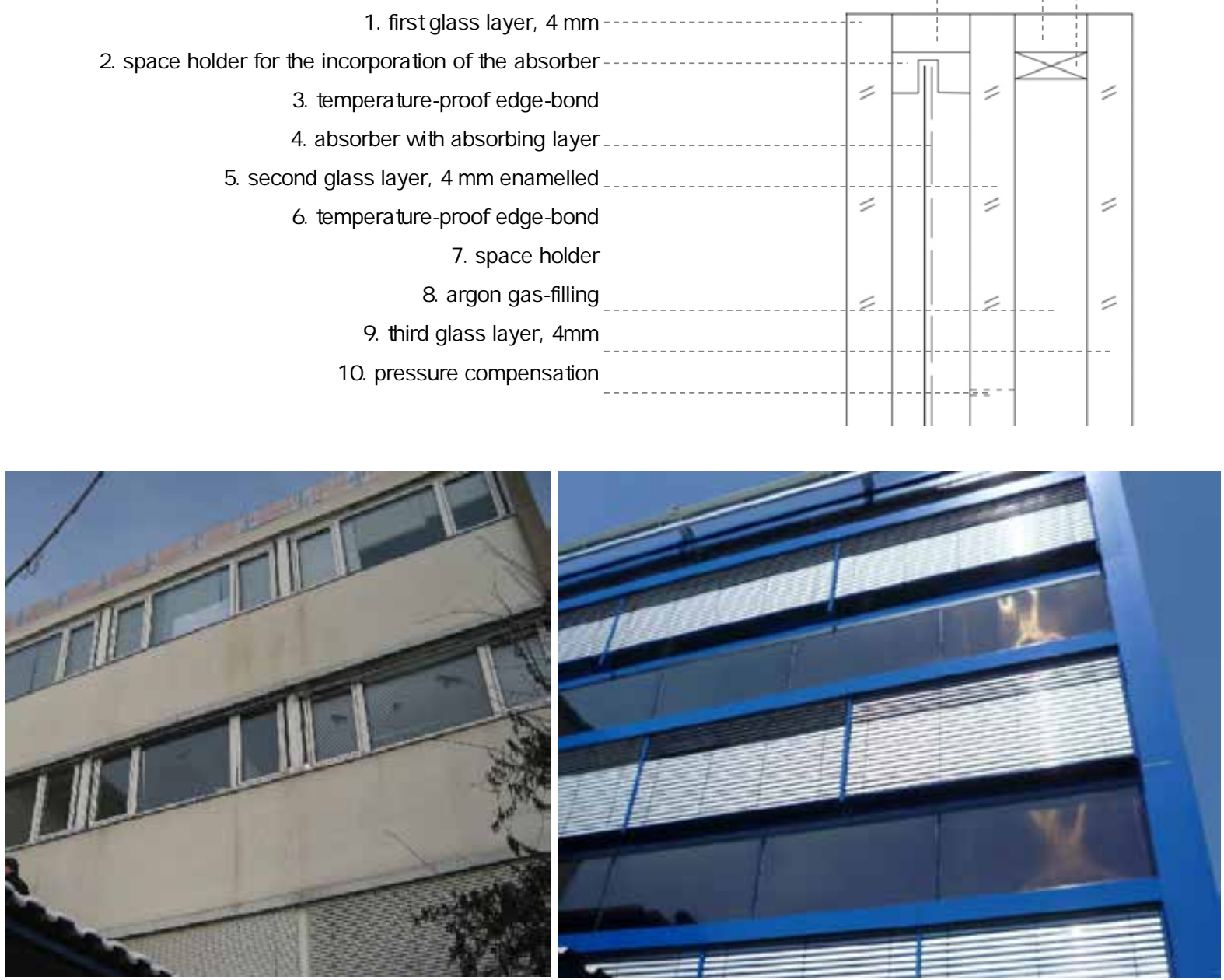



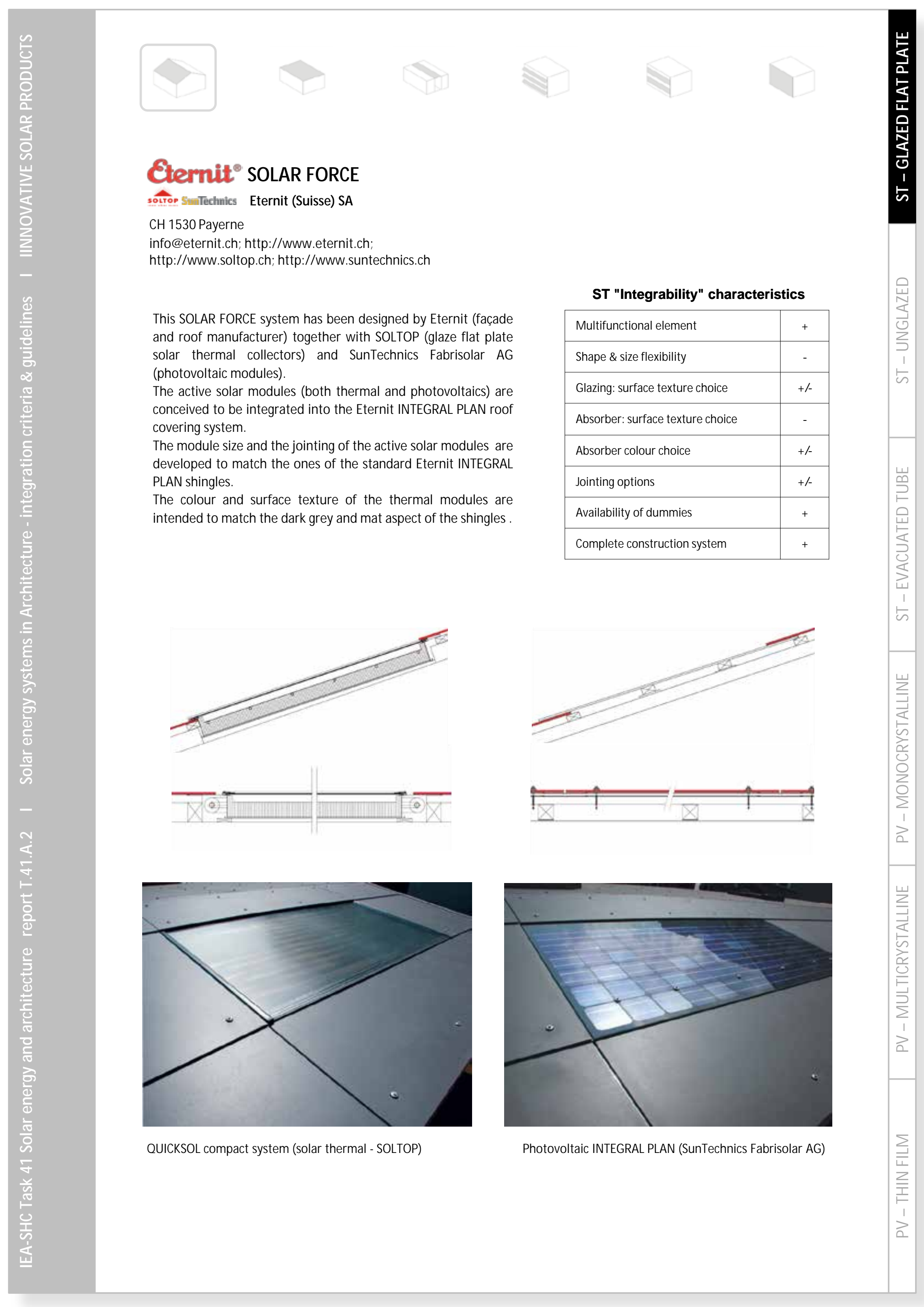





\section{s.solar Prisma}

\section{S-solar AB}

www.ssolar.com

Prisma is a glazed flat plate system for solar heating or cooling. Prisma is a thin (70 mm excluding glass) construction with high efficiency that is designed to be integrated in the conventional façades. The dimensions of the façade element is adjusted after the façade proportions as well as the glass thickness in relation to building codes. The collector has a maximum size of $1200 \mathrm{x}$ $2200 \mathrm{~mm}$ behind the glass. Prisma has a colorprint at the edges of the glass that can be customized in color, as well as the surface of the glass can be in milky white as well as transparent. The product has a very high efficiency due to very low heat losses and is Solar Keymark Certified. Weight excluding glass is 5 $\mathrm{kg}$, standard glass thickness is $6-10 \mathrm{~mm}$. Prisma can be integrated in traditional mounting systems.

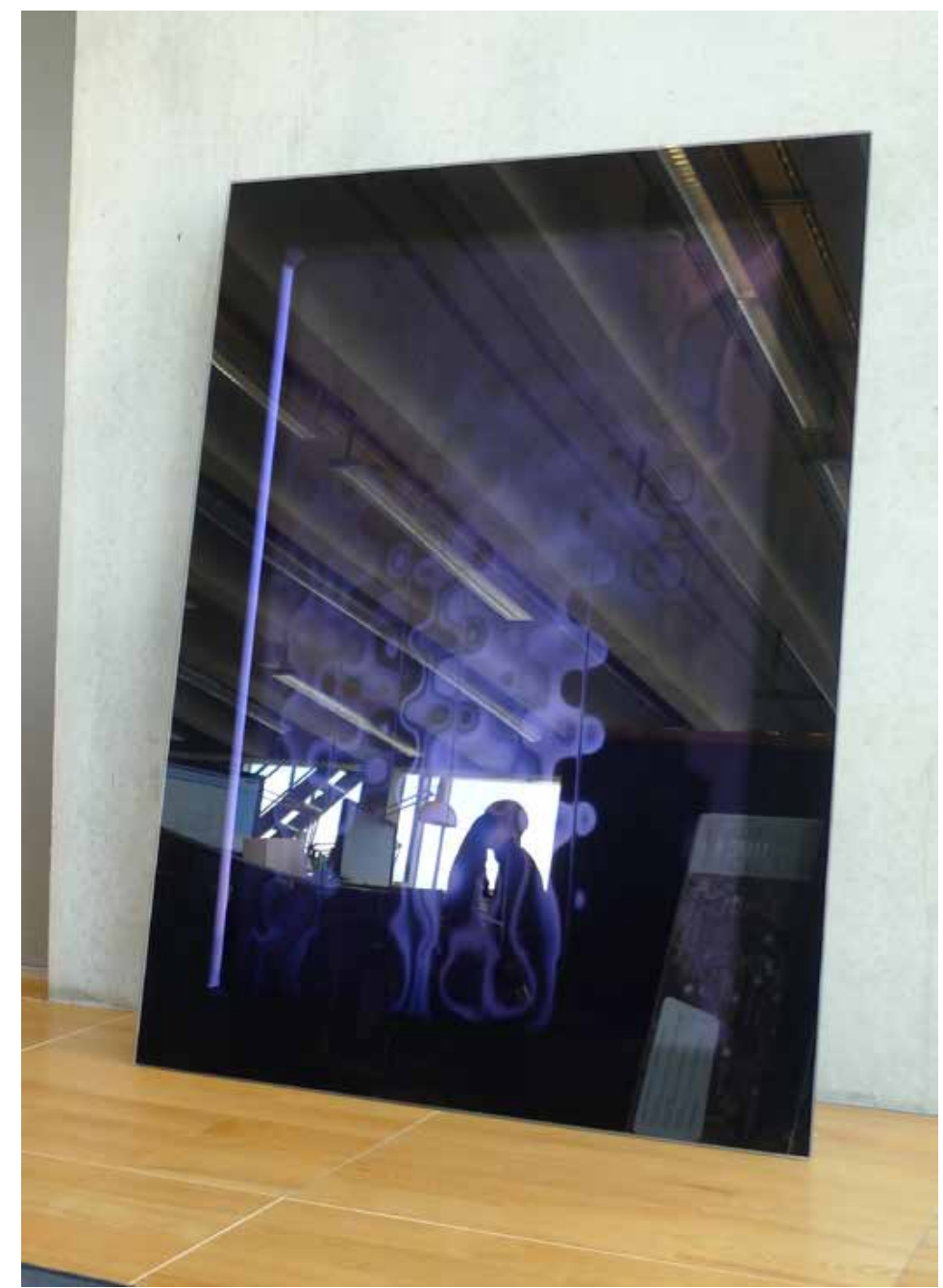

\section{ST "Integrability" characteristics}

\begin{tabular}{|l|c|}
\hline Multifunctional element & + \\
\hline Shape \& size flexibility & + \\
\hline Glazing: surface texture choice & $+f$ \\
\hline Absorber: surface texture choice & - \\
\hline Absorber colour choice & - \\
\hline Jointing options & + \\
\hline Availability of dummies & - \\
\hline Complete construction system & + \\
\hline
\end{tabular}

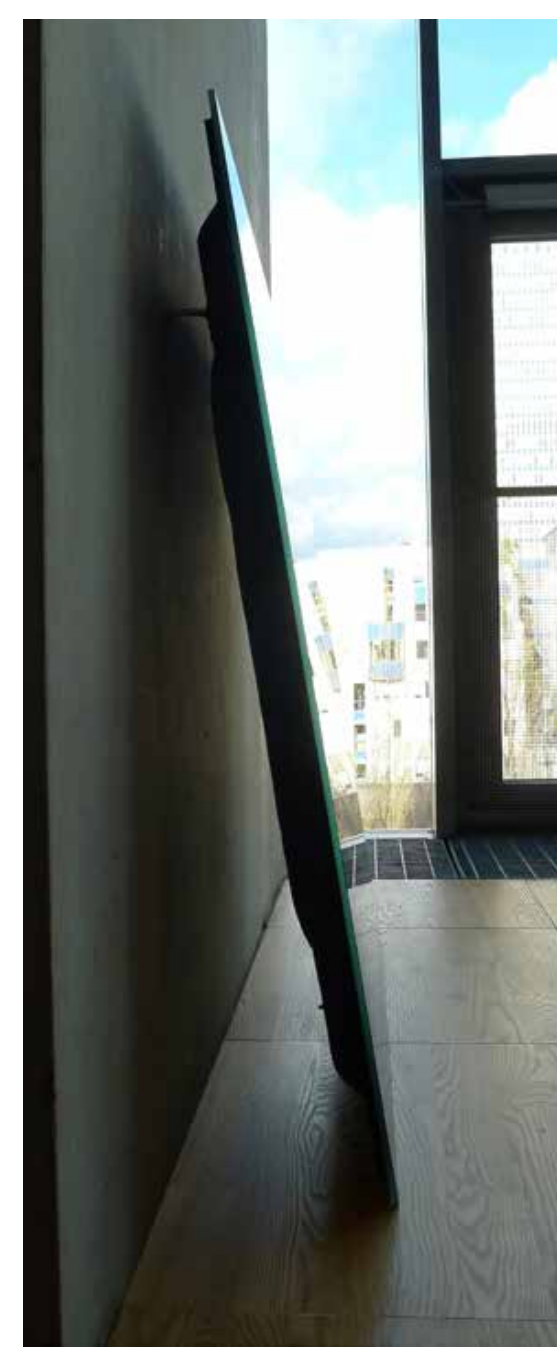





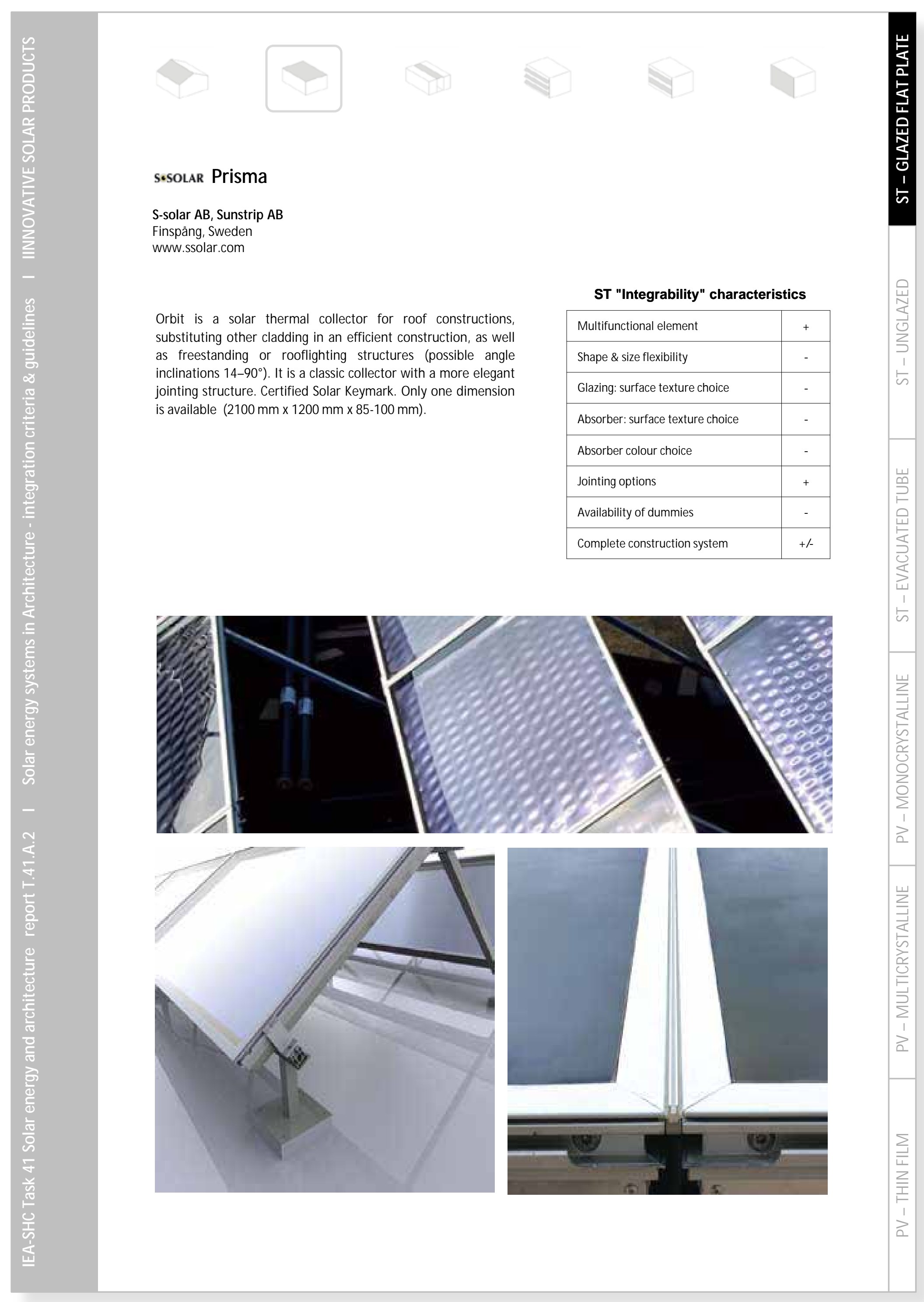





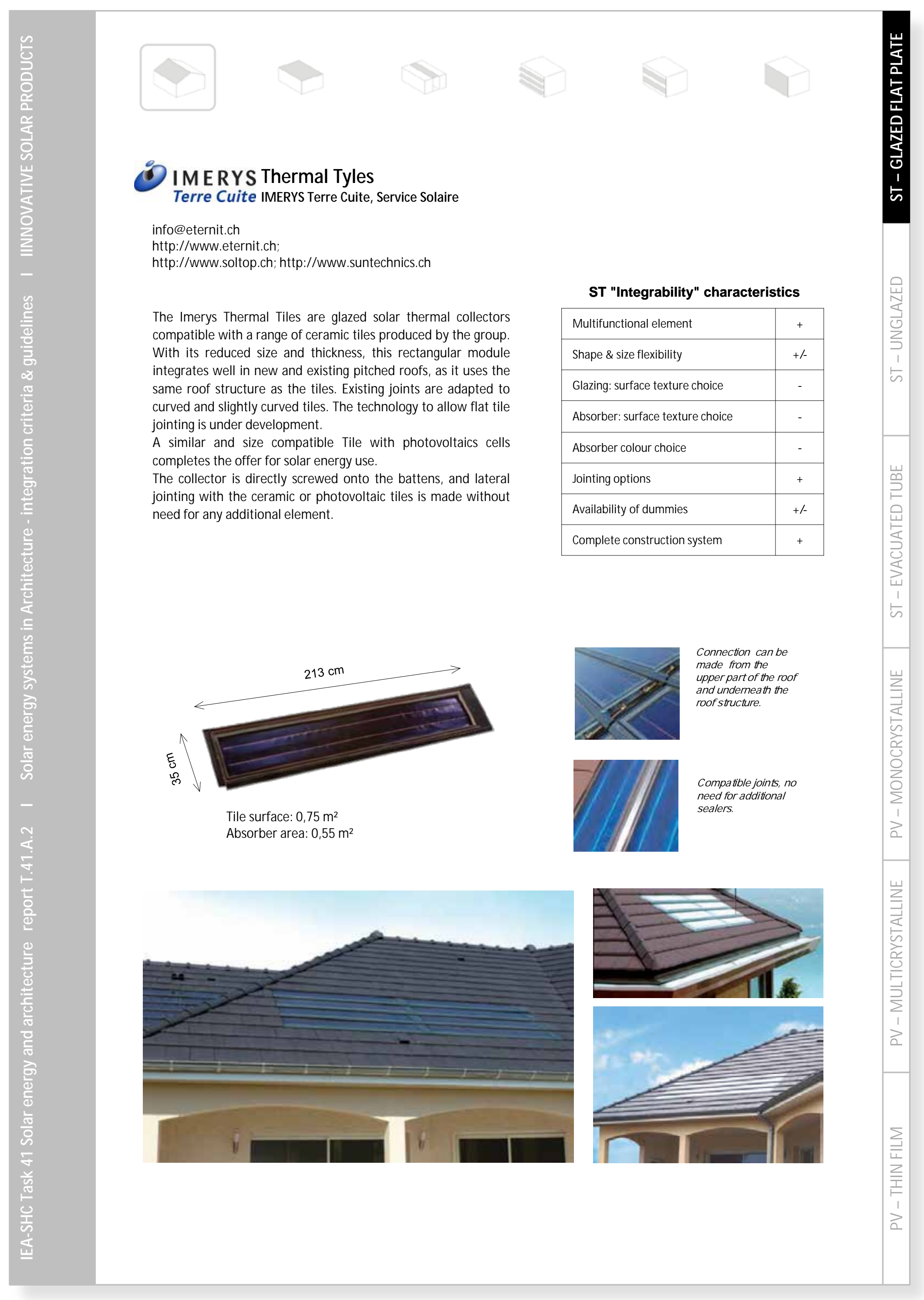





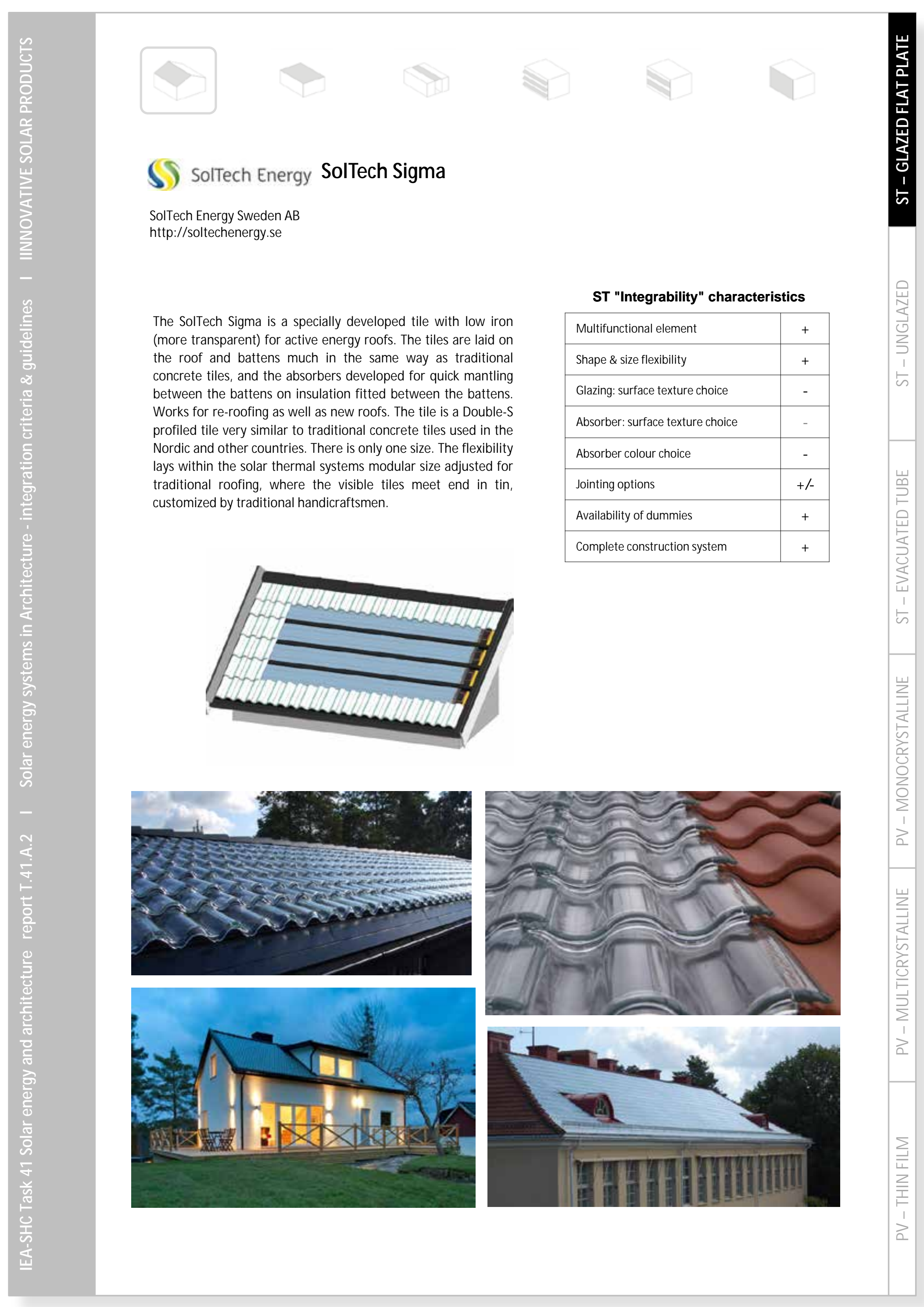





\section{axsnkg olat Polymer flat plate solar collector}

\section{AventaSolar - Aventa AS}

Trondheimsveien 436 a, N - 0962 OSLO, Norway

epost@aventa.no

www.aventa.no

The AVENTASOLAR collector is a glazed flat plate collector with the absorber and the glazing made of polymeric materials. The collector consists of two twin-wall sheets of high temperature resistant plastics, fixed in an aluminium frame. The solar radiation is converted to heat in the absorber sheet.

The collector is conceived as a standard building element that can replace other types of roof or facade coverings, with a weight of only $8 \mathrm{~kg} / \mathrm{m}^{2}$ while filled $\left(6.5 \mathrm{~kg} / \mathrm{m}^{2}\right.$ without water). The building modules come in 4 different lengths up to 6 metres and a fixed width of $60 \mathrm{~cm}$. No dummies are available, and no flexibility is allowed in the texture and colour of the absorber and the polymeric glazing. Yet the grey, mat appearance of the collector surface can be interesting for façade applications.

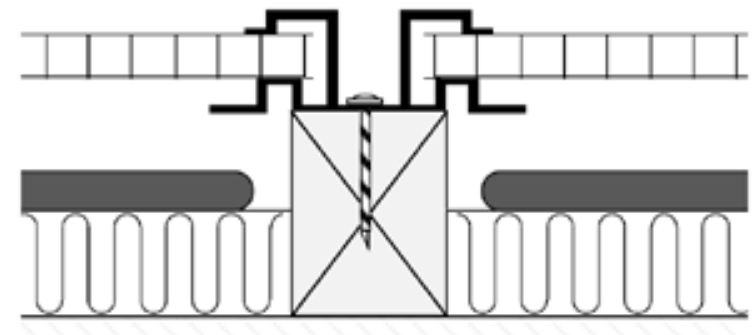

Figure 2 Cross section of the solar collector
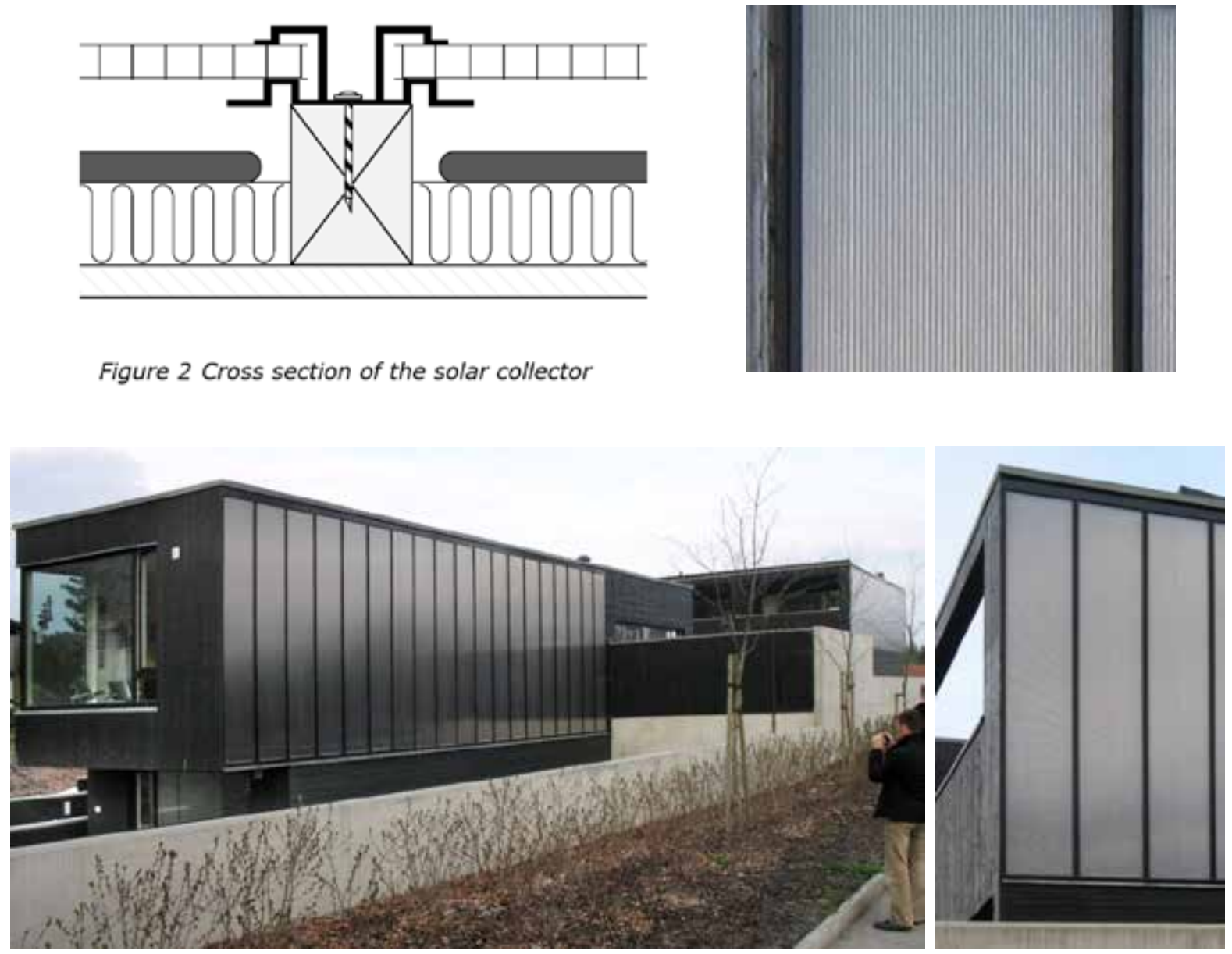

\begin{tabular}{|l|c|}
\hline Multifunctional element & + \\
\hline Shape \& size flexibility & $+\digamma$ \\
\hline Glazing: surface texture choice & $+\digamma$ \\
\hline Absorber: surface texture choice & $+\digamma$ \\
\hline Absorber colour choice & - \\
\hline Jointing options & $+\digamma$ \\
\hline Availability of dummies & - \\
\hline Complete construction system & $+\digamma$ \\
\hline
\end{tabular}





\section{ZROBIN SUN RobinSun Solar Thermal Glass}

\section{Robin Sun}

Rue fossé des tailleurs,2 - 67000 Strasbourg, France

robinsun@robinsun.com

http://www.robinsun.com

The RobinSun Solar Thermal Glass is a multifunctional doubleglazed insulating glass unit (I.G.U.) integrating a semitransparent solar thermal collector. This innovative collector contributes to natural lighting and building insulation and is conceived for integration into fixed façade window frames (wood, aluminium, pvc). The energy collected by the solar absorber integrated into the glass is transferred by water circulation into storage and the hydraulic connections are innovatively fitted into the frames. The collector is available in four standard dimensions, and custom sizes are possible on demand. No dummies are available, and no flexibility is offered regarding the colour of the absorber.

ST "Integrability" characteristics

\begin{tabular}{|l|c|}
\hline Multifunctional element & + \\
\hline Shape \& size flexibility & + \\
\hline Glazing: surface texture choice & + \\
\hline Absorber: surface texture choice & - \\
\hline Absorber colour choice & $+f$ \\
\hline Jointing options & + \\
\hline Availability of dummies & - \\
\hline Complete construction system & $+\digamma$ \\
\hline
\end{tabular}
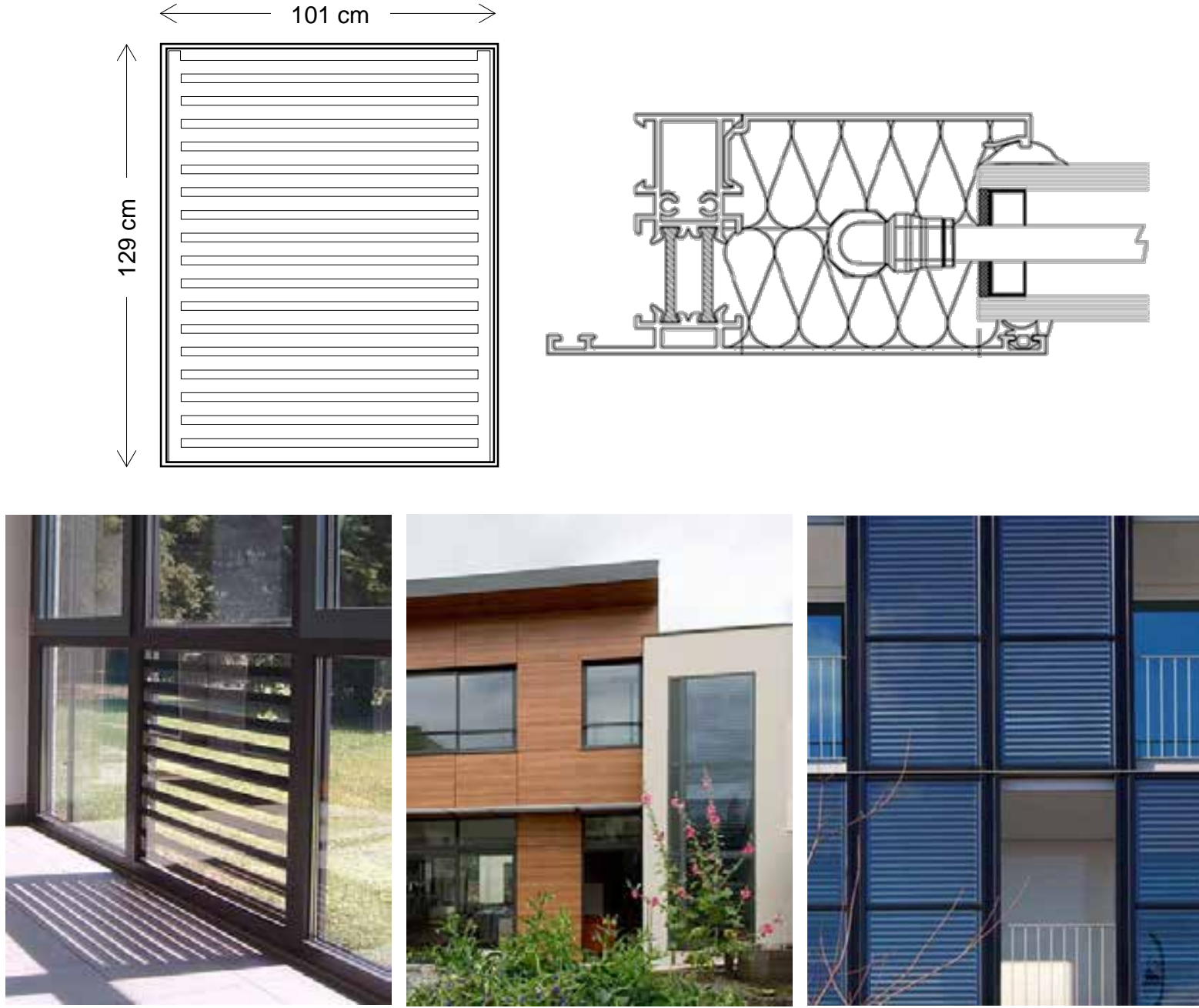


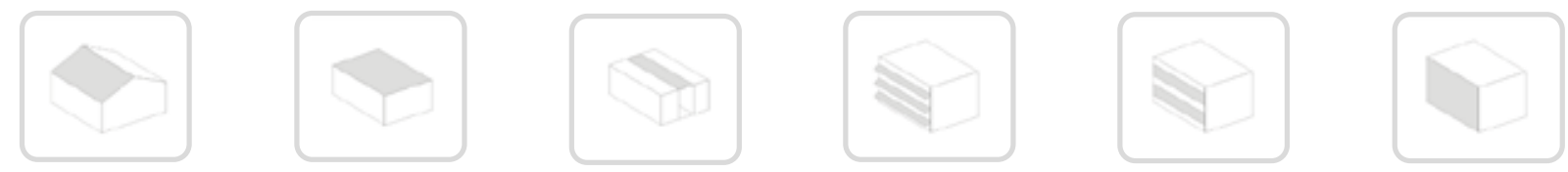

\section{(f)}

\section{EPFL/ LESO - SwissInso}

Ecole Polytechnique Fédérale de Lausanne - Laboratoire d'Energie Solaire

Station 18, CH-1015 Lausanne (Switzerland)

http://leso.epfl.ch/

www.swissinso.com

Glazed flat plate thermal collectors are generally characterized by the black appearance of the solar absorber, with surface imperfections and welding points appearing through the glazing. The LESO Coloured Glazing is conceived to tackle these issues and is an alternative to transparent collector glazing. It can be cut to measure and can be mounted on any solar thermal collector system.

Through specifically designed selective filters, this coloured glazing hides completely the collector absorber placed behind, while letting most of solar energy pass through (with less than $10 \%$ energy loss). Several colours and surface finishes can be produced.

The same glazing can be used both as collector glazing in front of solar absorbers and as facade cladding on the non exposed areas of the building envelope, making possible to have a homogeneous building appearance of active and non-active

\section{ST "Integrability" characteristics}

\begin{tabular}{|l|c|}
\hline Multifunctional element & + \\
\hline Shape \& size flexibility & + \\
\hline Glazing: surface texture choice & + \\
\hline Absorber: surface texture choice & n.r. \\
\hline Absorber colour choice & n.r. \\
\hline Jointing options & + \\
\hline Availability of dummies & + \\
\hline Complete construction system & + \\
\hline
\end{tabular}
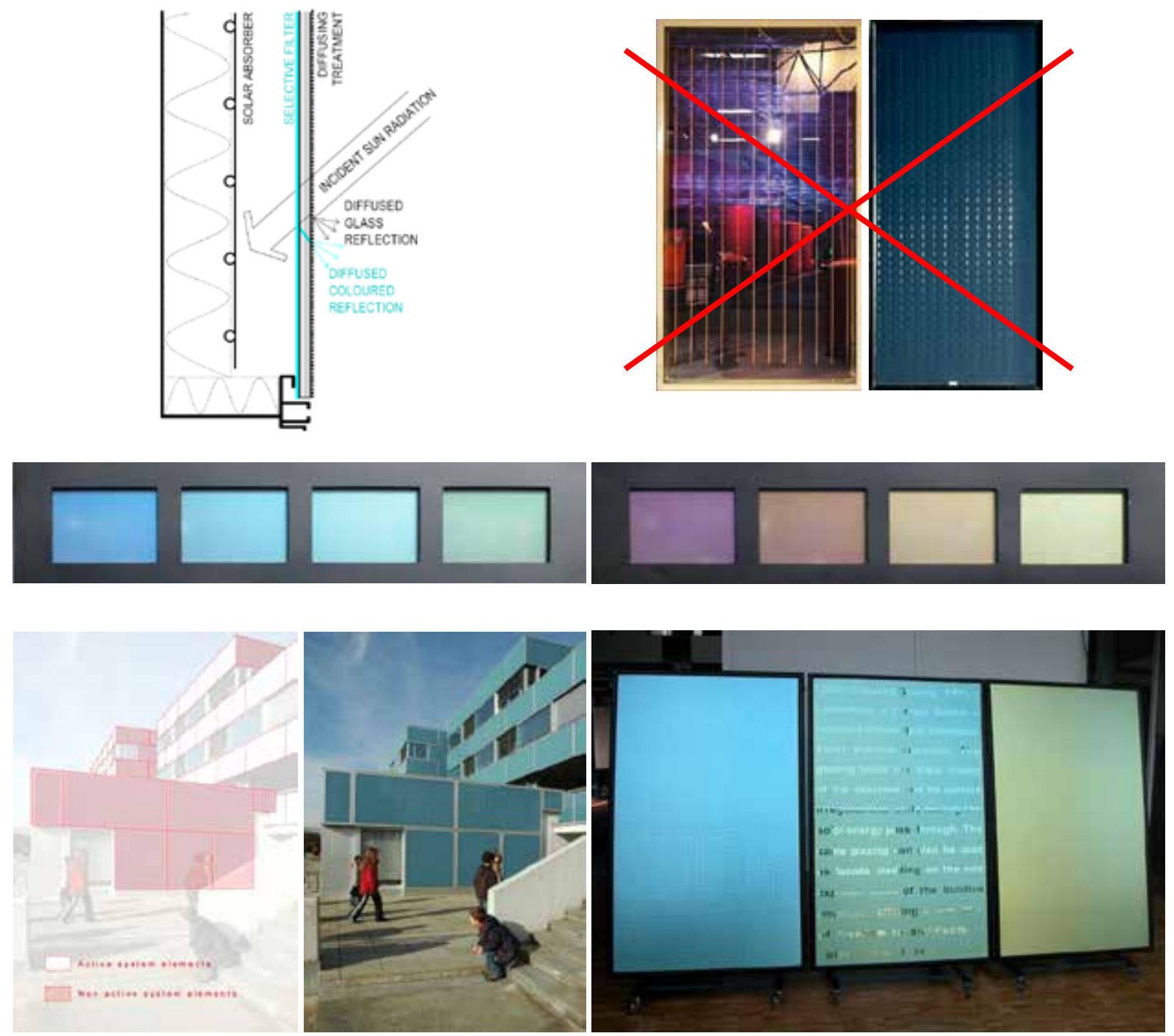



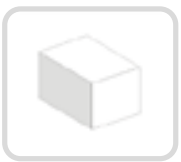

\section{Solar Roof}

\section{Energie Solaire SA}

ZI. Ile Falcon 3960 Sierre / Valais / Suisse

info@energie-solaire.com

http://www.energie-solaire.com

The Energie Solaire Solar Roof is an unglazed solar thermal system characterized by its absorber: a flat fully irrigated heat exchanger made of two structured stainless steel sheets.

The collector is conceived as a multifunctional element for roof covering, but can also be used on façades.

Its peculiar structure allows the integration on all types of roof profiles, even curved ones.

No flexibility is offered for surface geometry and colour, nor for module dimensions. Nevertheless the double sheet structure of the absorber allows the use of non active elements (made of the external metal sheet only) of any shape and size to complete the façade/roof covering system, and the selective black surface allows very good energy performance for an unglazed system.

ST "Integrability" characteristics

\begin{tabular}{|l|c|}
\hline Multifunctional element & + \\
\hline Shape \& size flexibility & $+f$ \\
\hline Glazing: surface texture choice & n.r. \\
\hline Absorber: surface texture choice & - \\
\hline Absorber colour choice & - \\
\hline Jointing options & $+f$ \\
\hline Availability of dummies & + \\
\hline Complete construction system & + \\
\hline
\end{tabular}

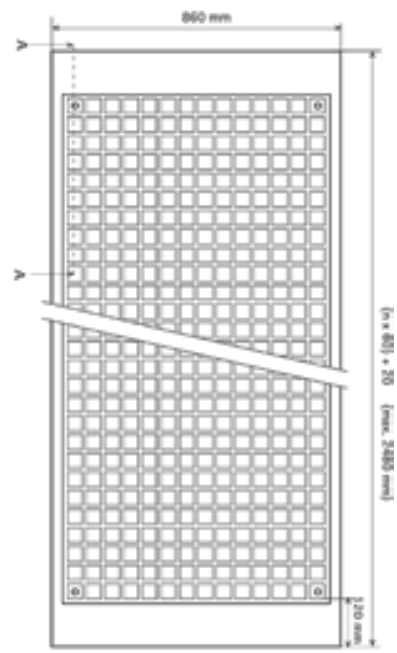

SOLAR ABSORBERS:

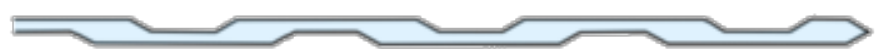

Double structured metal sheet filled with liquid (fixed dimensions)

NON ACTIVE ELEM ENTS (ROOF COVERING/FAÇADE CLADDING):

External metal sheet only (any dimensions)

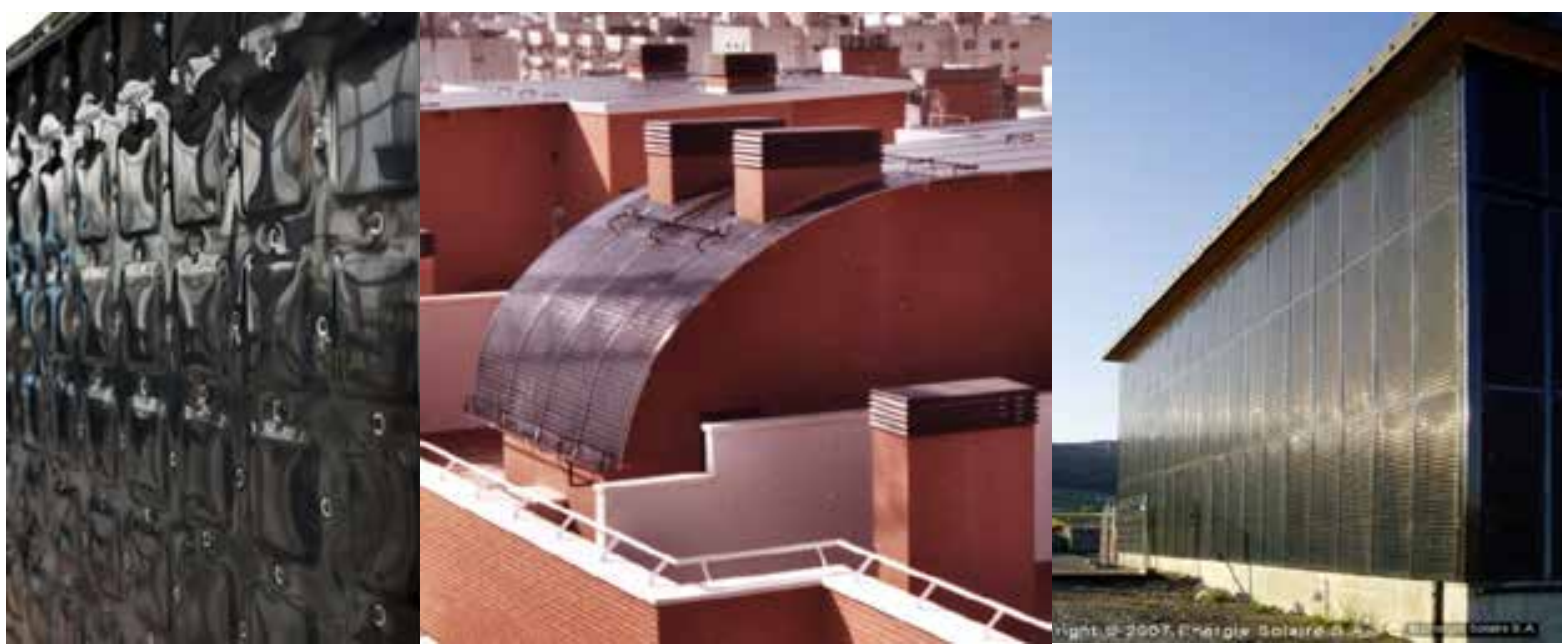





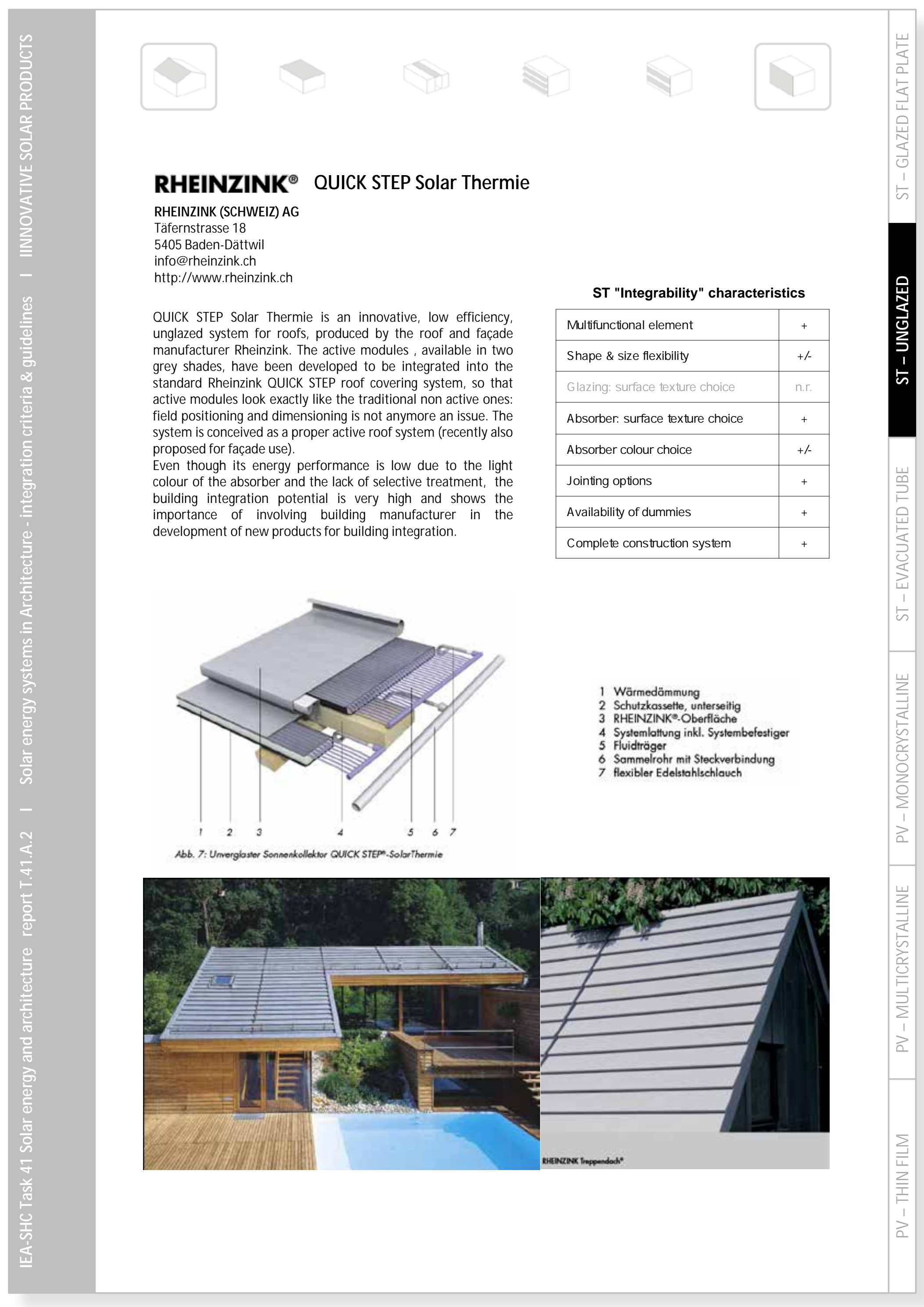





\section{KME TECU ${ }^{\circledR}$ Solar System}

\section{KME Italy}

Via Corradino d’Ascanio, 4 - 20142 Milano, Italy

tecusolarsystem@kme.com

http://www.kme.com/tecu-solarsystem

The TECU Solar System is a roof covering in copper in which copper collectors are integrated. The modules make use of solar radiation to produce domestic hot water and to feed the heating system.

Under the absorbing surface is a copper serpentine pipe in which an antifreeze glycol liquid flows.

There is some flexibility for module dimensions and colour. The company proposes a standard dimension of $35 \mathrm{~cm}$ in width and a length of $2 \mathrm{~m}$ or $3 \mathrm{~m}$ up a maximum of $5 \mathrm{~m}$, but it is also possible to have tailored sizes. The product is available in the pre-oxidised and in the green pre-patinated surfaces.

Even if the energy performance is lower than black selective metal absorbers, this product can be very well integrated as roof covering and it interfaces perfectly with the TECU product range with a very good homogeneous result.

ST "Integrability" characteristics

\begin{tabular}{|l|c|}
\hline Multifunctional element & + \\
\hline Shape \& size flexibility & + \\
\hline Glazing: Surface texture choice & n.r. \\
\hline Absorber: surface texture choice & + \\
\hline Absorber colour choice & + \\
\hline Jointing options & + \\
\hline Availability of dummies & + \\
\hline Complete construction system & + \\
\hline
\end{tabular}
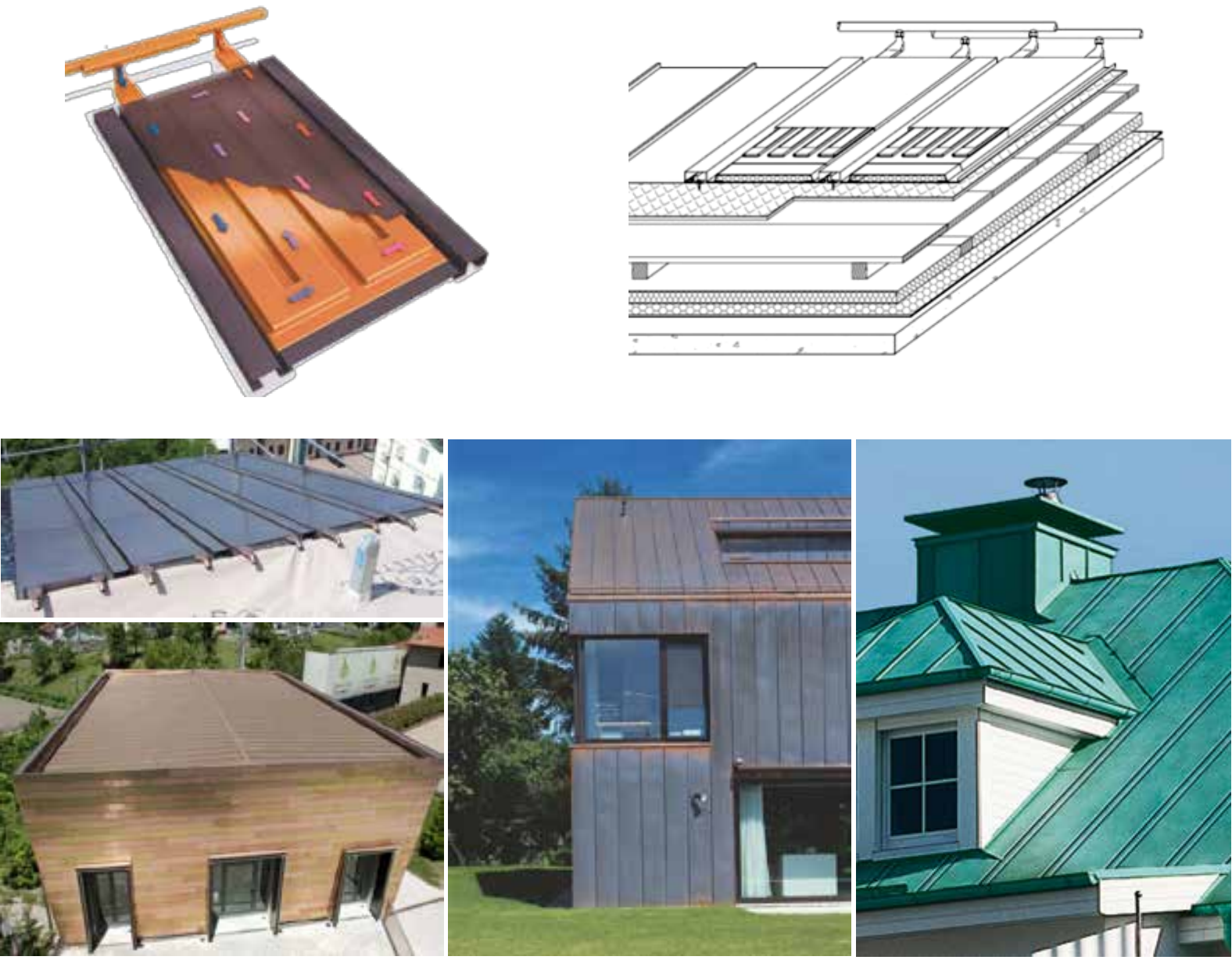



\section{A T M $(+2)$ VA Biberschwanz/Classic}

Atmova

Weidenstrasse, 50 - 4143 Dornach, Switzerland

info@atmova.ch

http://www.atmova.ch

ST "Integrability" characteristics

The Atmova copper roof covering is an unglazed solar thermal system in the shape of traditional flat tiles, well suitable for historical buildings. Three different tile shapes are available, together with the corresponding dummies to complete the roof covering (i.e. the standard tiles).

Although the integration is excellent, the drawback of this product lies in the lower temperature and energy production compared to a classic unglazed flat plate collector, since there is no selective paint on the surface. It is then necessary to connect the solar thermal system to a heat pump if higher temperatures are needed.

\begin{tabular}{|l|c|}
\hline Multifunctional element & + \\
\hline Shape \& size flexibility & + \\
\hline Glazing: surface texture choice & n.r. \\
\hline Absorber: surface texture choice & + \\
\hline Absorber colour choice & + \\
\hline Jointing options & + \\
\hline Availability of dummies & + \\
\hline Complete construction system & + \\
\hline
\end{tabular}
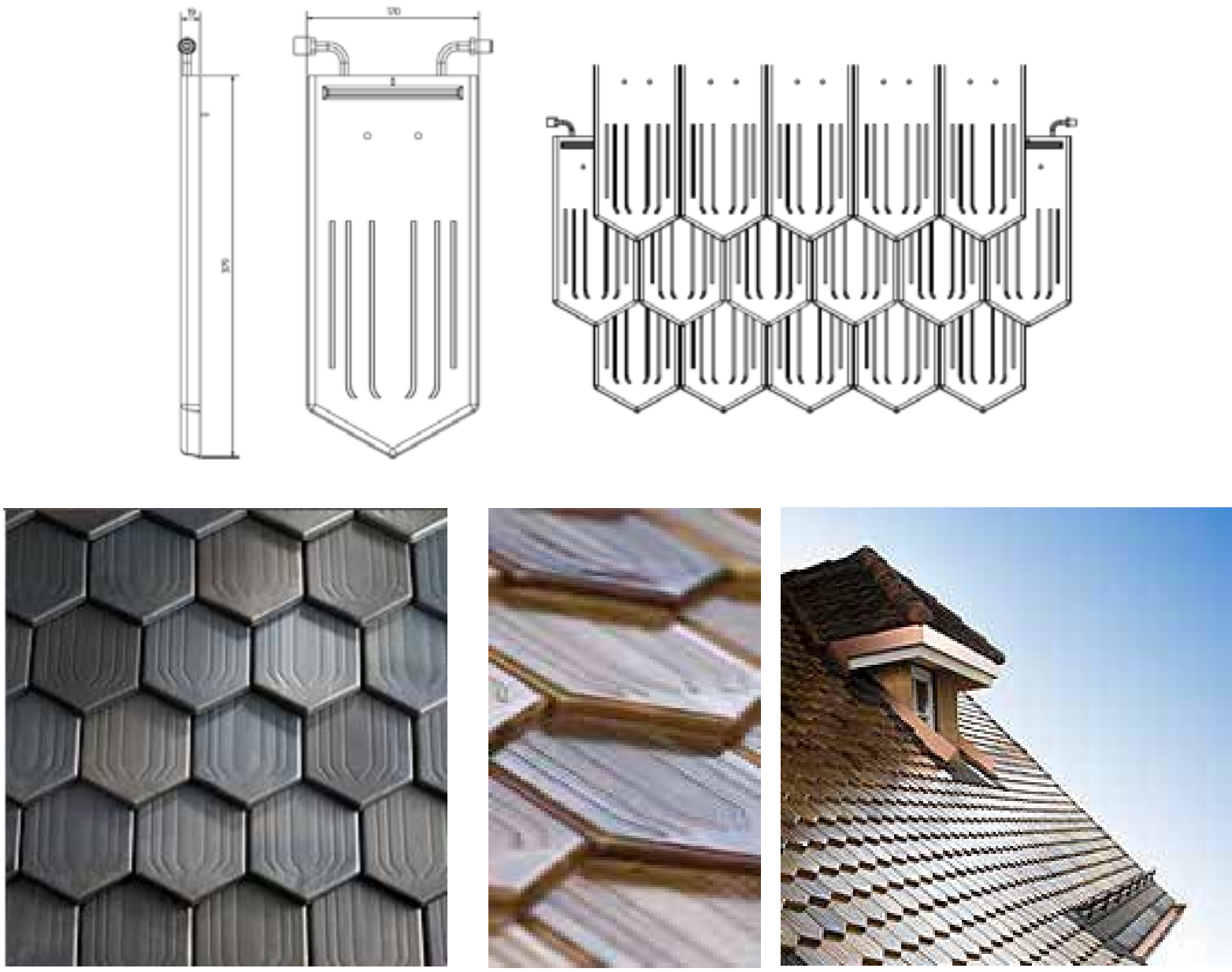



\section{S.larkal Solar Air Heating System}

\section{SolarWall}

Conserval Engineering, Inc

200Wildcat Road, Toronto, Ontario M 3J 2N5

info@solarwall.com

http://www.solarwall.com

ST "Integrability" characteristics

The Solar Wall unglazed air system is a perfect multifunctional façade system.

Its appearance is very similar to the one of profiled metal sheet for façade cladding. Its low extra cost allows using the same profile both on exposed and non exposed envelope area, solving the issue of dummy elements.

The colour palette is as large as any standard façade cladding palette. It comprises both high and low efficiency shades, leaving to the architect the choice of using a more or less efficient colour according to building and context specificities.
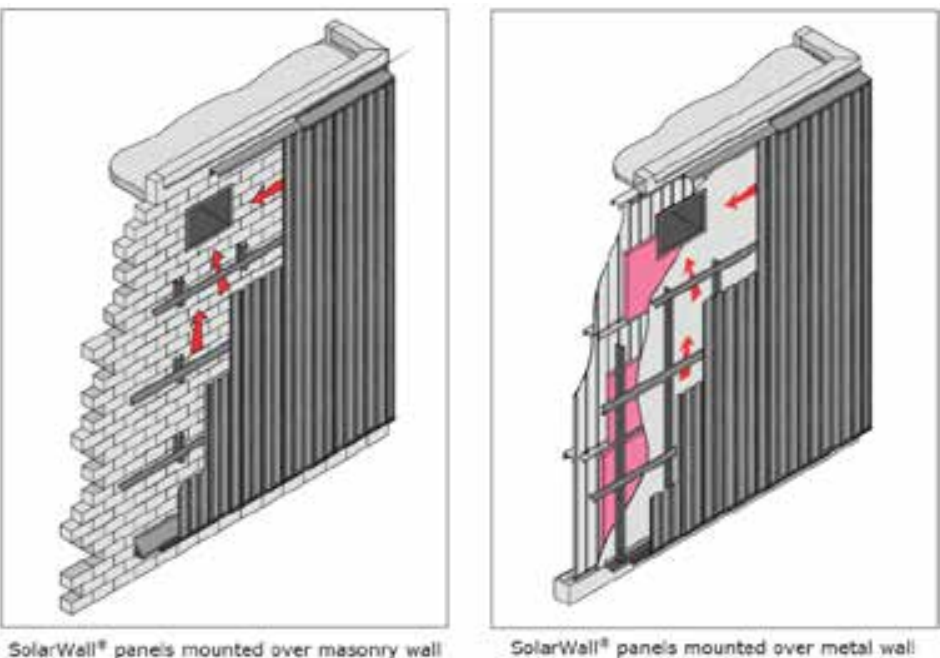

SolarWall panels mounted over metal wal

\begin{tabular}{|l|c|}
\hline Multifunctional element & + \\
\hline Shape \& size flexibility & + \\
\hline Glazing: surface texture choice & n.r. \\
\hline Absorber: surface texture choice & $+f$ \\
\hline Absorber colour choice & + \\
\hline Jointing options & + \\
\hline Availability of dummies & + \\
\hline Complete construction system & + \\
\hline
\end{tabular}

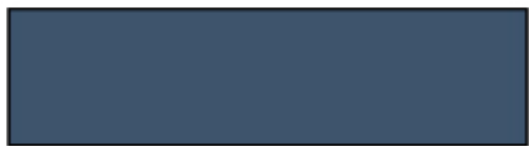

Heron Blue Albsorptivity 0.9-WW16079

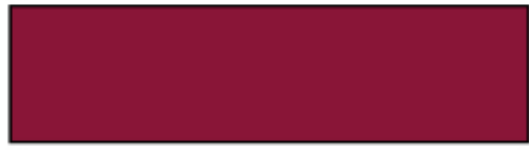

Tile Red Absorptivity 0.69 - WW16086

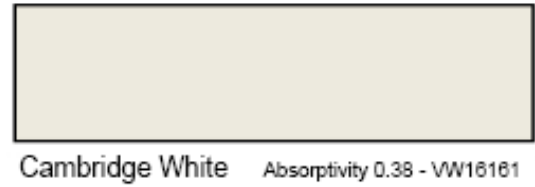

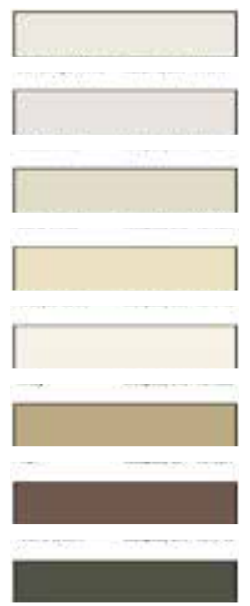
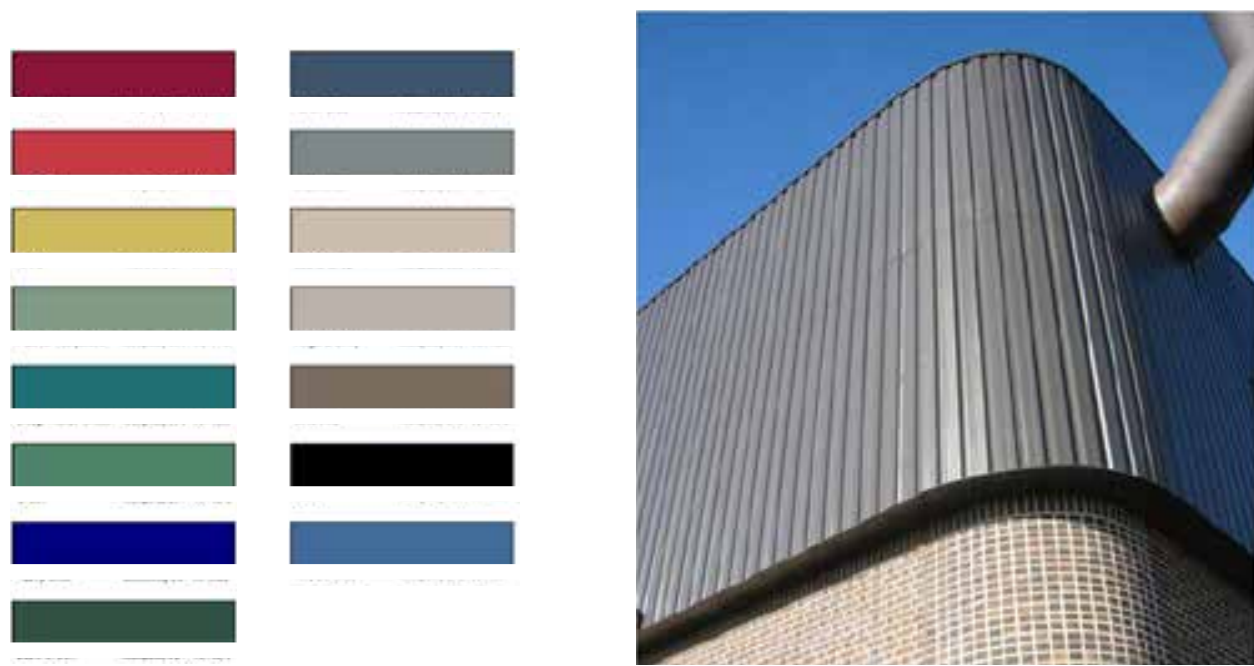

HelioPower Slate Roofs

\section{Heliopower}

www.heliopower.dk

Slate Roofs is a very innovative unglazed system with low efficiency (20-30\% of solar irradiation) but high integrability. It is a quick and easy to mount system covered by traditional slate roofs, perfect for retrofit as well as new constructions. Mounting angles can vary from 20 to 90 degrees, so it can be used for facades as well as for roofs. Heat can be used for floor heating and pool water.
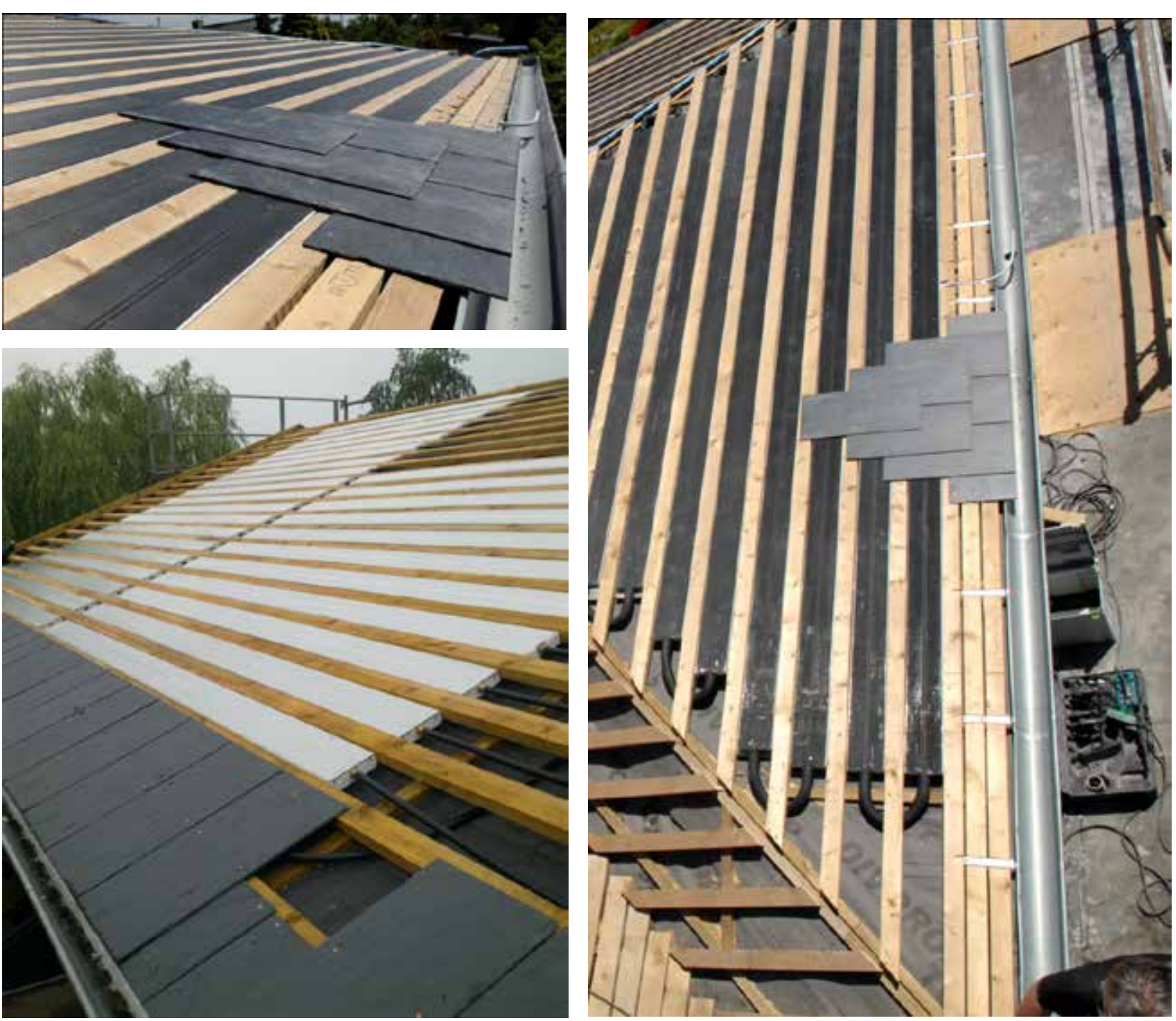

ST "Integrability" characteristics

\begin{tabular}{|l|c|}
\hline Multifunctional element & + \\
\hline Shape \& size flexibility & + \\
\hline Glazing: surface texture choice & n.r. \\
\hline Absorber: surface texture choice & $+\digamma$ \\
\hline Absorber colour choice & $+\digamma$ \\
\hline Jointing options & + \\
\hline Availability of dummies & $+\digamma$ \\
\hline Complete construction system & + \\
\hline
\end{tabular}

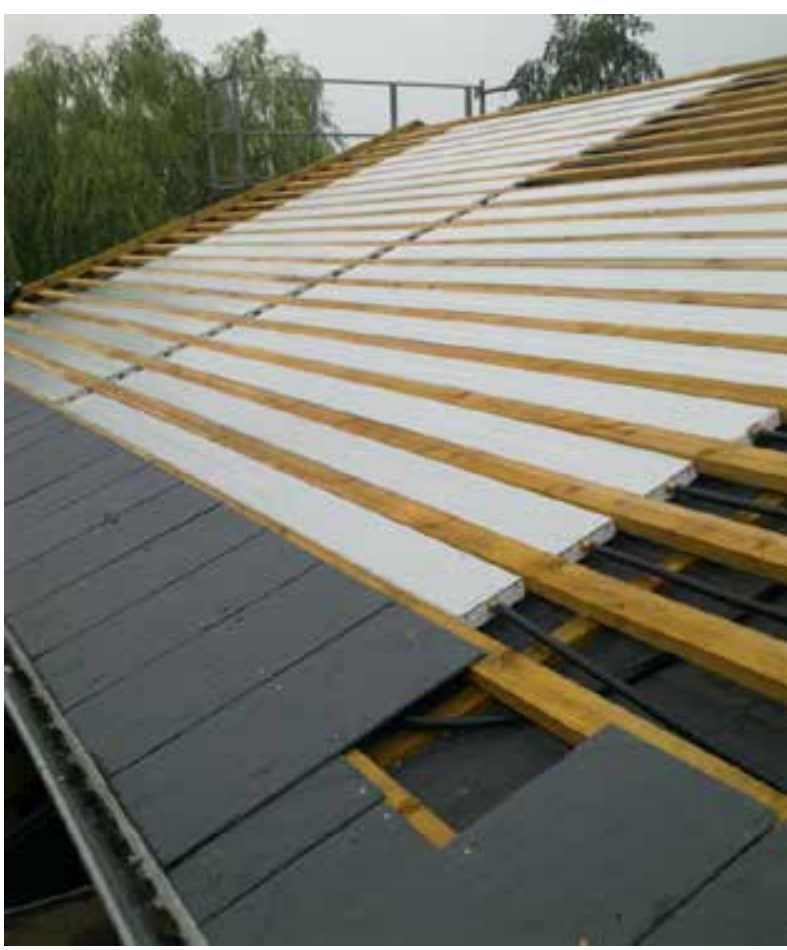





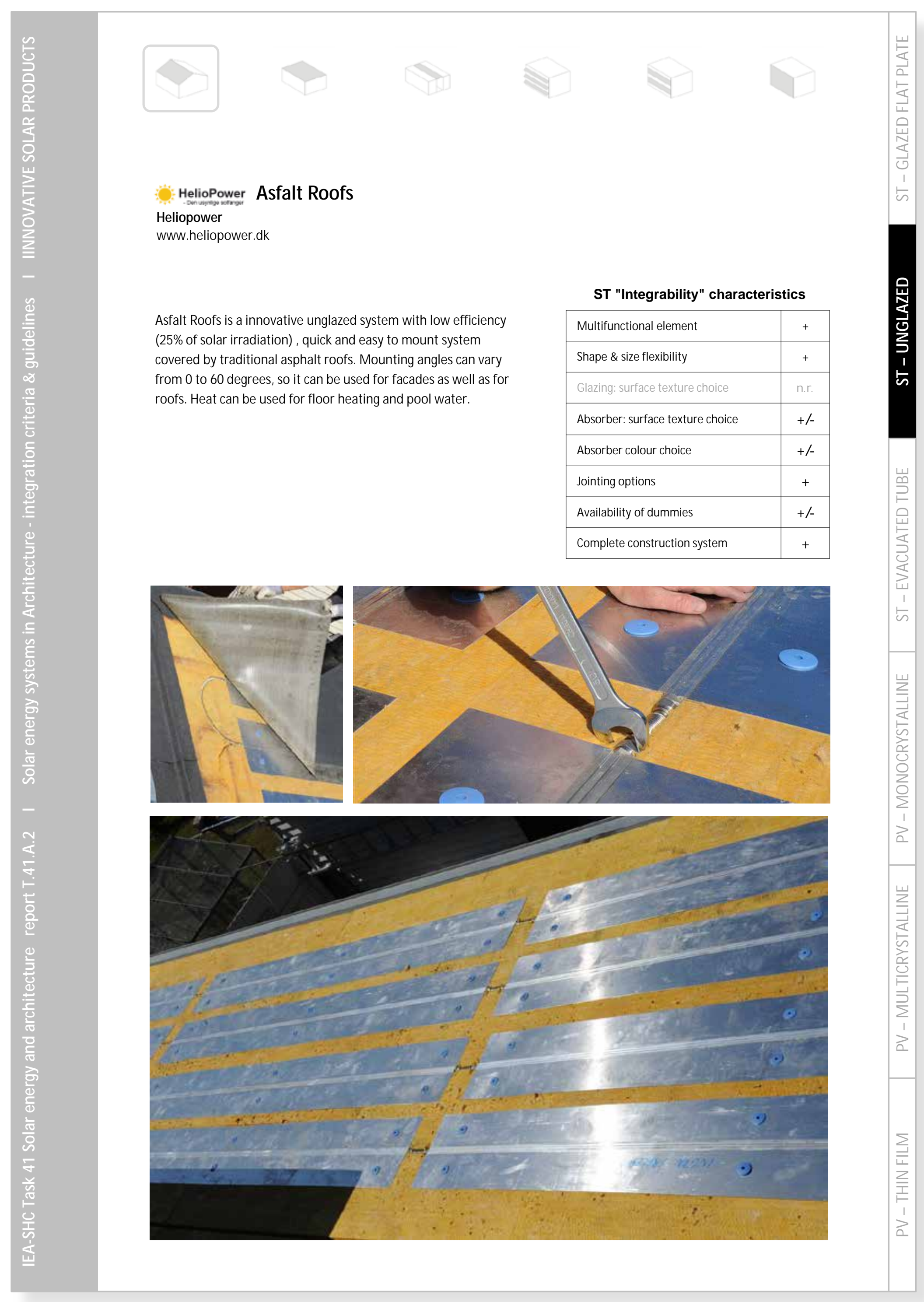





\section{S.SOLAR 777 กำ Protected Strip \\ S-solar AB \\ Finspång, Sweden \\ www.ssolar.com}

Protected Strip is a solar thermal product to be used between glass in the nordic regions, and without glass in the southern hemisphere. It can also be used as an activated indoor solar shading in buildings without solar glass, in retrofit, atrium etc. The protected strip has a high flexibility in lengths from 600 to $7000 \mathrm{~mm}$. There are two widths; 143 or $122 \mathrm{~mm}$ or $70 \mathrm{~mm}$. The product has a high efficiency surface coating method that can be applied on one or two sides, colours can be customized within certain frames to an extra cost. Protected strip can be integrated in the indoor bearing structure.
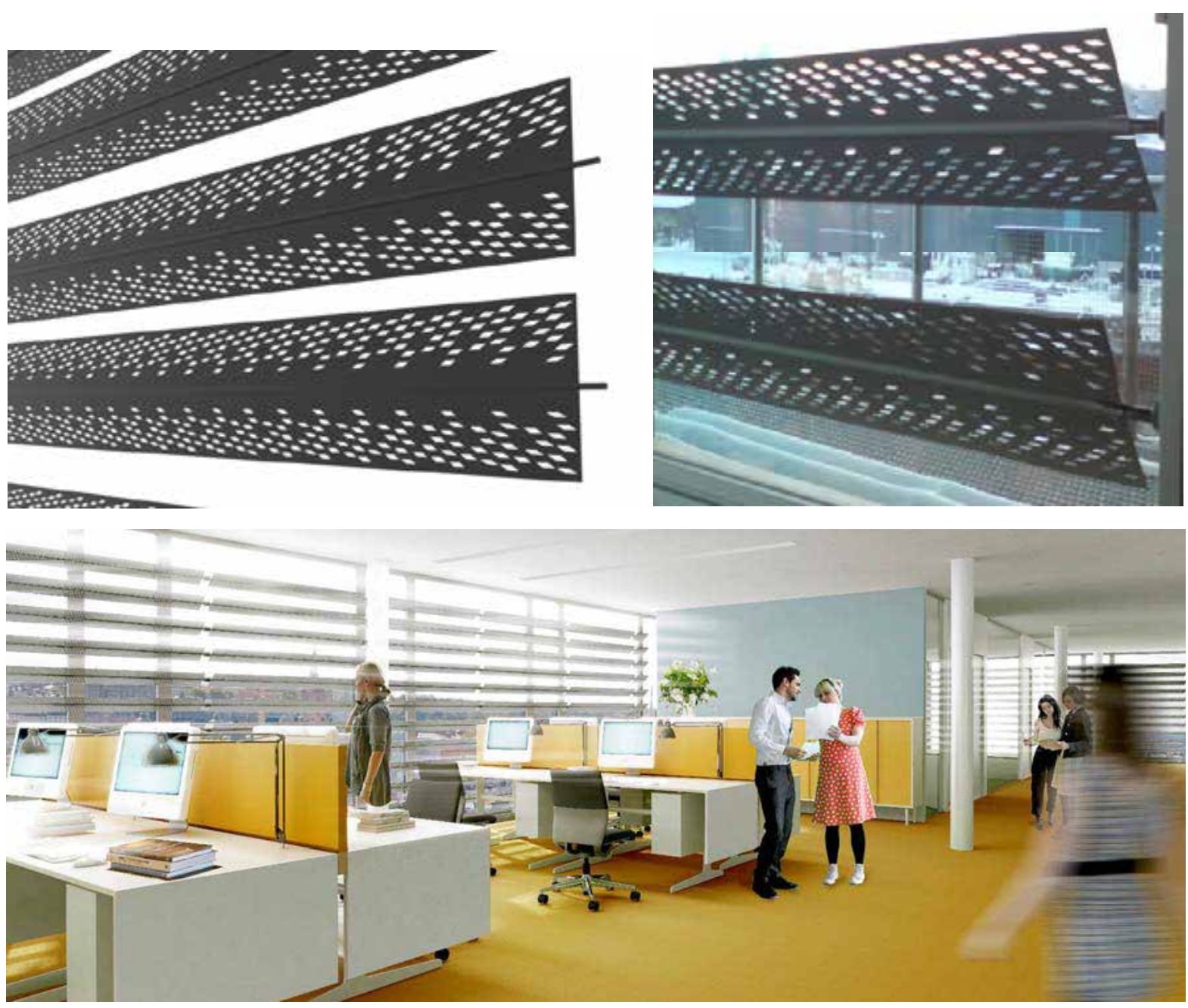

\begin{tabular}{|l|c|}
\hline Multifunctional element & + \\
\hline Shape \& size flexibility & + \\
\hline Glazing: surface texture choice & n.r. \\
\hline Absorber: surface texture choice & + \\
\hline Absorber colour choice & + \\
\hline Jointing options & + \\
\hline Availability of dummies & - \\
\hline Complete construction system & + \\
\hline
\end{tabular}

Protected strip, illustrations White arkitekter AB. 



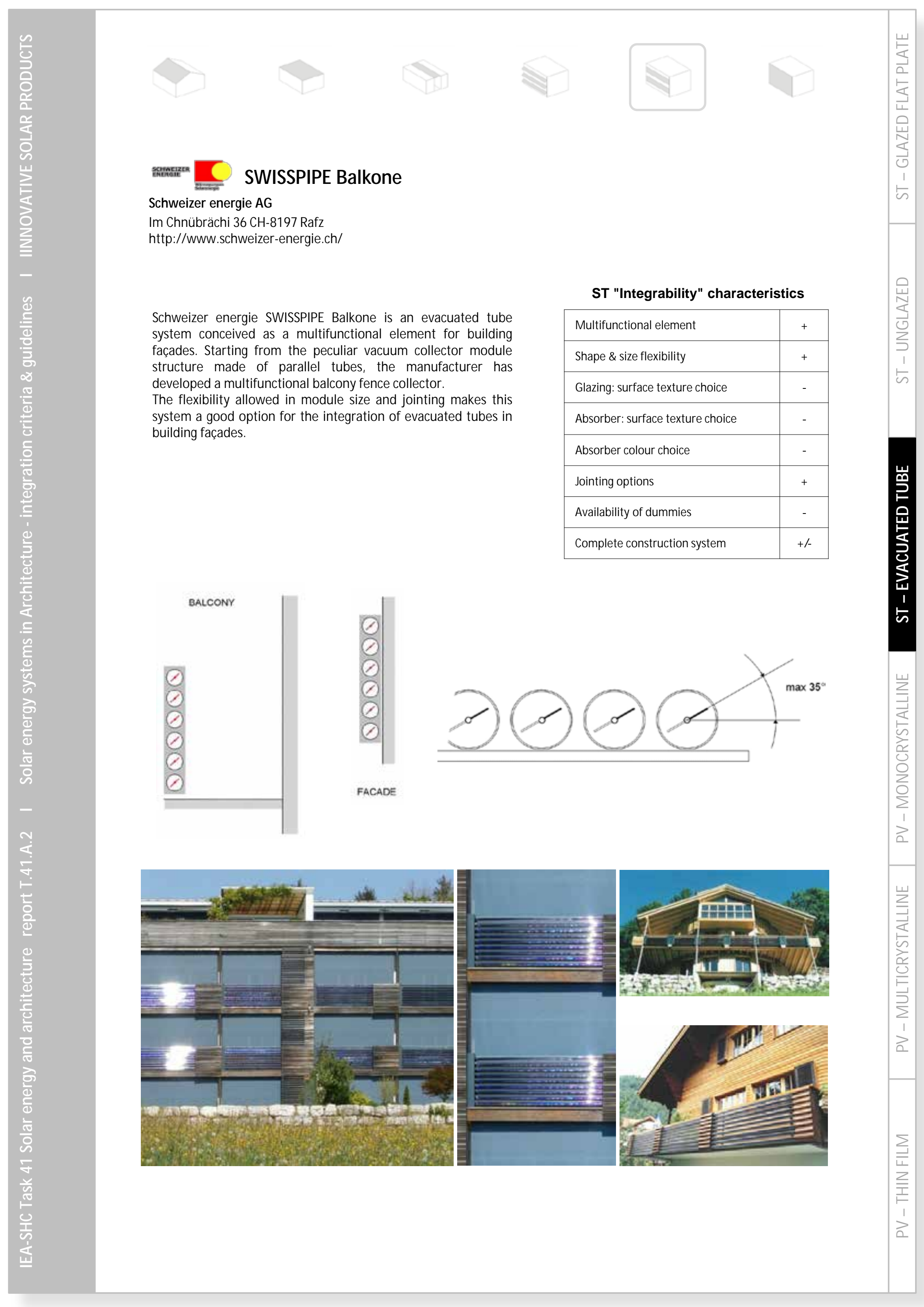





\section{CPC Office/ System WICONA, Facade collector *}

Dipl.-Ing. Tina Volzrung

Universität Stuttgart-Institut für Baukonstruktion 2

http:// www.uni-stuttgart.de/ibk2

solar collectors: Schott-Rohrglas

http://www.schott.com

This system integrates evacuated tube collectors (made by the manufacturer Schott-Rohrglas) into a global glazed façade concept targeted for office buildings. The collectors are multifunctional: they produce solar thermal heat and cool (solar cooling), and work as sun shading offering a partial protection against direct solar radiation over office glazing, while letting daylight into the building.

* The system has been developed in close cooperation with several industrial partners (Hydro Building Systems WICONA, Frener \& Reifer M etallbau, Ritter Energie und Umwelttechmik, M etallbau Früh) and research partners (technical University of M unich) and will soon be available on the market.

ST "Integrability" characteristics

\begin{tabular}{|l|c|}
\hline Multifunctional element & + \\
\hline Shape \& size flexibility & $+\digamma$ \\
\hline Glazing: surface texture choice & - \\
\hline Absorber: surface texture choice & - \\
\hline Absorber colour choice & - \\
\hline Jointing options & + \\
\hline Availability of dummies & - \\
\hline Complete construction system & $+\digamma$ \\
\hline
\end{tabular}
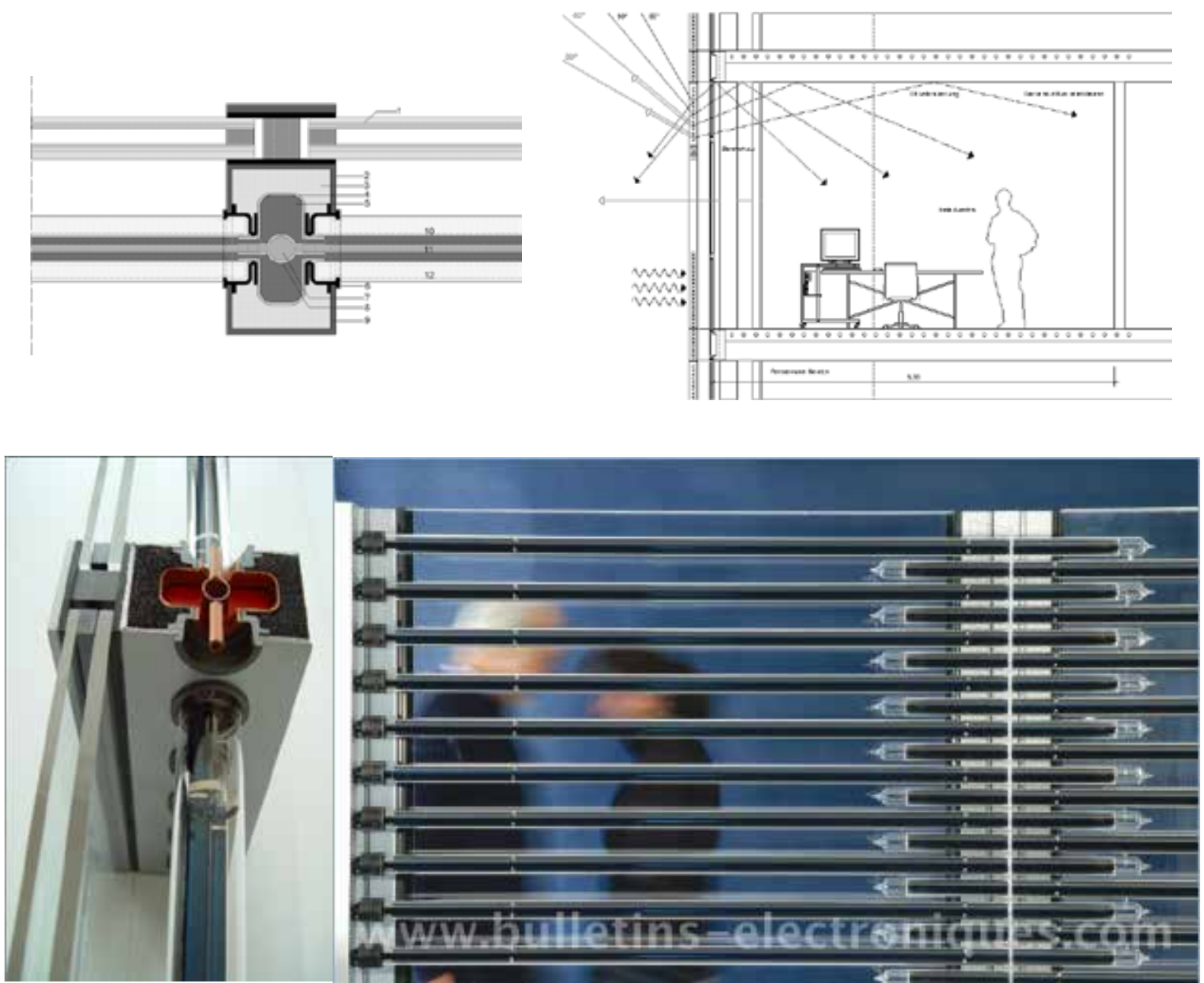



\section{CONCLUSION}

Broader use of building integration of solar thermal is a present necessity. One major reason why solar thermal technologies are still not commonly used by architects and planners is the lack of adapted products for building integration. This was confirmed by the international survey that has been conducted in the framework of IEA SHC Task 41, showing that the availability of suitable products for building integration is considered urgent by architects to enhance the use of solar thermal in everyday architectural practice [2]. Solar thermal modules for building integration should not be developed only as added technical elements but as building components that fulfil the functional, constructive and formal requirements of the building components they replace: i.e. multifunctionality is the key concept.

In the present guidelines, produced within IEA SHC Task 41, the authors aimed to address solar thermal manufacturers to support development and production of attractive and cost-effective modules for building integration, finally helping architects implement this technology in their designs. With the present situation aiming at complete substitution of fossil energies by renewable ones, the world needs joint efforts of all actors to improve the chances to reach this goal within a reasonable time frame.

Solar thermal technologies are clearly key players in this field. 


\section{REFERENCES AND FURTHER READING}

[1] MC Munari Probst, C Roecker, Architectural integration and design of solar thermal systems, PPUR -Routledge, Taylor\&Francis, 2011

[2] Klaudia Farkas (NTNU, Norway), Miljana Horvat (Ryerson University, Canada) T.41.A.1: Building Integration of Solar Thermal and Photovoltaics - Barriers, Needs and Strategies May 2012

[3] IEA SHC Task 41, Report T.41.A-2: Solar Energy systems in Architecture: Integration criteria and guidelines, ed. MC.Munari Probst and C.Roecker, March 2013.

[4] I. Bergmann "Facade integration of solar thermal collectors - A new opportunity for planners and architects", in Renewable Energy World, June 2002.

[5] A.G Hestnes, "Building integration of solar energy systems", in Solar Energy, 67 (4-6), 181-187, 2000.

[6] Munari Probst MC. Architectural integration and design of solar thermal systems PhD thesis EPFL n. 4258, 2008.

[7] Munari Probst MC, Roecker C, Architectural integration of solar thermal system, in Detail Green 01/2010 pp.46-49.

[8] IEA SHC Task 41, Report T.41.B.3a: Solar Design of Buildings for Architects: Review of Solar Design Tools, ed. Miljana Horvat and Maria Wall, July 2012.

[9] MC.Munari Probst, C.Roecker, A. Schueler, Architectural integration of solar thermal collectors: results of an European survey", in Proceedings ISES 2005, Orlando, Florida, 2005.

[10] W. Weiss Editor "Solar Heating systems for Houses - A design handbook for solar combisystem"-James and James 2003: Book prepared as an account of work done within the Task26 "Solar Combisystem" of the IEA Solar Heating and Cooling Programme.(Chapter 5: "Building related aspects of solar combi systems", Kovaks P., Weiss W. Bergmann I., Meir M., Rekstad J., especially $\S 5.2 .2 .4$ The thermal and humidity behaviour of walls with façade collectors).

[11] C. Philibert, Barriers to Technology Diffusion: The Case of Solar Thermal Technologies, International Energy Agency, Organisations for Economic and Development, 2006.

[12] Farkas, K., Munari Probst, M.C., Horvat, M., Barriers and Needs for Building Integration of Solar Thermal and Photovoltaics, In the Proceedings of EuroSun 2010, Graz, Sept. 2010.

[13] Thomas Matiska and Borivoj Sourek, Facade Solar Collectors, in Solar Energy 80 (2006) 1443-1452.

[14] T. Muller et al., Colourface- Coloured Collector facades for solar heating systems and building insulation, Eurosun 2004.

[15] W. Weiss, Franz Mauthner, Solar Heat Worldwide, IEA Solar Heating and Cooling Programme, 2010. 
[16] A.M. Papadopoulos, Active solar heating and cooling for buildings, in Solar thermal technologies for building - the state of the art, James and James, 2003, M. Santamouris Editor.

[17] R. Krippner, T. Herzog, Architectural aspects of solar techniques - Studies on the integration of solar energy systems. In Proceedings EUROSUN 2000, 3rd ISES-Europe Solar Congress, Copenhagen, Denmark, 2000.

[18] IEA SHC Task 39 Projects database:http://www.iea-shc.org/task39/projects/default.aspx

[19] Schueler, A. et al. "On the feasibility of colored glazed thermal solar collectors based on thin film interference filters" In Solar Energy Materials \& Solar Cells, vol. 84 (2004), p. 241254.

[20] Munari Probst, M.-C.; Roecker, C. "Architectural integration of solar thermal collectors: results of a European survey" , Presented at ISES 2005 Solar World Congress, Orlando, USA, August, 6-12.

[21] Website on "Façade collector with a view" http://www.bine.info/en/topics/renewableenergy-sources/solar-heat/publikation/fassadenkollektoren-mit-durchblick/ 


\section{ANNEX: IEA SOLAR HEATING AND COOLING PROGRAM}

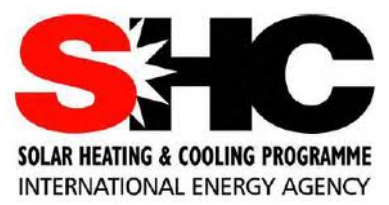

\section{IEA Solar Heating and Cooling Programme}

The Solar Heating and Cooling Programme was founded in 1977 as one of the first multilateral technology initiatives ("Implementing Agreements") of the International Energy Agency. Its mission is to "advance international collaborative efforts for solar energy to reach the goal set in the vision of contributing $50 \%$ of the low temperature heating and cooling demand by 2030."

Its primary area of work is the facilitation of research, development \& demonstration (RD\&D) in the field of solar thermal energy and solar buildings. To this end international research projects (so called "Tasks") are sponsored by the IEA SHC members.

A total of 51 such projects have been initiated to-date, 39 of which have been completed already. The current projects are:

A Solar Energy in Urban Planning (Task 51)

A Advanced Lighting Solutions for Retrofitting Buildings (Task 50)

A Solar Heat Integration in Industrial Processes (Task 49)

A Quality Assurance and Support Measures for Solar Cooling Systems (Task 48)

A Solar Renovation of Non-Residential Buildings (Task 47)

A Solar Resource Assessment and Forecasting (Task 46)

A Large Scale Solar Heating and Cooling Systems (Task 45)

A Solar and Heat Pump Systems (Task 44)

A Solar Rating and Certification Procedures (Task 43)

A Compact Thermal Energy Storage (Task 42)

A Net Zero Energy Solar Buildings (Task 40)

A Polymeric Materials for Solar Thermal Applications (Task 39)

In addition to the project work, a number of special activities - Memorandum of Understanding with solar thermal trade organizations, statistics collection and analysis, conferences and workshops - have been undertaken. An annual international conference on solar heating and cooling for buildings and industry was launched in 2012 and the $2^{\text {nd }}$ conference was held September 2013 in Freiburg, Germany. 
Current members of the IEA SHC

$\begin{array}{lll}\text { Australia } & \text { Germany } & \text { Portugal } \\ \text { Austria } & \text { Finland } & \text { Singapore } \\ \text { Belgium } & \text { France } & \text { South Africa } \\ \text { China } & \text { Italy } & \text { Spain } \\ \text { Canada } & \text { Mexico } & \text { Sweden } \\ \text { Denmark } & \text { Netherlands } & \text { Switzerland } \\ \text { ECREEE - Sponsor } & \text { Norway } & \text { United States } \\ \text { European Commission } & & \end{array}$

\section{Further information:}

For up to date information on the IEA SHC work, including many free publications, please visit www.iea-shc.org 